Universidad de Lima

Facultad de Ciencias Empresariales y Económicas

Carrera de Economía

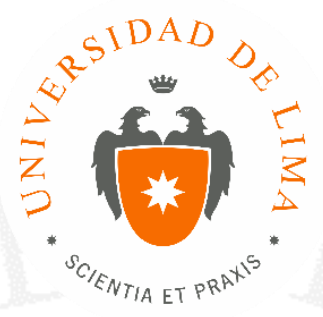

ANÁLISIS DE LA DECISIÓN DE

FINANCIAMIENTO BANCARIO DE LAS

PEQUEÑAS Y MEDIANAS EMPRESAS

(PYMES) SEGÚN SU NIVEL DE VENTAS,

INVENTARIOS, FLUJO DE CAJA Y TASA DE

INTERÉS. PERIODO 2014

Trabajo de investigación para optar por el título profesional de Economista

Juan Diego Zamudio Romero

20071185

Asesor

Dr. Napoleón Ambrocio Barrios

Lima - Perú

Septiembre del 2018 


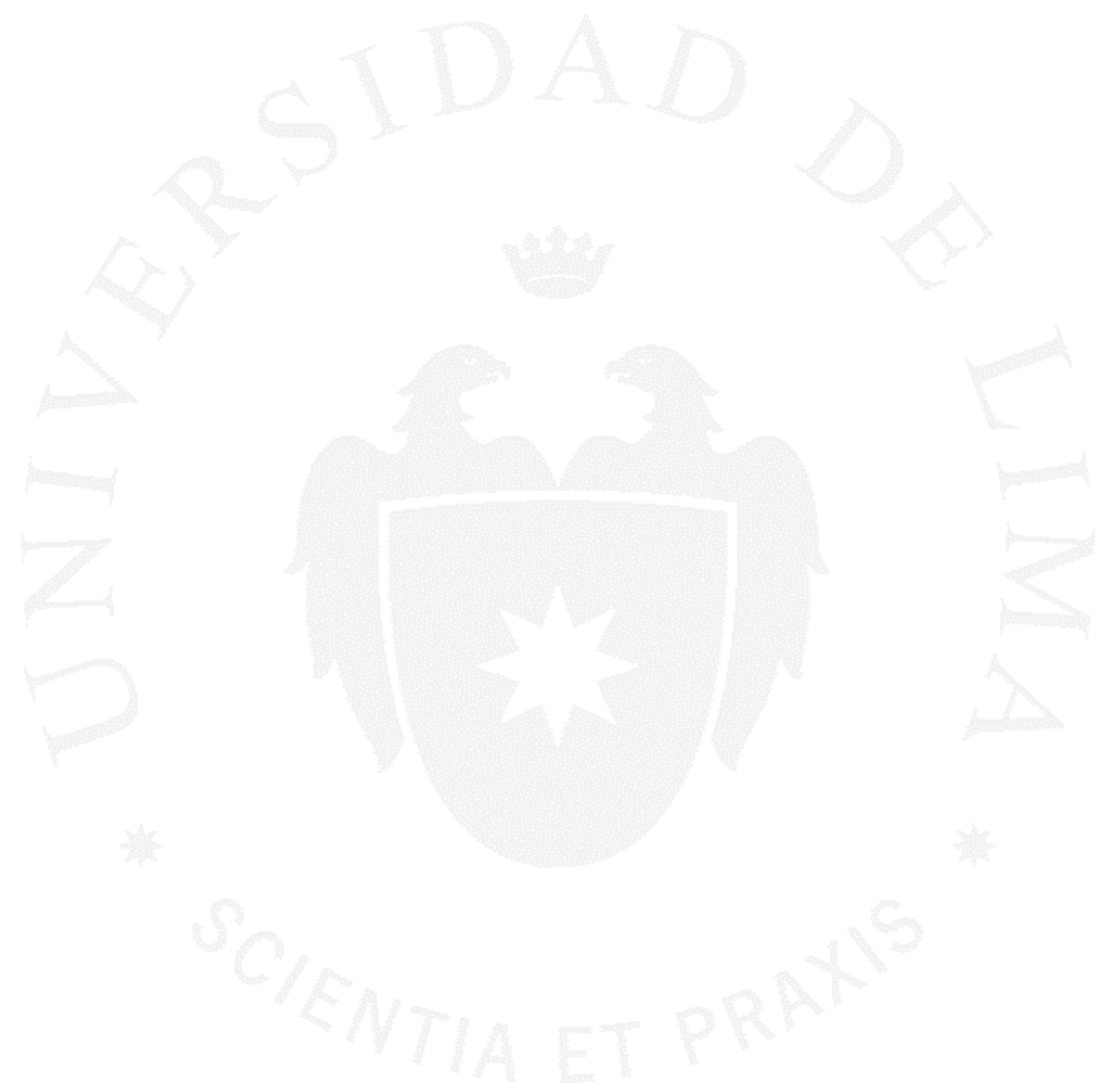




\section{ANÁLISIS DE LA DECISIÓN DE FINANCIAMIENTO BANCARIO DE LAS PEQUEÑAS Y MEDIANAS EMPRESAS (PYMES) SEGÚN SU NIVEL DE VENTAS, INVENTARIOS, FLUJO DE CAJA Y TASA DE INTERÉS. PERIODO 2014}




\section{TABLA DE CONTENIDO}

\section{INTRODUCCIÓN}

CAPÍTULO I: MARCO TEÓRICO......................................................................................4

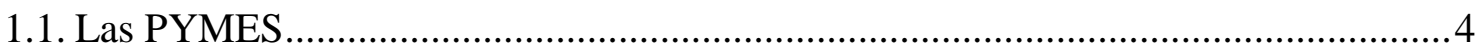

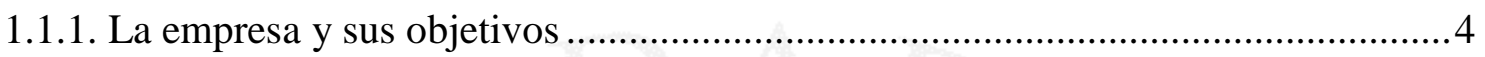

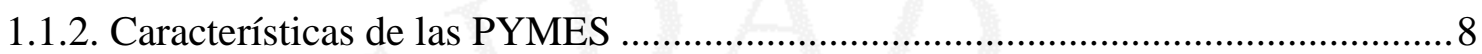

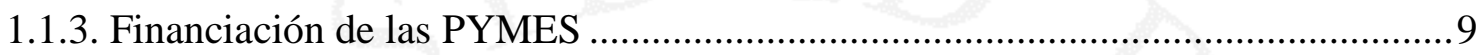

1.1.4. Marco legal-institucional de las políticas de financiamiento a PYMES .............. 14

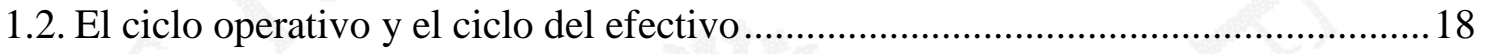

1.2.1. Definición del ciclo operativo y ciclo del efectivo ........................................... 18

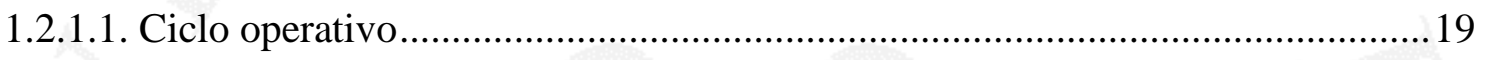

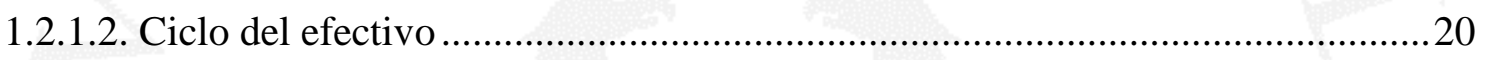

1.2.2. Importancia del ciclo operativo y el ciclo del efectivo para las decisiones de

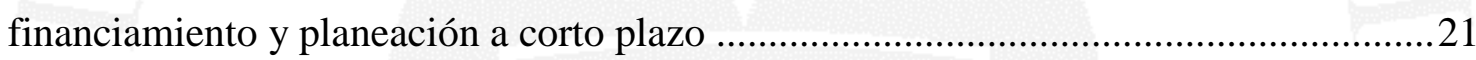

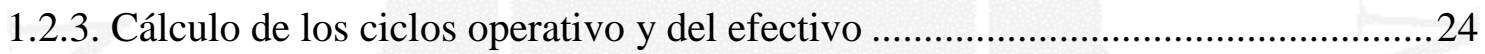

1.3. Análisis de la relación económica de las variables del modelo ...............................28

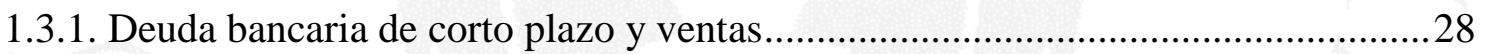

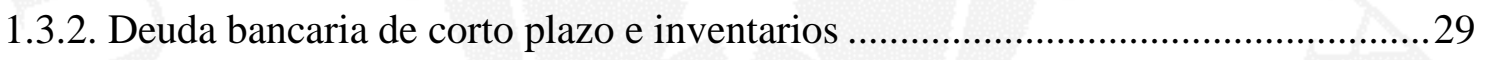

1.3.3. Deuda bancaria de corto plazo y flujo de caja ....................................................29

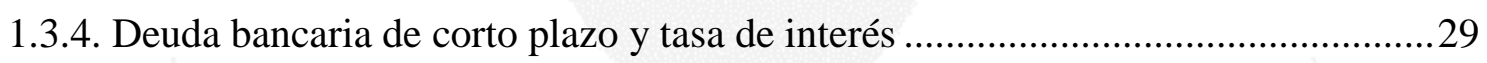

CAPÍTULO II: EVOLUCIÓN DE LAS VARIABLES ...........................................32

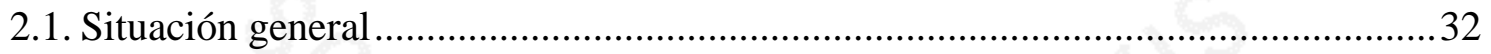

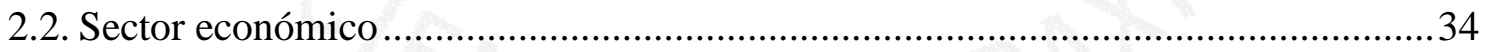

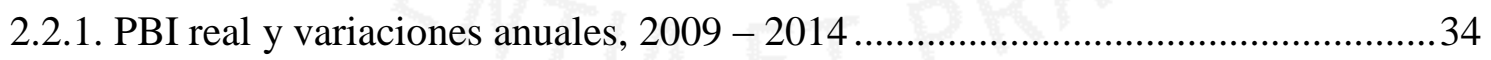

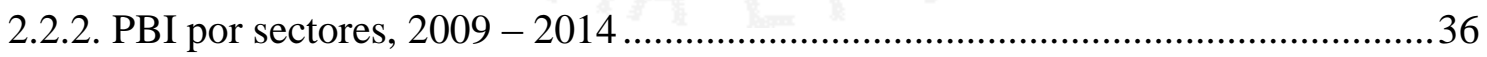

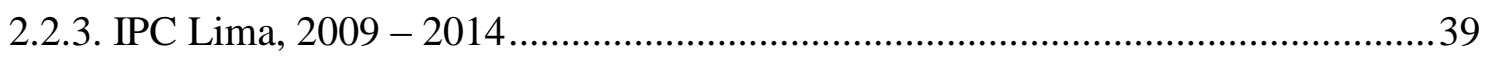

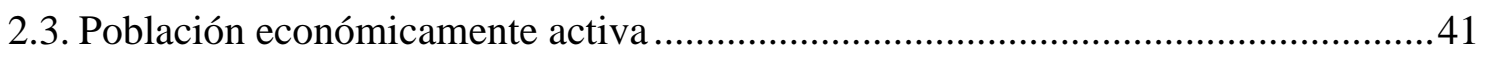

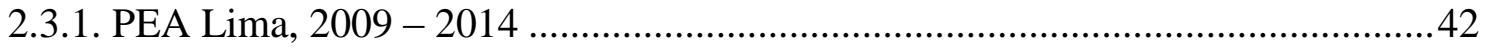

2.3.2. PEA ocupada Lima, por categorías, 2009 - 2014 ............................................... 45

2.3.3. PEA ocupada Lima por tamaño de empresa ............................................................ 48

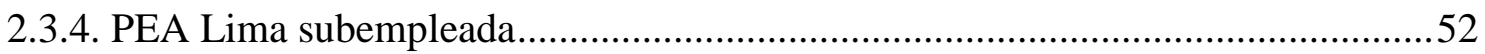




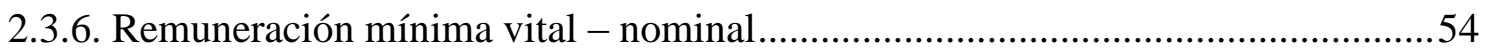

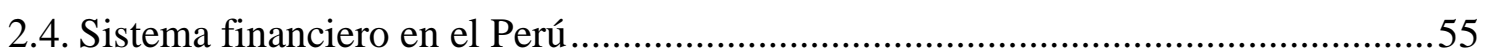

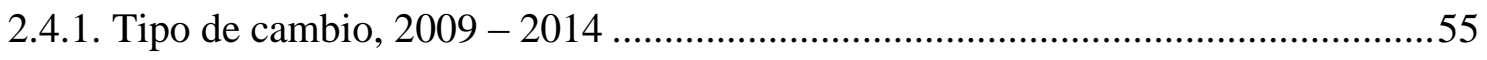

2.4.2. Evolución de las colocaciones a PYMES del total del sistema bancario ..............57

2.4.3. Créditos directos a microempresas, entidades bancarias $(2009-2014)$...............58

CAPÍTULO III: CONTRASTACIÓN DE HIPÓTESIS..............................................62

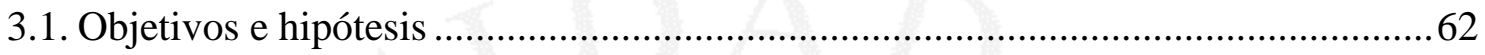

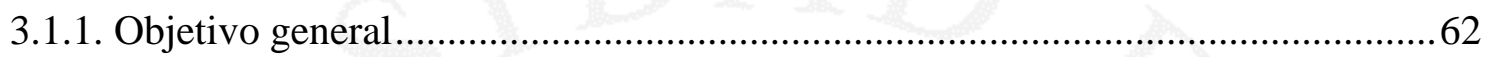

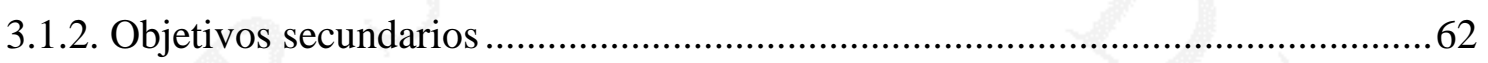

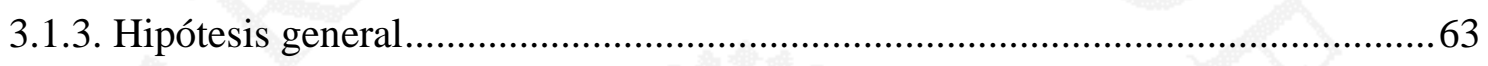

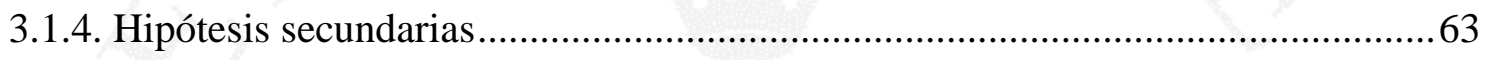

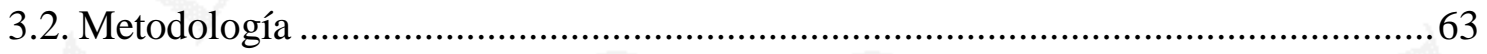

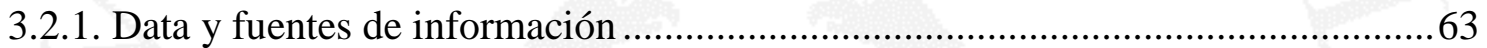

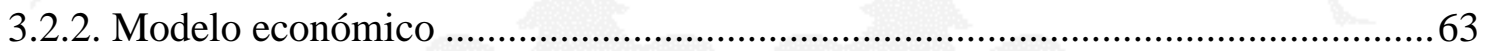

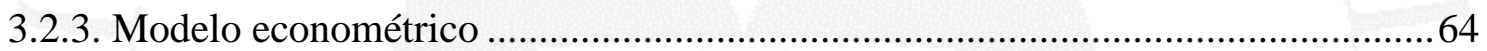

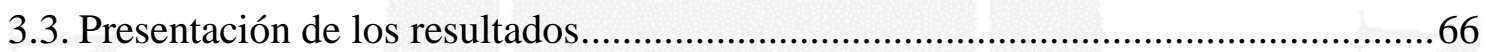

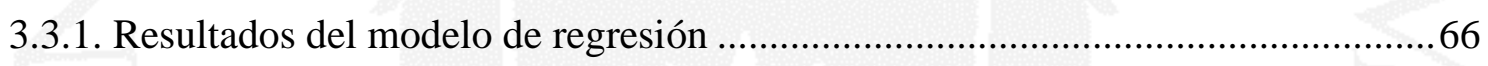

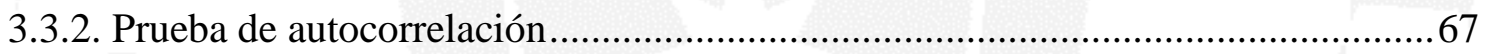

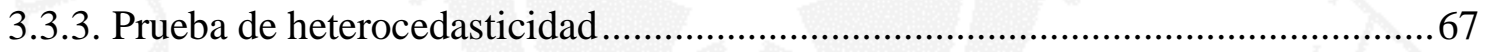

3.3.4. Modelo de regresión corregido por el problema de heterocedasticidad ................68

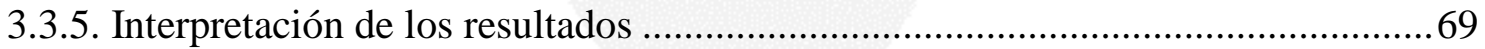

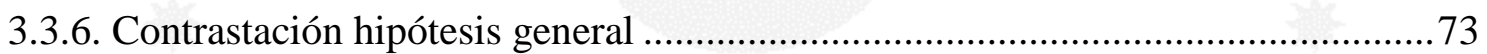

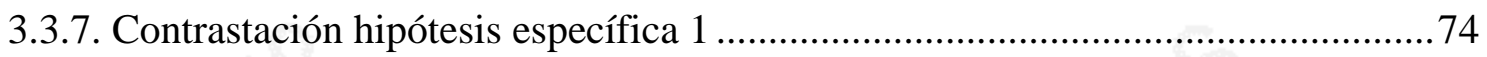

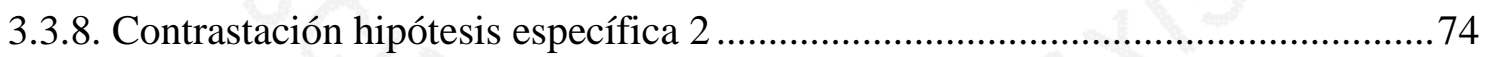

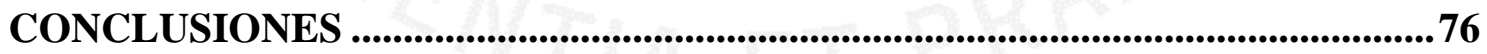

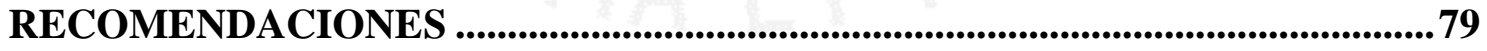

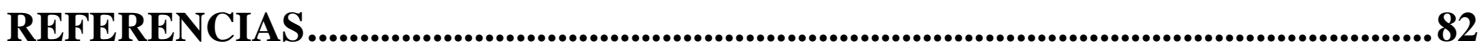

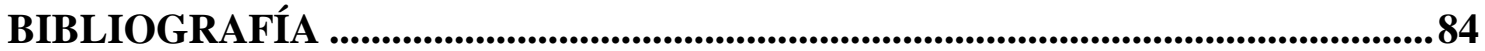

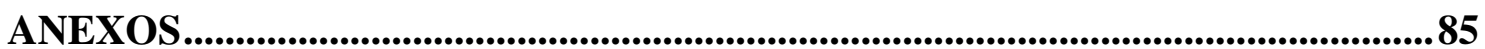




\section{ÍNDICE DE TABLAS}

Tabla 1.1. MIPYME por tamaño, según departamento, 2012 ...................................

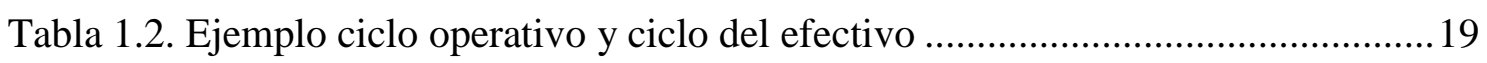

Tabla 1.3. Ejemplo de balance general (miles de dólares) ............................................24

Tabla 1.4. Ejemplo de estado de resultados (miles de dólares) .....................................25

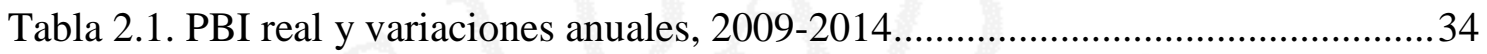

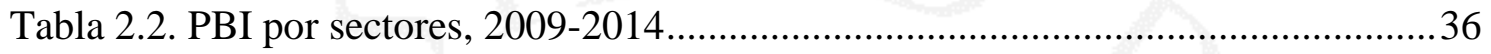

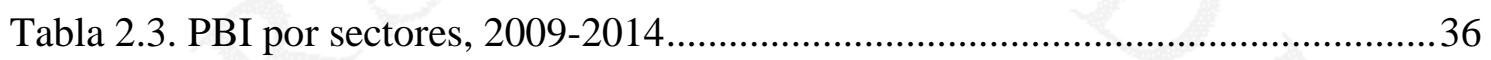

Tabla 2.4. Ranking del PBI real por sector económico (2014)..................................... 38

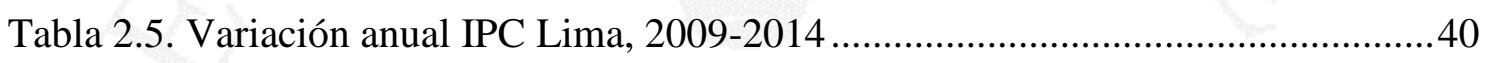

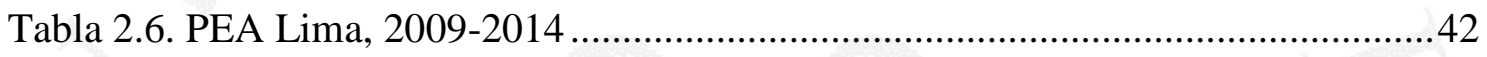

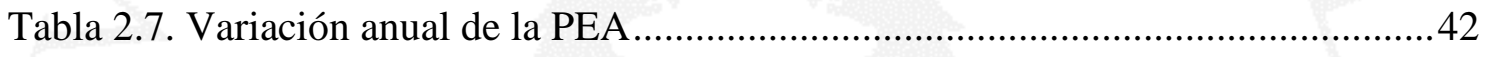

Tabla 2.8. Ratio PEA ocupada/PEA total de Lima. 2009-2014 ....................................43

Tabla 2.9. PEA ocupada Lima por tamaño de empresa. De 1 a 10 trabajadores (miles de personas)

Tabla 2.10. PEA ocupada de Lima por tamaño de empresa. De 11 a 51 trabajadores (miles de personas)

Tabla 2.11. PEA ocupada de Lima por tamaño de empresa. De 51 a más trabajadores (miles de personas) .50

Tabla 2.12. Tipo de cambio, 2009-2014. .55

Tabla 2.13. Crédito directo a microempresas, según entidades bancarias. 2009-2014 (miles de nuevos soles) .58

Tabla 2.14. Variación del crédito otorgado a las PYMES por las entidades bancarias .. 59

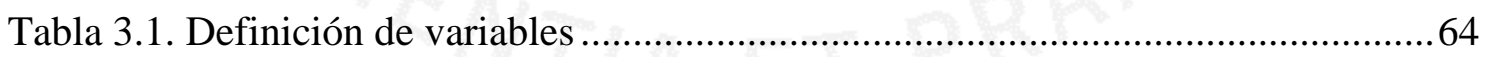

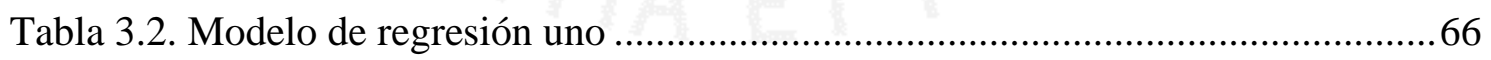

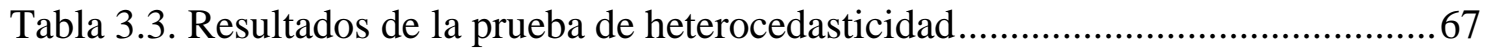

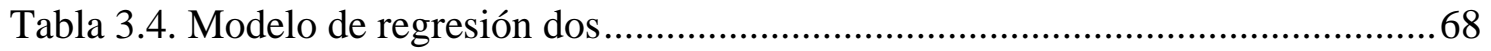

Tabla 3.5. Ejemplo práctico del efecto de las ventas en la deuda.................................. 70

Tabla 3.6. Ejemplo práctico del efecto de los inventarios en la deuda.......................... 71

Tabla 3.7. Ejemplo práctico del efecto del flujo de caja en la deuda .............................72

Tabla 3.8. Ejemplo práctico del efecto de la tasa de interés en la deuda........................73 


\section{ÍNDICE DE FIGURAS}

Figura 2.1. Tendencia del PBI real y de las variaciones del PBI. Periodo 2009-2014 ... 35

Figura 2.2. PBI por sectores económicos, 2009 - 2014 37

Figura 2.3. Tendencia IPC Lima y variación IPC Lima anual, 2009-2014 . .40

Figura 2.4. Empleo mensual en Lima Metropolitana. 2009-2014 ................................. 44

Figura 2.5. PEA ocupada en Lima, por categorías. 2009-2014 .......................................45

Figura 2.6. PEA ocupada Lima, por categorías. Año 2014 ......................................... 47

Figura 2.7. Distribución y evolución de la PEA ocupada por tamaño de empresas ........51

Figura 2.8. PEA subempleada Lima Metropolitana. 2009 - 2014 ...................................52

Figura 2.9. Tasa de desempleo en Lima Metropolitana. 2009 - 2014.............................53

Figura 2.10. Evolución de la remuneración mínima vital en Perú. 2009 - 2014 ............54

Figura 2.11. Tipo de cambio bancario promedio nominal. 2009-2014 ..........................56

Figura 2.12. Evolución de las colocaciones a PYMES................................................57 


\section{ÍNDICE DE ANEXOS}

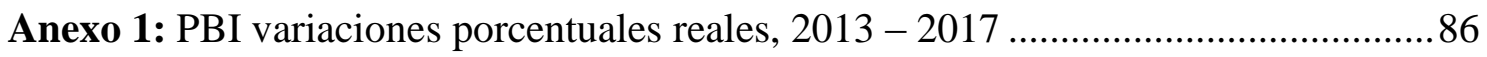

Anexo 2: Índice de competitividad mundial, 2008 - 2017 ..............................................8 87

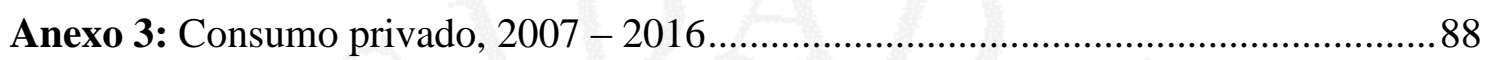

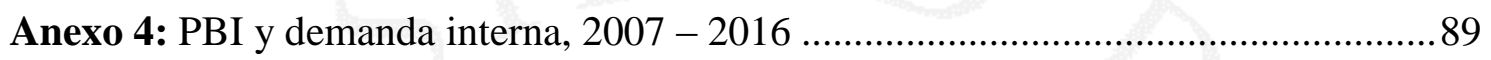

Anexo 5: Producto bruto interno por tipo de gasto, 2014 - 2016 ..................................90

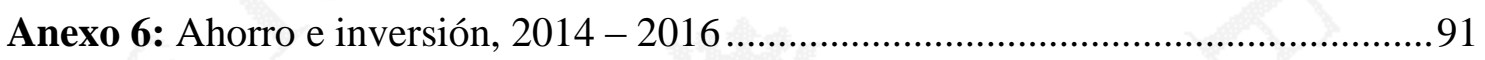

Anexo 7: Precios mundiales de diversos productos básicos, 2010 - 2014 ..................... 92 


\section{INTRODUCCIÓN}

El sistema financiero es un elemento determinante para el desarrollo económico, debido a que canaliza el dinero de la economía a través de entidades para el financiamiento. De la misma forma, las PYMES en Perú, son parte importante de la economía ya que representan la gran mayoría del total de empresas en el país.

Bajo esta premisa, resulta interesante realizar una investigación que involucre al financiamiento bancario de las PYMES. Un financiamiento que podría servir como herramienta para promover el crecimiento y desarrollo de dichas empresas.

Sin embargo, el enfoque que se propone en ésta investigación es analizar puntualmente cuatro variables financieras que en teoría deberían influir sobre el financiamiento bancario que asumen las PYMES. Las variables a analizar son las ventas, los inventarios, el flujo de caja y la tasa de interés.

La investigación será dividida en tres capítulos en los cuales se analizará la economía desde un enfoque distinto para cada uno de ellos.

En el primer capítulo se evaluará el marco teórico del sistema financiero, analizando los principales motivos por los cuáles las empresas requieren financiamiento. Asimismo se explicarán las alternativas de financiamiento que tienen las empresas, así como los elementos claves para entender el por qué una empresa necesita liquidez, explicando el ciclo operativo y ciclo de efectivo.

En el segundo capítulo se conocerá la evolución de las variables de la economía. La delimitación del estudio es sobre el financiamiento bancario de corto plazo que asumen las PYMES de la ciudad de Lima durante el año 2014. De esta manera, es necesario conocer el comportamiento de la economía a nivel nacional y sobre todo en la ciudad de Lima durante los años previos al 2014, con la intención de entender el panorama previo y durante el año de estudio.

Se analizará a la economía a través de tablas y figuras que muestren datos relevantes y que evalúen las tendencias del periodo previo al estudio. 
En el tercer capítulo se contrastarán las hipótesis planteadas aplicando distintas pruebas econométricas para llegar a resultados que lleven a una posterior interpretación estadística y económica. Estos resultados permitirán aceptar o rechazar las hipótesis propuestas para luego obtener conclusiones tanto del modelo econométrico, como del tema en general.

Como conclusión general, la investigación se realizará de la siguiente manera:

En primer lugar se analizará teóricamente porque las empresas necesitan financiarse y que beneficios genera la obtención de liquidez para su crecimiento.

En segundo lugar, se conocerá como han evolucionado las distintas variables de la economía y del sistema financiero en el tiempo.

Finalmente, se determinará si las ventas, inventarios, flujo de caja y tasa de interés son significativas para la deuda bancaria de corto plazo que asumen las PYMES.

El estudio servirá para conocer el nivel de influencia de las variables propuestas sobre la deuda. Esta información permitirá conocer el grado de importancia de las variables sobre el modelo para posteriormente aceptar o rechazar las hipótesis planteadas. A partir de la obtención de los resultados se podrán sacar conclusiones sobre el estudio, las cuales se detallarán al final de ésta investigación.

Se eligió el año 2014 como año de estudio, ya que fue un periodo donde hubo algunos datos estadísticos en el sector económico que llaman la atención. Si bien la economía peruana viene experimentando un crecimiento sostenido durante los últimos años, existen sucesos que desaceleran o aceleran aún más dicho crecimiento y generan fluctuaciones en las curvas de evolución económica.

La investigación consiste en analizar el acceso al financiamiento bancario que tienen las PYMES en el mercado, ya que representan más del $90 \%$ del total de empresas en el país y sus operaciones son un indicador que tiene incidencia sobre el producto bruto interno.

De esta manera, se puede determinar que si las PYMES tuviesen acceso al financiamiento y por lo tanto, la oportunidad de desarrollarse económicamente, esto podría tener un impacto positivo sobre el PBI.

Al evaluar algunos indicadores de los últimos años podemos concluir que el 2014 fue el año donde hubo una menor variación porcentual real del PBI de los últimos 5 años, 
alcanzando un crecimiento de $2.4 \%$, a diferencia de otros años, donde se experimentó una mayor evolución.

Otro dato que resulta interesante para elegir el 2014 como periodo de estudio, es que en dicho periodo, se experimentó la mayor caída en el ranking de Índice de Competitividad Mundial.

El Índice de Competitividad Mundial, desarrollado por el International Institute for Management Development (IMD), en alianza con CENTRUM Católica, mide cómo una economía gestiona la totalidad de sus recursos y competencias, para elevar su productividad e incrementar el bienestar de su población. Este índice está conformado por veinte factores, distribuidos en cuatro pilares (desempeño económico, eficiencia del gobierno, eficiencia en los negocios e infraestructura), comparando los resultados de 63 países a nivel mundial.

Por otro lado, se ha evidenciado un retroceso en Perú en cuanto a la competitividad mostrada, ya que se percibe menos eficiente en cuanto al uso de recursos (legales, financieros, macroeconómicos, etc.) en comparación a otros países de la región.

Esta caída permite identificar al año 2014 como un año atípico dentro del comportamiento económico, por lo que resulta oportuno realizar un estudio sobre el año donde se experimentó una caída tanto en el PBI como en el Índice de Competitividad Mundial. 


\section{CAPÍTULO I: MARCO TEÓRICO}

En este capítulo se analizan las principales teorías que sustentan esta investigación, así como los diferentes estudios realizados sobre la importancia del financiamiento para el crecimiento y la creación de valor para las empresas.

\subsection{Las PYMES}

La información a continuación fue obtenida tomando como referencia el libro "Gestión administrativa y tributaria de PYMES” de la autora Gemma Acedo Muñoz, el cuál sirvió como complemento teórico para redactar el siguiente punto.

\subsubsection{La empresa y sus objetivos}

Para empezar el estudio, es importante conocer los significados y definiciones de los términos más importantes para la investigación. En primer lugar, se pretende conocer cuáles son las funciones principales de las empresas y posteriormente analizar a las PYMES

El estudio propuesto se enfoca en las pequeñas y medianas empresas y el financiamiento que éste tipo de entidades requieren. Por lo que para empezar, definiremos a una empresa y posteriormente detallaremos sus principales características.

Acedo (2011) habla de los factores que pueden de una u otra manera formar parte fundamental de una empresa y menciona que

La empresa es un conjunto de factores humanos, factores económicos y factores de la producción ordenados bajo la dirección y gestión de una unidad directiva. Una empresa, se crea y se mantiene para alcanzar unos objetivos propuestos, estos objetivos determinarán la tipología de empresa y determinarán la forma de su organización. (p.20)

Para que una empresa consiga las metas propuestas, su misión, visión, valores y objetivos deberán ser coherentes con la meta a la cual se desea llegar. Por lo tanto, el éxito dependerá de que exista una cohesión entre sus miembros hacia una sola dirección, que le permita lograr los objetivos. 
Un tema importante para la consecución de los objetivos es el compromiso e identificación con la empresa por parte de sus miembros. Para lograr mejores resultados y cumplir con los objetivos trazados, un punto clave dentro de la organización es que cada una de las unidades de la institución entienda la misión, visión y valores del lugar donde trabajan. Entender que quiere la empresa y comprometerse con ello es un factor determinante para lograr los objetivos planteados.

En cuanto a los objetivos, estos deben cumplir con una serie de características que les permita ser coherentes con las actividades que desarrolla la empresa. Plantear metas al inicio de un periodo sirve para ver hacia donde apuntan las organizaciones.

Los objetivos propuestos deben contar con cuatro características que propone la autora del libro "Gestión administrativa y tributaria de PYMES” y que serán citados a continuación “(...) las características que deben tener los objetivos empresariales:

- Deben ser claros y específicos

- Deben ser reales y alcanzables

- Deben ser medibles

- Deben ser motivadores (Acedo, 2011, p.20).

Estas cuatro características que deben tener los objetivos empresariales son claves para la consecución de los mismos. Por ende lo que se entiende por cada uno de ellos es lo siguiente:

Los objetivos deben ser claros y específicos para que cada una de las partes de la empresa sepa y conozca qué es lo que se quiere conseguir. Si se entiende a donde se quiere llegar, es más sencillo que suceda.

Asimismo, éstos deben ser reales y alcanzables. Con esto nos referimos a que las metas propuestas deben encontrarse dentro de nuestras posibilidades económicas y humanas de conseguir. Proponer un objetivo que esté fuera del alcance de la entidad solo generará una frustración para las partes de la empresa, por lo que los objetivos tienen que estar dentro de las posibilidades de la misma.

Los objetivos, como todos los resultados deben ser cuantificables. Esto significa que uno debe proponerse metas que se puedan medir. El hecho de poder medir un objetivo, permitirá ver si al final del periodo propuesto se consiguieron los resultados esperados. 
Por último, los objetivos deben ser motivadores. Un objetivo motivador es un reto para la empresa y para cada una de las partes involucradas en su consecución. Para que un objetivo tenga estas características, este debe ser claro, alcanzable y cuantificable; aparte de esto puede existir algún incentivo de por medio para que haya mayor motivación para conseguirlo.

Como parte del marco teórico, es determinante conocer que tan significativas son las PYMES para la economía tanto del país, como de la ciudad de Lima. Por lo tanto, se obtuvo información del Ministerio de Producción para conocer qué porcentaje del total de las empresas en la ciudad de Lima son micro, pequeñas y medianas empresas.

La investigación propuesta evalúa el financiamiento bancario de corto plazo que obtienen las PYMES de Lima. Es por este motivo que es necesario conocer la cantidad de micro, pequeñas y medianas empresas hay.

Para el año 2012, habían 640547 MIPYMES en la ciudad de Lima y 1340703 en todo el Perú, lo que significa que del 100\% de las MIPYMES, el $47.78 \%$ pertenecen a la ciudad de Lima. Esto indica que las MIPYMES de la ciudad de Lima son una parte importante de la economía nacional, por lo que se considera oportuno investigar sobre el financiamiento bancario que estas asumen, ya que de eso depende gran parte de su crecimiento.

En ese sentido es importante recalcar que en la ciudad de Lima habían un total de 646206 empresas para el año 2012, lo que quiere decir que el 99.12\% del total de las empresas en dicha ciudad eran micro, pequeñas y medianas empresas.

Tal y como se muestra en la Tabla 1.1, se concluye que Lima es la ciudad peruana con mayor influencia sobre la economía del país, ya que concentra cerca de la mitad de pequeñas y medianas empresas del total. Además, incluyendo a las grandes empresas, la ciudad de Lima cuenta con 646206 organizaciones de un total de 1348611 que hay a nivel nacional. Esto significa que para el año 2012, el 47.92\% de las empresas en el Perú se ubicaban en la ciudad de Lima. 
Tabla 1.1

MIPYME por tamaño, según departamento, 2012

\begin{tabular}{|c|c|c|c|c|c|c|}
\hline Departamento & $\begin{array}{c}\text { Micro } \\
\text { empresa }\end{array}$ & $\begin{array}{l}\text { Pequeña } \\
\text { empresa }\end{array}$ & $\begin{array}{l}\text { Mediana } \\
\text { empresa }\end{array}$ & $\begin{array}{c}\text { Total } \\
\text { MIPYME }\end{array}$ & $\begin{array}{c}\text { Gran } \\
\text { empresa }\end{array}$ & $\begin{array}{c}\text { Total } \\
\text { empresas }\end{array}$ \\
\hline TOTAL & 1270009 & 68243 & 2451 & 1340703 & 7908 & 1348611 \\
\hline Amazonas & 7294 & 239 & 10 & 7543 & 14 & 7557 \\
\hline $\begin{array}{l}\text { Áncash } \\
\text { Apurímac }\end{array}$ & $\begin{array}{l}39206 \\
9596\end{array}$ & $\begin{array}{l}1501 \\
288\end{array}$ & $\begin{array}{l}40 \\
1\end{array}$ & $\begin{array}{l}40747 \\
9885\end{array}$ & $\begin{array}{l}73 \\
16\end{array}$ & $\begin{array}{l}40820 \\
9901\end{array}$ \\
\hline $\begin{array}{l}\text { Arequipa } \\
\text { Ayacucho } \\
\text { Cajamarca }\end{array}$ & $\begin{array}{l}73123 \\
14229 \\
27293\end{array}$ & $\begin{array}{l}3180 \\
476 \\
1167\end{array}$ & $\begin{array}{l}114 \\
15 \\
32\end{array}$ & $\begin{array}{l}76417 \\
14720 \\
28492\end{array}$ & $\begin{array}{l}268 \\
29 \\
79\end{array}$ & $\begin{array}{l}76685 \\
14749 \\
28571\end{array}$ \\
\hline $\begin{array}{l}\text { Callao } \\
\text { Cusco }\end{array}$ & $\begin{array}{l}40329 \\
49248\end{array}$ & $\begin{array}{l}2197 \\
1440\end{array}$ & $\begin{array}{l}82 \\
32\end{array}$ & $\begin{array}{l}42608 \\
50720\end{array}$ & $\begin{array}{l}360 \\
86\end{array}$ & $\begin{array}{l}42968 \\
50806\end{array}$ \\
\hline $\begin{array}{l}\text { Huancavelica } \\
\text { Huánuco }\end{array}$ & $\begin{array}{l}5046 \\
17040\end{array}$ & $\begin{array}{l}118 \\
565\end{array}$ & $\begin{array}{l}2 \\
20\end{array}$ & $\begin{array}{l}5166 \\
17625\end{array}$ & $\begin{array}{l}2 \\
48\end{array}$ & $\begin{array}{l}5168 \\
17673\end{array}$ \\
\hline $\begin{array}{l}\text { Ica } \\
\text { Junín }\end{array}$ & $\begin{array}{l}32654 \\
47135\end{array}$ & $\begin{array}{l}1469 \\
1374\end{array}$ & $\begin{array}{l}31 \\
42\end{array}$ & $\begin{array}{l}34154 \\
48551\end{array}$ & $\begin{array}{l}131 \\
88\end{array}$ & $\begin{array}{l}34285 \\
48639\end{array}$ \\
\hline $\begin{array}{l}\text { La Libertad } \\
\text { Lambayeque }\end{array}$ & $\begin{array}{l}67371 \\
45406\end{array}$ & $\begin{array}{l}2829 \\
1604\end{array}$ & $\begin{array}{l}79 \\
56\end{array}$ & $\begin{array}{l}70279 \\
47066\end{array}$ & $\begin{array}{l}220 \\
125\end{array}$ & $\begin{array}{l}70499 \\
47191\end{array}$ \\
\hline $\begin{array}{l}\text { Lima } \\
\text { Loreto } \\
\text { Madre de Dios }\end{array}$ & $\begin{array}{l}\mathbf{5 9 7 4 4 8} \\
21853 \\
9067\end{array}$ & $\begin{array}{l}\mathbf{4 1 4 7 3} \\
1260 \\
499\end{array}$ & $\begin{array}{l}\mathbf{1 6 2 6} \\
42 \\
21\end{array}$ & $\begin{array}{l}\mathbf{6 4 0 5 5 4 7} \\
23155 \\
9587\end{array}$ & $\begin{array}{l}\mathbf{5 6 5 9} \\
103 \\
74\end{array}$ & $\begin{array}{l}\mathbf{6 4 6 2 0 6} \\
23258 \\
9661\end{array}$ \\
\hline Moquegua & 9262 & 250 & 6 & 9518 & 17 & 9535 \\
\hline Pasco & 8242 & 310 & 3 & 8555 & 18 & 8573 \\
\hline Piura & 50489 & 2097 & 53 & 52639 & 162 & 52801 \\
\hline Puno & 25796 & 1008 & 38 & 26842 & 101 & 26943 \\
\hline San Martín & 23143 & 931 & 23 & 24097 & 69 & 24166 \\
\hline Tacna & 22254 & 700 & 28 & 22982 & 52 & 23034 \\
\hline Tumbes & 9946 & 331 & 13 & 10290 & 26 & 10316 \\
\hline Ucayali & 17539 & 937 & 42 & 18518 & 88 & 18606 \\
\hline
\end{tabular}

Nota: Distribución de las MIPYME según su tamaño y ubicación geográfica.

Fuente: Ministerio de Producción del Perú (2013)

La interpretación estadística sirve como base para rescatar la importancia del tema de la investigación. La delimitación del tema propuesto es sobre el financiamiento bancario de las PYMES en la ciudad de Lima, por lo que este punto permite conocer que el $47.78 \%$ de las PYMES del Perú se encuentran en dicha ciudad. Esta información comprueba que el haber tomado a la ciudad de Lima para realizar el análisis es un buen indicador, ya que representa a gran parte de las empresas peruanas.

Para que una empresa opere, tiene primero que identificar su rubro, objetivos, plan de trabajo, metas a corto y largo plazo, entre otros. Para ello, es importante que antes de tomar alguna decisión sobre la ejecución de algún plan, se planee y se tengan claros a donde se quiere llegar. 
Los autores Arturo y José Antonio Morales Castro (2014) en su libro "Finanzas" definen como es que debe ser la planeación de una empresa y mencionan que

La planeación tiene como objetivo establecer los objetivos que se desean alcanzar, después de hacer un análisis de la compañía y su interacción con el medio ambiente donde se desarrollan los caminos para alcanzar los objetivos, a esas vías se les denominan estrategias y tácticas. (p. 2)

Según la fuente consultada, deben existir fases para definir la planificación, es por ello que se deben definir en orden las siguientes fases: Desarrollo de la misión y los objetivos, diagnóstico FODA, desarrollo de estrategias, preparación del plan estratégico, preparación de planes tácticos, control y diagnóstico de resultados y una planeación continua.

Paralelamente, para poder ejecutar los planes luego de definir el mercado y los tipos de estrategias a utilizar, se debe realizar una planificación financiera, la cual brindará la liquidez necesaria para poder cumplir con los planes establecidos. Para esto es fundamental los conceptos que se verán más adelante que son la inversión y el financiamiento.

\subsubsection{Características de las PYMES}

En el libro "Análisis organizacional en PYMES y empresas de familia" de Aldo Schlemenson (2013), se identifican características de este tipo de entidad. Algunas condiciones que se destacan son las siguientes:

- Está creada y dirigida por un emprendedor. Este usuario cumple tres roles dentro de su función, ya que es catalogado como el accionista mayoritario, ejecutivo principal y presidente del directorio. Esto crea una gran responsabilidad porque es la persona llamada a hacerse cargo del éxito del negocio.

- El objetivo de la entidad coincide con los objetivos del dueño, por ser este el creador y administrador de la PYME.

- El cliente es un agente determinante para las empresas de éstas características, ya que prevalece la orientación a darle un buen servicio a los usuarios. El trabajo debe ser ofrecido como "hecho a medida" del cliente. Este enfoque debería resultar favorable para la aceptación de la empresa en el mercado. (p. 243) 
Además de las características, es importante conocer cuál es la dinámica adecuada que debería emplear una PYME para direccionarse hacia un camino exitoso, que le permita alcanzar sus objetivos. Si bien el financiamiento es una de las claves para ejecutar los planes y acercarse más a lograr las metas propuestas, es oportuno analizar cuál es la dinámica que debe seguir una PYME para aumentar las probabilidades de conseguir el éxito.

Asimismo, Ruiz (2008) en su libro "Gestión de la empresa familiar” habla de los factores de corto y largo plazo para alcanzar el éxito, y en el cuál destacan a cinco de ellos:

- La importancia de la rentabilidad como resultado de una cadena de factores a corto y largo plazo.

- La necesidad de ser exitoso en el corto plazo para perdurar en el largo plazo.

- El papel relevante que tiene el hecho de disponer de una organización eficaz para ser exitoso en el corto plazo.

- La importancia para perdurar en el medio plazo de renovarse continuamente.

- Las personas como eje de la orientación de la empresa a la longevidad. (p. 58)

\subsubsection{Financiación de las PYMES}

La información a continuación fue obtenida tomando como referencia el libro "La PYME del siglo XXI. Tecnologías de la información, mercados y organización empresarial” de los autores Carlos Tirado, José R. Granger y María Nieto. Prólogo de Cándido Velázquez-Gaztelu. Este libro sirvió como complemento teórico para redactar el siguiente punto.

Las PYMES son empresas que, como todas, necesitan financiarse para la creación de valor del negocio. Sin embargo, debido a su tamaño y no tan alto nivel de facturación, la gran mayoría no cuenta con los recursos necesarios para poder autofinanciarse y así evitar tomar un préstamo bancario, que le generará intereses y pagos periódicos.

Tomar un préstamo para financiarse tiene un costo de la deuda, debido a que además de pagar el monto tomado, se pagan de intereses progresivamente durante un periodo determinado. 
Debido a este motivo, es importante analizar en un punto del capítulo el financiamiento de las PYMES, ya que es necesario conocer las condiciones y diferenciación que existe entre el acceso al crédito de las pequeñas empresas contra la obtención y condiciones de crédito que se otorgan a las grandes corporaciones.

En ese sentido, y recurriendo al libro anteriormente mencionado se puede inferir que Tirado, Granger y Nieto (1995) acotan que

Los estudios realizados sobre este colectivo destacan el peso específico de los recursos financieros a corto plazo, que es muy superior al de aquellos obtenidos a medio y largo plazo, especialmente en las empresas más pequeñas. La política financiera de la pequeña y mediana empresa debería reforzar el peso de la autofinanciación, una vez superada la fase de creación y despegue de la explotación, donde la financiación ajena es fundamental, de forma que se alcanzase un equilibrio entre los recursos propios y ajenos. Esta sería la base de la solvencia económica de la empresa. (p. 46)

Las pequeñas y medianas empresas son las que necesitan mayor financiamiento debido a su falta de recurso propios para autofinanciarse, sin embargo, por ser entidades con menor facturación, tamaño, e historial que la denominadas “empresas grandes”, éstas encuentran muchas trabas con las empresas del sistema financiero.

Los tres puntos en contra de las PYMES para la obtención de financiamiento, en búsqueda de su crecimiento son las limitaciones y condiciones que les imponen las propias entidades bancarias.

La primera, es que los bancos o fuentes de financiamiento exigen avales a las pequeñas y medianas empresas debido a que no quieren asumir riesgos con éstas debido a que no tienen un gran respaldo económico. De esta manera, una PYME necesita contar con un aval para obtener un financiamiento bancario. Primera restricción y diferenciación que marcan los bancos entre las PYMES y las empresas grandes, lo que resulta una limitación para la obtención de crédito para los pequeños empresarios.

En segundo lugar, a diferencia de las grandes empresas, las PYMES no pueden imponer sus condiciones de financiamiento en los bancos, ya que no tienen el poder de hacerlo por sus condiciones de empresas pequeñas y porque no solicitan un monto para el préstamo tan elevado. Debido a esto, los bancos son aquellos que imponen las condiciones, beneficiándose a costa de las pequeñas y medianas empresas. 
Por último, la tasa de interés bancario que reciben las PYMES para acceder al crédito no es la misma que la tasa de interés que se les brinda a empresas grandes y consolidadas en el mercado. Para los bancos, las PYMES significan un riesgo mucho mayor, por lo que para compensar tal riesgo, imponen altas tasas de interés bancario, lo que es un punto en contra de las pequeñas y medianas empresas. Esta tasa mayor puede significar una limitación, ya que como veremos más adelante, se plantea una relación inversa entre la tasa de interés bancaria y la deuda a corto plazo que asumen las PYMES.

De esta forma, se concluye que la exigencia de un aval, la imposición de condiciones por parte del banco y las altas tasas de interés son tres factores que restringen de cierta forma la obtención de financiamiento bancario por parte de las PYMES. Estos tres factores son la principal diferenciación entre las pequeñas y grandes empresas para la obtención del crédito; por lo que representan una limitación para el financiamiento de los pequeños empresarios.

En ese sentido Tirado, Granger y Nieto (1995) acotan que

Las soluciones a este problema pueden venir por dos vías: o aumentando el nivel de autofinanciación de las empresas, o bien captando fondos de los inversores en la adquisición de acciones de las PYME. Cualquiera de estas dos formas de actuar conseguiría que las empresas de este colectivo tuviesen una estructura más saneada y una menor dependencia crediticia del exterior. (p.47)

Bárbara Stallings y Rogério Studart (2006) hacen mención a este concepto en su libro "Financiamiento para el desarrollo: América Latina desde una perspectiva comparada" y lo refuerzan en el capítulo I, "Financiamiento para el desarrollo: Problemas y tendencias" ya que en este se explica que gran parte del desarrollo de las economías emergentes se basa en el financiamiento como aspecto fundamental.

Se señala que antiguamente no se priorizaba al sector financiero como una herramienta para el desarrollo, por lo contrario, se le daba mayor importancia al sector "real" de la economía, dándole mayor enfoque a la industrialización y a la tecnología como principales fuentes de desarrollo.

Si bien es cierto que ambos son métodos válidos que permiten el desarrollo y el crecimiento, en los últimos tiempos es donde el hecho de financiarse ha tomado mayor protagonismo en los mercados actuales, y resulta un método eficiente para alcanzar los objetivos empresariales y de desarrollo. 
Además, cabe recalcar que los autores Stallings y Studart vinculan al financiamiento con el crecimiento y señalan que la financiación debería considerarse como la variable independiente en un modelo de éxito.

Las PYMES representan un gran porcentaje del PBI y brindan trabajo a gran parte de la PEA, sin embargo, tal como señalan Vásquez, Carbajo y López (2010) en el libro "Manual para la financiación de la PYME", uno de los puntos en contra de las PYME es que presentan serios problemas para conseguir la financiación necesaria para su realizar sus actividades. Mientras que por otro lado, se concluye que las pequeñas empresas tienen, como todas las otras empresas, una necesidad de financiación para poder evolucionar.

Asimismo, Vásquez, Carbajo y López (2010) hablan de la formación del capital bruto en las empresas y acotan que

Uno de los grandes temas de la literatura clásica es la formación bruta de capital en las empresas, su estructura óptima de financiación y el estudio de cómo afectan las decisiones de financiación a los resultados y sobre la elección de los proyectos de inversión. (p.45)

Tal como dice la cita, la formación de capital y por lo tanto, obtención de liquidez, permitirá ejecutar los planes de inversión que se tengan, lo que en teoría significa la generación de futuras utilidades para la empresa.

En dicho libro, los autores señalan que contar con una estructura financiera óptima es de suma importancia para poder realizar el proyecto empresarial que tengan en mente, con ciertas garantías de éxito.

Asimismo, los autores hablan de un tema de importancia para la decisión y obtención de financiamiento. La negociación bancaria es un punto clave para definir la tasa de interés, las condiciones del préstamo (en caso se dé) y otros factores relevantes para cerrar el acuerdo.

La PYME, al ser una empresa pequeña, tiene poca influencia sobre las condiciones que el banco le ofrece, sin embargo, en caso haya una negociación entre la empresa y la entidad bancaria, se deberán tomar en consideración dos factores:

- El factor riesgo. Esto se refiere a la posibilidad que la entidad bancaria conceda o no el préstamo. Este es un factor que es ajeno a las facultades de negociación por 
parte de la empresa y se tiene poca influencia sobre este punto, ya que se decide el préstamo a partir de una evaluación por parte del banco.

- El factor precio. En caso se apruebe el préstamo por parte del banco, es aquí donde se definen las condiciones de pago de acuerdo a las exigencias del banco y a las características de la empresa. Se puede inducir que la tasa de interés es un factor sumamente determinante para aceptar el préstamo y para fijar las cantidades.

Otro tema relevante para el acuerdo de un posible préstamo por parte del banco a la empresa, se puede hallar en el capítulo XII del libro "Manual para la financiación de la PYME”. Los derechos y obligaciones que hay en el acuerdo son claves para definir las condiciones en el préstamo. En el libro Vásquez, Carbajo y López (2010) señalan que "en las relaciones que mantienen las entidades financieras con sus clientes, las obligaciones de éstos suelen estar muy claras, pues quedan explicitadas en los documentos y contratos que se suscriben cuando se formaliza una operación financiera" (p. 159).

En este caso, en el acuerdo entre ambas partes, los derechos de los clientes son: Información, disponibilidad, exactitud, confidencialidad y protección de los datos.

Una de las variables más importantes para la obtención de financiamiento es el tamaño de las empresas. Una empresa más grande (con mayor facturación y mayor número de trabajadores), será una empresa más atractiva para las entidades financieras como cliente, ya que su historial y características representan un menor riesgo para los bancos, por lo tanto, aumentan las posibilidades de obtener un préstamo y por ende, podrían mejorar las condiciones del contrato.

Por otro lado, Galindo (2005) en su libro "El tamaño empresarial como factor de diversidad", señala que la dimensión de la empresa constituye una variable decisiva en su financiación, lo que comprueba y fortalece la relación planteada en el párrafo anterior.

Asimismo, hace mención al tamaño de la empresa como factor clave de competitividad y habla sobre las repercusiones que tendrían las PYMES al tener mayores trabas para el financiamiento. Fundamenta su posición acotando que

Según todos nuestros antecedentes, la financiación se considera una de las principales causas de desventajas competitivas de las empresas de menor dimensión, tanto en su creación, como en sus oportunidades de crecimiento. (p.152)

Para ahondar más sobre el tema del financiamiento, se tomó como referencia al autor Roberto Bertossi (2009) en su libro "Financiamiento de pequeñas y medianas 
empresas", donde indica que existe una excesiva exigencia por parte del mercado de crédito, lo que deriva en una reducción de actividades por parte de las PYMES.

Es pertinente identificar que la dificultad de otorgamiento de crédito hacia estas empresas pequeñas, tiene como consecuencia el estancamiento y la desaparición de muchas de ellas por su falta de recursos para llevar a cabo los planes. Este es un tema relevante y a tomar en cuenta para nuestra economía, considerando el alto porcentaje que representan las PYMES del total de empresas.

Biasca (2005) hace referencia a las altas tasas de interés que reciben las PYMES para financiarse y poder ejecutar sus proyectos y en su libro "PYMES más competitivas. Experiencias prácticas de transformación de empresas en América Latina” señala que

En general la PYME se endeuda a corto plazo y no hace planes financieros a largo plazo.

Muchas veces se desaprovechan líneas de crédito de fomento para PYMES. Para desarrollar sus planes, para invertir o para afrontar necesidades de capital de trabajo, la PYME solicita usualmente créditos a un banco y encuentra que las garantías reales exigidas para solicitar créditos son numerosas o elevadas, y que además, se tiene que justificar en detalle para que se va a usar el dinero. (p. 22)

Si bien el tamaño de una empresa y la facturación de la misma es un indicador medible para ser calificada como PYME, hay otros factores de carácter cualitativo que "por lo general" identifican a este tipo de empresas. La informalidad suele ser un problema de este tipo de empresas, ya que suelen descuidar los aspectos legales. Cuando las PYMES se crean, no se suele investigar cual es el tipo de sociedad más adecuada para el tipo de operación que se va a ejercer, además, no suele registrar sus marcas o patentes, no toma precauciones en los contratos laborales y evita en muchos casos el pago de gastos legales. Este tipo de informalidad por la que suelen ser conocidas las PYMES, proyecta poca seriedad a los bancos, por lo tanto representa un riesgo más grande para los mismos. Esto genera que el banco sea más cauteloso para otorgar préstamos y en caso de darlos, las condiciones son mucho más rigurosas que para empresas más serias y de otras características.

\subsubsection{Marco legal-institucional de las políticas de financiamiento a PYMES}

El documento "Las políticas para el financiamiento de las PYMES en el Perú" preparado para CEPAL por Miguel Jaramillo y Néstor Valdivia sirvió como referencia para citar algunas partes que se considera pertinente resaltarlas, así como para el conocimiento de 
la parte legal-institucional de las políticas financieras, lo que sirvió como base para redactar este punto.

El marco legal e institucional explica de manera clara y detallada como se regula el sistema financiero y en particular el de las entidades de microfinanzas en el Perú.

La Superintendencia de Banca, Seguros y Administradora de Fondo de Pensiones (SBS), es la entidad del estado encargada de regir el funcionamiento del sistema financiero para que este funcione de manera eficiente.

La regulación y la supervisión de las entidades de microfinanzas en el Perú están a cargo de la Superintendencia de Banca, Seguros y Administradoras de Fondo de Pensiones (SBS). Entre las principales actividades de la SBS está la supervisión y la evaluación de riesgos crediticios, de mercado, de liquidez, operacional y legal del sistema financiero del país. El sistema financiero se rige de acuerdo a lo establecido por la Ley No. 26702 (...). Bajo lo establecido en esta normativa, en el sistema operan en la actualidad, además de la banca comercial o banca múltiple, tres tipos de instituciones orientadas a las microfinanzas (IMF): las Cajas Municipales de Ahorro y Crédito (CMAC), las Cajas Rurales de Ahorro y Crédito (CRAC) y las Entidades de Desarrollo de la Pequeña Empresa y Microempresa (Edpymes).

Un diseño del marco legal e institucional adecuado es la base para que el sistema financiero y las políticas de financiamiento se desenvuelvan de la mejor manera para la economía. Un diseño eficiente permitirá lograr los resultados esperados en la búsqueda de un buen manejo financiero. El objetivo de mejorar el sistema financiero desencadena finalmente en tener un impacto social y económico. Una buena normativa que permita tener leyes acorde con los objetivos propuestos impulsará al país a tener un crecimiento sostenido en el tiempo.

La importancia de este punto dentro del capítulo se debe a que es necesario conocer cuáles son las entidades que regulan el manejo y desenvolvimiento del sistema financiero a través del tema legal, así como comprender cuál es la importancia de estos organismos para la economía en general.

Las modificaciones o variaciones que ocurran dentro del marco legal tendrán un impacto en el sistema financiero. Estos cambios podrían afectar de manera directa el financiamiento de las empresas, por lo que la aplicación de políticas en favor de las PYMES promovería un crecimiento de éstas pequeñas y medianas empresas. Debido a 
esto, es importante conocer los temas más resaltantes del marco para evaluar cómo su gestión influyó en el acceso al crédito.

Por su parte Jaramillo y Valdivia (2005) hablan del diseño legal en el que se basa el sistema financiero y mencionan que

Ha habido un avance importante en el diseño de un marco legal e institucional adecuado para el desarrollo de políticas financieras en general y las del microcrédito, en particular. A inicios de la década de los noventas se llevó a cabo una reforma financiera orientada a hacer más eficiente el mercado financiero en un contexto de una economía abierta de libre mercado, cuyos cambios tuvieron un impacto positivo sobre el sistema bancario (Morris 2000). Esta reforma incluyó el diseño de un nuevo marco normativo, que reemplazó al que proveía la Ley de Bancos de 1932, y otorgó un nuevo rol a la entidad supervisora del sistema, fortaleciendo sus capacidades de supervisión. (p.4)

El nuevo marco normativo, el cual se detalla en el documento, resalta algunos elementos claves para la obtención de mejores resultados en el sistema financiero.

Además, Jaramillo y Valdivia (2005) mencionan aristas importantes en el nuevo marco legal, que busca entre otras cosas el fomento de la competencia, eliminación de controles, etc. Para sustentarlo los autores mencionan que

Algunos de los elementos más asaltantes de este nuevo marco son: la ampliación de las actividades de los bancos, a través del concepto de banca múltiple; el impedimento de que el Estado sea propietario de empresas financieras de primer piso; fomento de la competencia (...); y eliminación de controles a la asignación del crédito y tasas de interés. Así mismo, se dio una nueva Ley Orgánica de la Superintendencia de Banca y Seguros, que amplió sus instrumentos de fiscalización y facultades de sanción. La estabilidad del sistema financiero en este periodo, a pesar de las diferentes crisis internacionales, es un buen indicador de los efectos positivos de la reforma emprendida. (p. 5)

De esta manera se puede determinar que el nuevo marco normativo ha traído consecuencias favorables al sistema financiero y a la economía en general. Ésta modificación además de promover la ampliación de las actividades de los bancos, el fomento de la competencia, la eliminación de controles a la asignación del crédito y tasas de interés, entre otras medidas; también se establecieron leyes sobre el crédito y el mercado de las microfinanzas en general, promoviendo el desarrollo económico.

Asimismo, una de las leyes más importantes del proceso fue la No. 26702, la cual dividió el crédito en cuatro tipos distintos: comercial, de consumo, hipotecario y crédito 
a microempresas. Además, promovió el desarrollo de las CMAC, CRAC y de las EDPYMES fomentando la competencia en el mercado en beneficios de las pequeñas empresas.

Este nuevo marco normativo dado en la década de los noventas, generó una expansión y crecimiento significativo del sector financiero y en especial de las pequeñas y medianas empresas. Las microfinanzas eran un tema al cual no se le daba tanta importancia, previa imposición de este marco, sin embargo a partir de él hubo una mayor preocupación hacia este sector y se aplicaron leyes y normas que promuevan el crédito financiero para las PYMES.

¿Qué impacto ha tenido este marco normativo en la actualidad? La promoción del crédito y regulación del sistema financiero ha permitido que exista un mayor financiamiento empresarial que impulse la economía del país. Las pequeñas y medianas empresas representan un porcentaje más que significativo del total de empresas en el Perú y la promoción del crédito y brindarles mayores facilidades sobre el sistema financiero en general, impulsan a que estas entidades se financien y creen valor a través de sus operaciones.

En cuanto a los principales actores de las políticas financieras para las PYMES, las entidades que destacan por tener un papel determinante en el crédito son la Corporación Financiera de Desarrollo (COFIDE), cuya función es canalizar el crédito por medio del sistema financiero, supervisado y regulado por la Superintendencia Nacional de Banca, Seguros y AFP.

Otra de las entidades que es importante para el tema de las PYMES es el Fondo de Garantía para Préstamos a la Pequeña Industria (FOGAPI). La tarea de esta entidad es la de dar garantía para los créditos otorgados a las pequeñas y medianas empresas.

Asimismo, existen algunos fondos que se enfocan en las PYMES como lo son el Fondo de Asistencia a la Pequeña Empresa (FAPE) que se encarga de proveer capital a aquellas pequeñas empresas dedicadas a las exportaciones, y que participan de estas entidades siendo parte minoritaria en el accionariado.

Además del Fondo de Asistencia a la Pequeña Empresa, otro fondo que opera en la banca comercial es el FONDEMI. Si bien su aporte no es tan grande, igualmente han servido como parte del financiamiento para el crecimiento de las pequeñas empresas. 
Otro elemento determinante para el crecimiento y evolución del sistema financiero en general son las centrales de riesgo. Las cuales de dedican en investigar el historial crediticio de personas naturales y jurídicas con la intención de evaluar el riesgo. Estas entidades son Infocorp y Certicom.

Finalmente se concluye que el marco legal-institucional es determinante para administrar, regular y promover el financiamiento empresarial en búsqueda del desarrollo económico del país.

Para ver su impacto y relación con el tema, fue necesario conocer cada una de las entidades que lo componen, así como las políticas que se aplicaron en favor del acceso al crédito de las PYMES, lo que refuerza el conocimiento acerca del contexto en el que operan dichas empresas.

\subsection{El ciclo operativo y el ciclo del efectivo}

¿Cuál es uno de los principales problemas de las finanzas a corto plazo? Uno de los grandes problemas es que las entradas y salidas de efectivo de las empresas no se encuentran sincronizadas. ¿Qué significa esto? Que por ejemplo, la compra de inventarios de una empresa y la salida de efectivo por tal adquisición no sucede el mismo día que el ingreso de efectivo por la venta de sus productos.

Por lo tanto, los días de diferencia entre la salida de efectivo por compras y el ingreso de efectivo por las ventas de una empresa, genera una brecha que habrá que analizar.

\subsubsection{Definición del ciclo operativo y ciclo del efectivo}

Para definir el ciclo operativo y ciclo del efectivo, resulta más dinámico entenderlo a través de un ejemplo práctico que explique las brechas que existen entre las salidas e ingresos de efectivo de una empresa a través de sus operaciones.

Para explicarlo de forma sencilla se tomó un ejemplo del libro "Fundamentos de finanzas corporativas" de los autores Ross, Westerfield y Jordan (2010), que se detalla a continuación.

Empiécese con un caso sencillo. Un día, al que se le llamará Día 0, se compran 1000 dólares en inventario a crédito. La factura se paga 30 días más tarde y después de 
otros 30 días alguien compra 1000 dólares en inventario por 1400 dólares. Este comprador no paga sino después de otros 45 días. Estos acontecimientos se resumen en forma cronológica como sigue:

Tabla 1.2

Ejemplo ciclo operativo y ciclo del efectivo

\begin{tabular}{c|cc}
\hline Día & Actividad & Efecto en el efectivo \\
\hline 0 & Adquirir inventario & Ninguno \\
30 & Pagar el inventario & $(-) \$ 1,000$ \\
60 & Vender el inventario a crédito & Ninguno \\
105 & Cobrar la venta & $(+) \$ 1,400$ \\
\hline
\end{tabular}

Nota: Ejemplo del ciclo operativo y ciclo del efectivo.

Fuente: Ross, Westerfield y Jordan (2010)

\subsubsection{Ciclo operativo}

El ciclo operativo dentro del ejemplo podría ser definido como "el ciclo total”. Es decir, es el periodo de tiempo desde que una empresa comprar sus inventarios, hasta que cobra el efectivo por la venta. Durante ese periodo de tiempo, como se ve en el ejemplo, suceden cuatro etapas:

La primera es la adquisición de los inventarios en el día 0. En la segunda etapa (únicamente si es que el proveedor le otorga crédito a la empresa) se realiza el pago por la materia prima adquirida en el día 30. En la tercera etapa se venden los inventarios o productos terminados al día número 60 , donde los inventarios salen de la empresa, sin embargo aún no se cobra por la venta de los mismos. Finalmente la cuarta etapa consta del cobro en efectivo por la venta de los productos terminados, la cual en el ejemplo sucede en el día 105.

Si bien en el ejemplo se muestran cuatro etapas, éstas se dividen en dos componentes en las finanzas de corto plazo. El primero de ellos es el periodo de tiempo en el que se adquiere y vende el inventario, al cual se le denomina periodo de inventario. Además, la segunda parte es el tiempo que transcurre desde la venta al crédito de los inventarios, hasta el ingreso del efectivo por la venta. Este segundo componente el ciclo operativo es llamado periodo de cuentas por cobrar. 
De esta manera, al ciclo operativo se le puede definir como la suma del periodo de inventarios y el periodo de cuentas por cobrar.

Dentro del ejemplo, el periodo de inventario sería de 60 días y el periodo de cuentas por cobrar de 45 días. De esta manera, se concluye que el ciclo operativo en el ejemplo seria de 105 días.

En ese sentido Ross, Westerfield y Jordan (2010) hablan y analizan el ciclo operativo acotando que

El ciclo operativo describe cómo un producto se desplaza en las cuentas del activo circulante. El producto empieza a existir como inventario, se convierte en una cuenta por cobrar cuando se vende y, por último, se transforma en efectivo cuando se cobra la venta. Obsérvese que, en cada paso, el activo se acerca cada vez más al efectivo. (p. 582)

\subsubsection{Ciclo del efectivo}

Para entender el ciclo de efectivo, hay un nuevo término que es necesario conocer: el periodo de cuentas por pagar. Este periodo es el tiempo que transcurre desde que una empresa recibe los inventarios por parte de su proveedor (en el día 0) hasta el momento en el que paga por ellos. Es decir, dentro del ejemplo, mencionado líneas arriba, el periodo de cuentas por pagar sería de 30 días.

Se sabe que no se pagan los inventarios hasta 30 días después de haberlos adquirido, sin embargo, no se cobra por la venta de los mismos sino hasta 105 días después. De ésta forma se tiene que conseguir un financiamiento por la diferencia entre los 30 y los 105 días. El financiamiento se deberá conseguir por $105-30$ = 75 días. A este periodo se le denomina ciclo del efectivo.

Por ello, la definición del ciclo del efectivo es el número de días que transcurren desde que se paga a los proveedores por los inventarios, hasta el día que se recibe el dinero de la venta por parte de los clientes. Dicho de otra manera, el ciclo del efectivo es la diferencia que existe entre el ciclo operativo y el periodo de cuentas por pagar.

Para entender ésta definición de una forma más práctica, se tomará el ejemplo citado para hallar el ciclo del efectivo. Como se sabe, el ciclo del efectivo es el ciclo operativo menos el periodo de cuentas por pagar, por lo que en este caso la ecuación sería la siguiente: 
Ciclo del efectivo $=$ Ciclo operativo - Periodo de cuentas por pagar

El resultado sería que el ciclo de efectivo es de 105 días menos 30 días, lo que da un total de 75 días. Éstos 75 días son periodo de tiempo por el que la empresa necesitara financiamiento.

\subsubsection{Importancia del ciclo operativo y el ciclo del efectivo para las decisiones de financiamiento y planeación a corto plazo}

Las entradas y salidas de efectivo no se encuentran sincronizadas, por lo que esto genera brechas en los flujos de efectivo. El ciclo operativo detalla las cuatro etapas que existen por las que una empresa atraviesa al comprar y vender sus inventarios. Como vimos en puntos anteriores, estas cuatro etapas se dividen en dos componentes: el periodo de inventarios y el periodo de cuenta por cobrar.

De igual manera, se explicó como hallar el ciclo del efectivo, que es la diferencia que existe entre el ciclo operativo y el periodo de cuentas por pagar. Ésta diferencia genera una brecha, la cual deberá ser cubierta financieramente para mejorar los rendimientos de la empresa.

Cabe mencionar que existen dos alternativas que podría realizar la empresa para cubrir ésta brecha. La primera de ellas es modificar el periodo de inventarios, el periodo de cuentas por cobrar y el periodo de cuentas por pagar. ¿Cómo se haría esto? A través de la negociación con sus principales proveedores y clientes. Se explicará esta primera alternativa detallando que se podría hacer para mejorar cada uno de los periodos a continuación:

La intención sería alargar el periodo de cuentas por pagar, es decir, negociar con los principales proveedores para que se otorgue un plazo mayor para pagar por los inventarios que la empresa adquiere. Lo que se conseguiría ampliando este periodo, sería tener más tiempo para pagar por los inventarios, mejorando el periodo de cuentas por pagar y por lo tanto reduciendo el ciclo del efectivo.

De la misma manera, se debería negociar con los clientes para acortar el periodo promedio de cobro, es decir, que exista una brecha menor entre el tiempo en el que se le entregan los productos terminados a los clientes y el tiempo que se cobra por la venta de los mismos. Si se lograse reducir el periodo promedio de cobro, el ingreso de efectivo 
para la empresa sería en un lapso de tiempo menor, por lo que se dispondría de liquidez de manera más rápida.

Finalmente, se podría reducir el periodo que existe entre el tiempo que se adquieren los inventarios y el tiempo en el que se efectúa la venta de los mismos (periodo de inventarios). Este tema va más allá de las negociaciones con proveedores o clientes, ya que consta de la aplicación de nuevas y mejores estrategias comerciales por parte de la empresa para mejorar la rotación de inventarios. Una mayor rotación de inventarios tendrá un efecto directo sobre una venta más rápida de los productos, lo que reduciría el promedio de inventarios en favor de la empresa y así afectaría de forma positiva el ciclo operativo y por lo tanto, también el ciclo de efectivo.

La segunda alternativa para solucionar esta brecha del ciclo del efectivo, sería la tomar un financiamiento. Cabe mencionar que existe dos formas de financiamiento, la primera es hacerlo con recursos propios y la segunda tomando una deuda.

Recordando que el tema que se trata en ésta investigación es sobre las PYMES, se debe considerar que éstas por ser pequeñas y medianas empresas, la gran mayoría no cuentan con la liquidez suficiente para poder autofinanciar grandes montos de dinero. Por lo que la alternativa más coherente para su realidad financiera es la de tomar un préstamo de corto plazo.

El préstamo al que apliquen deberá ser evaluado según las condiciones que el banco o la entidad financiera les ofrezca. Se deberá evaluar la tasa de interés, los pagos periódicos que se tendrán que realizar, el tiempo que durará el préstamo y el monto recibido, entre otros factores. Además, una vez evaluada toda la información del posible préstamo, se decidirá si conviene aceptarlo o no.

¿Cómo se determina si conviene aceptar el préstamo? Primero se deberá saber que tanta necesidad de financiamiento tiene la empresa y segundo analizar si el beneficio que les brinde dicho financiamiento será mayor que los costos que tendrá realizar esta inversión.

Por lo tanto, se concluye que la primera alternativa para reducir la brecha del ciclo de efectivo es la de mejorar los periodos de inventario, cuentas por cobrar y cuentas por pagar, en favor de la empresa. Además, la segunda alternativa es la de tomar un financiamiento que le permita tener una mayor liquidez y cubrir la brecha del ciclo de efectivo. 
La gran mayoría de PYMES tienen un ciclo del efectivo negativo, debido a su bajo poder de negociación con los proveedores y clientes por ser empresas pequeñas, así como por contar con poca liquidez monetaria debido a que sus ventas no facturan grandes cantidades de dinero.

Las pequeñas y medianas empresas son aquellas que se encuentran con una mayor predisposición a tener un ciclo del efectivo mayor debido a que tienen un menor tamaño y facturación que las empresas grandes. Sin embargo, la gran mayoría de empresas en general cuentan con un ciclo del efectivo positivo, lo que las obliga a tomar un financiamiento.

Son muy pocas aquellas empresas las cuales poseen un ciclo del efectivo negativo, ya que para tenerlo necesitan ser empresas muy grandes, que tengan un alto grado de negociación con sus clientes y proveedores para ellos imponer sus condiciones de cobro y pago. Si se tuviese tal grado de negociación e influencia sobre sus principales stakeholders, además de la aplicación de otras estrategias; se podría llegar a tener un ciclo del efectivo negativo.

Ross, Westerfield y Jordan (2010) mencionan un ejemplo que retrata de forma eficiente lo que es el valor de mercado logrado a través de un manejo de sus recursos. Se trata del caso de la empresa Amazon, la cual a través de la aplicación de estrategias comerciales y financieras logró obtener un gran valor de mercado a través del manejo de un ciclo del efectivo negativo.

Amazon.com, vendedor de libros y minorista que opera vía internet, constituye un ejemplo interesante de la importancia de administrar el ciclo del efectivo. A mediados de 2008, el valor de mercado de Amazon.com era superior (de hecho casi 22 veces más alto) al de Barnes \& Noble, rey de las librerías tradicionales en instalaciones físicas, a pesar que las ventas de Amazon.com eran tan solo 2.7 veces más grandes.

¿Cómo podía Amazon.com valer tanto más? (...) En 2007 tuvo una rotación de inventarios de casi 11 veces al año, cuatro veces más rápida que la de Barnes \& Noble, así que su periodo de inventario fue mucho más corto. Lo que es aún más sorprendente, Amazon realiza el cargo en la tarjeta de crédito del cliente cuando le envía un libro y, por lo general, el emisor de la tarjeta de crédito le paga a Amazon en menos de un día. Esto significa que Amazon tiene un ciclo del efectivo negativo. (p. 583)

Amazon es un caso raro entre las empresas, ya que logró tener un ciclo del efectivo negativo gracias a la aplicación de estrategias y poder de negociación con los clientes y 
proveedores. Lograr resultados como una rotación de inventarios alta, un pago por parte de sus clientes casi inmediata y evitar costos fijos como vender vía web y no pagar por el local de una tienda para exhibir los libros; fue clave para obtener un ciclo del efectivo negativo.

\subsubsection{Cálculo de los ciclos operativo y del efectivo}

Para realizar el cálculo del ciclo operativo y el ciclo del efectivo, hay que empezar por analizar el balance general. En él se encontrará información referente a cuánto tarda una empresa en vender y cobrar los bienes que ofrece.

Se deberán analizar cuentas como la de inventarios, cuentas por cobrar y cuentas por pagar e identificar cual es la cifra inicial y final de cada año para poder obtener un promedio.

Asimismo, también resulta pertinente evaluar el estado de resultados de la empresa con la intención de identificar datos como las ventas y el costo de los bienes vendidos. Ésta información será útil para la hallar el ciclo operativo y el ciclo del efectivo.

Para entender de manera más clara y dinámica la teoría, se tomará un ejemplo práctico sobre cómo se realizan los cálculos del periodo promedio de inventario, periodo promedio de pago y periodo promedio de cobro. Estos tres componentes servirán para hallar el ciclo operativo y el ciclo del efectivo.

Ross, Westerfield y Jordan (2010) proponen un ejemplo que retrata dicha dinámica de manera eficiente.

Tabla 1.3

Ejemplo de balance general (miles de dólares)

\begin{tabular}{c|ccc}
\hline Partida & Inicial & Final & Promedio \\
\hline Inventario & $\$ 2,000$ & $\$ 3,000$ & $\$ 2,500$ \\
Cuentas por cobrar & 1,600 & 2,000 & 1,800 \\
Cuentas por pagar & 750 & 1,000 & 875 \\
\hline
\end{tabular}

Nota: Ejemplo de balance general para el cálculo de ratios financieros.

Fuente: Ross, Westerfield y Jordan (2010) 


\section{Tabla 1.4}

Ejemplo de estado de resultados (miles de dólares)

\begin{tabular}{c|c}
\hline Ventas netas & 11,500 \\
\hline Costo de los bienes vendidos & 8,200 \\
\hline
\end{tabular}

Nota: Ejemplo de estado de resultados para el cálculo de ratios financieros.

Fuente: Ross, Westerfield y Jordan (2010)

A partir de esos estados se calculan la rotación de inventarios, el periodo de inventarios, la rotación de cuentas por cobrar, etc.

Rotación de inventarios $=$ Costo ventas $/$ Promedio inventarios

Rotación de inventarios $=8200 / 2500=3.28$ veces

Periodo de inventario $=365$ días/ Rotación del inventario

Periodo de inventario $=365 / 3.28=111.3$ días

Rotación de cuentas por cobrar $=$ Ventas a crédito/Cuentas por cobrar promedio

Rotación de cuentas por cobrar $=11,500 / 1,800=6.4$ veces

Periodo de cuentas por cobrar $=365$ días $/$ Rotación de cuentas por cobrar

Periodo de cuentas por cobrar $=365 / 6.4=57$ días

El ciclo operativo es la suma de los periodos de inventario y de cuentas por cobrar:

Ciclo operativo $=$ Periodo de inventario + Periodo de cuentas por cobrar

Ciclo operativo $=111$ días +57 días $=168$ días

\section{El ciclo del efectivo (se requiere el periodo de cuentas por pagar)}

Rotación de cuentas por pagar $=$ Costo de ventas/Cuentas por pagar promedio

Rotación de cuentas por pagar $=8,200 / 875=9.4$ veces

Periodo de cuentas por pagar $=365$ días $/$ Rotación de cuentas por pagar

Periodo de cuentas por pagar $=365 / 9.4=39$ días

Por último, el ciclo del efectivo es la diferencia entre el ciclo operativo y el periodo de cuentas por pagar:

Ciclo del efectivo $=$ Ciclo operativo - Periodo de cuentas por pagar

Ciclo del efectivo $=168$ días -39 días $=129$ días

(Ross, Westerfield, Jordan, 2010, p.584-586). 
Interpretación del ejemplo:

La rotación de los inventarios fue de 3.28 veces, lo que indica que fue esa cantidad de veces las que se compraron y vendieron los inventarios.

El periodo promedio de inventario fue de 111.3 días, con lo que se determina que esa fue la cantidad de días que se mantuvieron los inventarios antes que estos sean vendidos.

En cuanto a la rotación de cuentas por cobrar, el resultado de éstas fue de 6.4 veces, lo que determinó un periodo de cuentas por cobrar de 57 días. Esto significa que los clientes a los que la empresa vendió sus inventarios, demoraron 57 días en darle el efectivo por la venta.

El ciclo operativo fue hallado sumando el periodo de inventarios y el periodo de cuentas por cobrar, lo que dio un total de 168 días. Esto significa que todo el proceso mencionado demora 168 días, es decir, desde el momento en el que la empresa compra los inventarios a sus proveedores, hasta que los vende y hace efectivo el cobro por la venta.

El periodo promedio de pago significa el periodo que la empresa demora en pagar por la compra de los inventarios o de la materia prima. El resultado obtenido del periodo de pago fue de 39 , días en lo que se demora en pagarle a sus proveedores.

Finalmente, el ciclo del efectivo es la resta del ciclo operativo menos el periodo de pago, por lo cual el resultado fue 129. Con esto se concluye que hay una brecha de 129 días entre el momento en que hay una salida de efectivo por el pago a los proveedores y el momento en el que ingresa efectivo por el cobro de los bienes vendidos.

Como se vio en puntos anteriores, el ciclo del efectivo es determinante para las decisiones de financiamiento de corto plazo de una empresa. Cuanto más corto sea el ciclo del efectivo menor será el financiamiento que requiera una compañía, sin embargo un mayor número de días del ciclo del efectivo ampliará la brecha de tiempo que hay entre el pago de los inventarios y el cobro por la venta de los mismos; lo que hará que el financiamiento que se necesite sea mayor.

El financiamiento se requiere para cubrir los inventarios y el tiempo que tardan los clientes en pagar (cuentas por cobrar). De esta manera, la intención de toda empresa deberá ser acortar el ciclo del efectivo de la siguiente manera: 
- Aumentando el periodo de pago.

- Reduciendo el periodo de inventarios.

- Reduciendo el periodo de cobro.

Un indicador básico para el análisis pueden ser los ratios de rentabilidad. Existe una relación entre el ciclo del efectivo y la rentabilidad de la empresa. La rotación de activos es indicador para medir la rentabilidad y crecimiento de una compañía, por lo que mientras mayor sea la el ratio Ventas/Activos, mayor será el rendimiento sobre los activos (ROA) y el rendimiento sobre el capital (ROE). De este modo, mientras menor sea el ciclo del efectivo, menor será la inversión en inventarios y cuentas por cobrar.

Para comprender lo anterior, cabe recalcar que el rendimiento sobre los activos (ROA) se define como la Utilidad neta/Ventas por las Ventas/Activos. De la misma forma, el rendimiento sobre el capital (ROE) se define como Utilidad neta/Ventas por Ventas/Activos por Activos/Patrimonio.

La relación del ciclo operativo y ciclo del efectivo con la investigación se evidencian con la siguiente pregunta: ¿Qué relevancia tienen el ciclo operativo y el ciclo del efectivo para analizar el financiamiento bancario de corto plazo que solicitan las PYMES?

Las empresas, en este caso las PYMES, solicitan préstamos bancarios de corto plazo con la intención de obtener liquidez para realizar inversiones en activos o para compensar la brecha de tener un ciclo del efectivo positivo.

Como se sabe, las pequeñas y medianas empresas en la gran mayoría de casos necesitan dinero para comprar inventarios o para compensar el tiempo en el que sus clientes se demoran en pagar.

El tema de la investigación surge a partir de la necesidad de financiamiento de las empresas, y como hemos visto teóricamente a lo largo de este capítulo, el financiamiento es la base para compensar brechas como la del ciclo del efectivo y para acercarse más al objetivo final de toda empresa: la creación de valor.

De esta forma, se determina que el financiamiento de las PYMES es elemental para su crecimiento y evolución a lo largo del tiempo, por lo que entender el ciclo operativo y el ciclo del efectivo era básico para conocer el por qué su necesidad de la obtención de recursos a través de una deuda de corto plazo. 


\subsection{Análisis de la relación económica de las variables del modelo}

El modelo económico que plantea esta investigación consta en la relación que existe entre cuatro variables financieras como son las ventas, inventarios, flujo de caja y tasa de interés; y su impacto sobre la variable dependiente que es la deuda bancaria a corto plazo que asumen las PYMES.

En el capítulo III se aplicará una regresión econométrica para una muestra de PYMES analizando la relación de las cuatro variables explicativas con la variable dependiente. Sin embargo, previo a realizar las distintas pruebas econométricas en busca de resultados cuantitativos, es necesario hacer un análisis teórico del porque se tomaron estas cuatro variables para explicar a la deuda de corto plazo que asumen las PYMES.

Para entender el modelo, es elemental identificar la relación teórica entre las variables exógenas y la endógena. De esta manera se evaluará teóricamente el efecto que podrían tener las ventas, los inventarios, el flujo de caja y la tasa de interés sobre la deuda bancaria de corto plazo.

A continuación se plantearan las relaciones individuales que existen entre cada una de las variables independientes con la variable dependiente. Lo que permitirá entender la relación económico-financiera que las relaciona y que posteriormente permitirá entender de manera más sencilla el modelo.

\subsubsection{Deuda bancaria de corto plazo y ventas}

Las PYMES son empresas que están en continuo crecimiento; pero un problema que enfrentan estas entidades es cómo financiarlo. Desde que la deuda de corto plazo de los bancos es una fuente de financiamiento de la PYMES, se espera que exista una relación positiva entre el crecimiento de las ventas y la deuda bancaria de corto plazo que éstas asumen.

Asimismo, la empresa no solo busca un crecimiento de sus ventas, si no también generar valor. Por este motivo, se busca mejorar el ciclo del efectivo a través de un financiamiento bancario de corto plazo, Esto les permitirá compensar el tiempo entre que vende sus inventarios y cobra por ellos. Por lo tanto, se esperaría que las PYMES en 
busca de la creación de valor para el negocio, tomen una deuda bancaria de corto plazo para financiarse y así mejorar su ciclo del efectivo.

\subsubsection{Deuda bancaria de corto plazo e inventarios}

Una de las decisiones que tienen que tomar las PYMES es cómo financiar sus inventarios. La teoría financiera de corto plazo indica que las empresas pueden financiar sus inventarios con cuentas por pagar (crédito de los proveedores), capital propio y con deuda bancaria de corto plazo. Por ello, se espera que exista una relación positiva entre el crecimiento de los inventarios de las empresas y la deuda de corto plazo bancaria que éstas asumen.

\subsubsection{Deuda bancaria de corto plazo y flujo de caja}

Una mayor disponibilidad de liquidez o mayor flujo de caja pueden ser utilizados para financiar las actividades operativas de las PYMES; es por ello que la teoría señala que a mayor liquidez, una empresa tendrá una mayor capacidad de pago. Esta capacidad de pago respalda a una empresa a obtener un mayor nivel de endeudamiento.

Los bancos establecen políticas de crédito que deben de cumplir las PYMES para tener acceso al crédito bancario. Dentro de estas políticas, la capacidad de pago del deudor es la variable fundamental para acceder a un crédito (ver resolución SBS No 808 2003, punto 2.1. relativo a los criterios de evaluación para el otorgamiento del crédito).

Así, los bancos en su proceso de evaluación crediticia tienen como variable fundamental la capacidad de pago y consideran el flujo de caja después de deuda para fijar el monto del préstamo. Por ello, se espera que exista una relación positiva entre el flujo de caja de las PYMES y la deuda bancaria de corto plazo que asumen.

\subsubsection{Deuda bancaria de corto plazo y tasa de interés}

La tasa de interés es el costo financiero que tienen que asumir las PYMES por el monto que piden prestado al banco. Por lo tanto, un incremento de la tasa de interés implicaría que las PYMES enfrenten un mayor costo financiero. Por tal motivo, las pequeñas y 
medianas empresas tendrán mayores incentivos para reducir su deuda y buscar otra fuente de financiamiento más económica. Debido a esto, se esperaría que exista una relación inversa entre la tasa de interés y el monto de deuda que asumen estas empresas.

En conclusión, se determina que es necesario conocer de manera teórica los principales puntos que envuelven a las PYMES y su financiamiento. Es por tal motivo que se explicaron sus objetivos y que porcentaje representan del total de empresas en el Perú y en la ciudad de Lima.

El marco legal-institucional de las políticas de financiamiento sirvió para conocer cuáles son las entidades que regulan el sistema financiero, y cuales otras promueven el apoyo a las pequeñas empresas. Además, a través de este punto se conocieron las medidas de apoyo que crearon las entidades reguladores para facilitar el acceso al crédito por parte de las PYMES.

El ciclo operativo y el ciclo del efectivo se explicaron de manera dinámica a través de un ejemplo práctico para entender porque las empresas necesitan financiamiento. Las empresas necesitan cubrir la brecha que les genera un ciclo del efectivo positivo, por lo que para reducir su financiamiento es necesario aplicar distintas estrategias que mejores este ciclo.

Se realizó un análisis de la relación económica que existe entre las cuatro variables exógenas del modelo como son las ventas, inventarios, flujo de caja y la tasa de interés; con la deuda bancaria de corto plazo. Este análisis teórico permite entender la relación económica que existe en el tema, para que posteriormente sea evaluada en el capítulo III a través de un modelo econométrico, que permita obtener resultados cuantitativos.

A través del estudio de este capítulo se concluye que las PYMES son una parte determinante de la economía del país ya que representan alrededor del $99 \%$ de las empresas en el país, por lo tanto, analizar su comportamiento para proponer estrategias de mejora es muy importante para la economía.

Asimismo, se entendió que el financiamiento es una herramienta fundamental para el crecimiento de las empresas, por lo que se deberán evaluar las alternativas existentes de acceso al crédito para tomar la mejor decisión financiera.

El ciclo del efectivo es el periodo de tiempo que hay que acortar para requerir un menor financiamiento bancario. Una disminución de la brecha del ciclo del efectivo mejorará la liquidez de las PYMES. 
Finalmente, se encontró una relación económica entre las variables que pretenden explicar el modelo y la deuda bancaria de corto plazo, por lo que el tema ahora está en ver el nivel de significancia de cada una de ellas e identificar cuál es el orden de importancia de cada variable para el modelo. 


\section{CAPÍTULO II: EVOLUCIÓN DE LAS VARIABLES}

En este capítulo se analiza la evolución de las principales variables en el marco del comportamiento de la economía.

\subsection{Situación general}

Para evaluar un tema económico o financiero, es necesario conocer los antecedentes. Para este caso, se requiere analizar a las pequeñas y medianas empresas, ya que éstas son el motor de la economía del país debido a que son un porcentaje más que significativo del total de empresas que hay en el Perú.

Evaluar el comportamiento de la economía, el producto bruto interno y el sector financiero, resultado determinante para conocer la realidad en la que se desenvuelve la investigación. Conocer el contexto con estadísticas y ver las líneas de tendencia que han seguido estos indicadores a través del tiempo permitirá entender el entorno y poder hacer un análisis más preciso.

La investigación consta en evaluar el crédito que obtienen las pequeñas y medianas empresas de una entidad bancaria y analizar cuáles son las variables financieras más significativas para la obtención del mismo. Es importante recalcar que el estudio fue hecho para el año 2014, por lo que es conveniente conocer cuál ha sido el comportamiento de la economía y del sector financiero en años previos al periodo de estudio.

Se realizará una evaluación de un periodo en la mayoría de los casos desde el año 2009 al año 2014 con la intención de evaluar la tendencia de las principales variables de la economía peruana y de la ciudad de Lima durante ese intervalo de tiempo. De la misma forma, se determinará a través de la información estadística datos como la evolución del producto bruto interno, el porcentaje de la PEA ocupada, la influencia de las MIPYMES en la economía, la cantidad de MIPYMES que hay en el país y que porcentaje representan entre las empresas peruanas; entre otros datos estadísticos que servirán como base para entender la realidad del país y la importancia del tema que se eligió para la investigación. 
Cabe mencionar que para la evaluación de gran parte de los datos, ya sea a través de tablas o de figuras que muestran la tendencia del comportamiento de las variables, se utilizó información de la ciudad de Lima ya que en la delimitación del tema se eligió dicha ciudad para evaluar las variables que influyen en la decisión de financiamiento bancario de corto plazo de las PYMES.

¿Por qué la ciudad de Lima? Como veremos en éste capítulo, es la ciudad más representativa económicamente para el país, ya que es la que cuenta con un mayor número de habitantes, de empresas, de entidades bancarias, entre otros factores determinantes para haber sido elegida.

Asimismo, sólo la ciudad de Lima cuenta con aproximadamente la mitad de las PYMES del país, por lo que es una referente para evaluar el comportamiento de estas pequeñas y medianas empresas.

En cuanto a la situación general, el país y la ciudad vienen experimentando un crecimiento económico sostenido desde hace ya algunos años atrás a pesar de la crisis inmobiliaria que afectó Estados Unidos a partir del año 2008. Ésta crisis tuvo una repercusión en la economía mundial, sin embargo, Perú a pesar de desacelerar su crecimiento económico, continuó teniendo una curva ascendente en cuanto a la evolución del PBI.

Por ello, para comprender el tema de investigación, se necesita hacer un análisis que mida la evolución de las variables económicas del país en el tiempo, tal como el PBI, la PEA, el desempleo, el sistema financiero; como se mencionó anteriormente. De esta forma, si se entiende el contexto en el que operan las PYMES, se podrá entender el tema de investigación con mayor exactitud.

La información obtenida a continuación fue de fuentes como el Instituto Nacional de Estadística e Informática (INEI), la Superintendencia de Banca, Seguros y AFP (SBS), el Banco Central de Reserva del Perú, el Ministerio de Producción, entre otras entidades que serán citadas a continuación, de acuerdo al aporte de cada una de éstas. 


\subsection{Sector económico}

La coyuntura macroeconómica y legal influye de manera significativa en el desarrollo de las PYMES, de tal manera resulta sumamente necesario analizar la dinámica de su comportamiento en el tiempo y su evolución.

\subsubsection{PBI real y variaciones anuales, 2009 - 2014}

Tabla 2.1

PBI real y variaciones anuales, 2009-2014

\begin{tabular}{c|cc}
\hline Fecha & PBI (mill. S/. de 2007) & PBI real (var. \%) \\
\hline 2009 & 352,584 & 1,0 \\
2010 & 382,380 & 8,5 \\
2011 & 407,052 & 6,5 \\
2012 & 431,273 & 6,0 \\
2013 & 456,159 & 5,8 \\
2014 & 466,844 & 2,4 \\
\hline \multicolumn{2}{|c}{ Nota: Evolución del PBI real y variación del PBI real. Periodo 2009-2014. } \\
\multicolumn{2}{|c}{ Fuente: Banco Central de Reserva del Perú (2018). }
\end{tabular}

En la tabla 2.1 se ha analizado la variación porcentual del producto bruto interno entre los años 2009 y 2014. Como se puede observar en la tabla, el año donde se experimentó un mayor crecimiento fue el año 2010, ya que se creció a una tasa de $8.5 \%$.

Asimismo, de acuerdo a estos números se puede concluir que Perú es uno de los países con mayor crecimiento económico de la región, ya que presenta una evolución en su PBI superior al de otros países de Sudamérica.

Como se ve en la figura 2.1, ha habido un crecimiento del producto bruto interno entre los años 2009 y 2014. El PBI del año 2009 fue de 352584 soles y el del año 2014 de 466844 soles; es decir, en este periodo de 6 años (2009-2014), ha habido un crecimiento de $32.41 \%$ entre el primer y el último año. Este crecimiento es realmente significativo considerando la crisis y desaceleración económica mundial que empezó en el año 2008 debido a la crisis inmobiliaria que hubo en Estados Unidos. Ésta crisis trajo consigo un impacto económico mundial, ya que afectó de manera directa a las demás 
economías del mundo, por lo que generó que estas contraigan su crecimiento o en el peor de los casos tengan una curva descendente en su PBI para los años mencionados.

Figura 2.1

Tendencia del PBI real y de las variaciones del PBI. Periodo 2009-2014

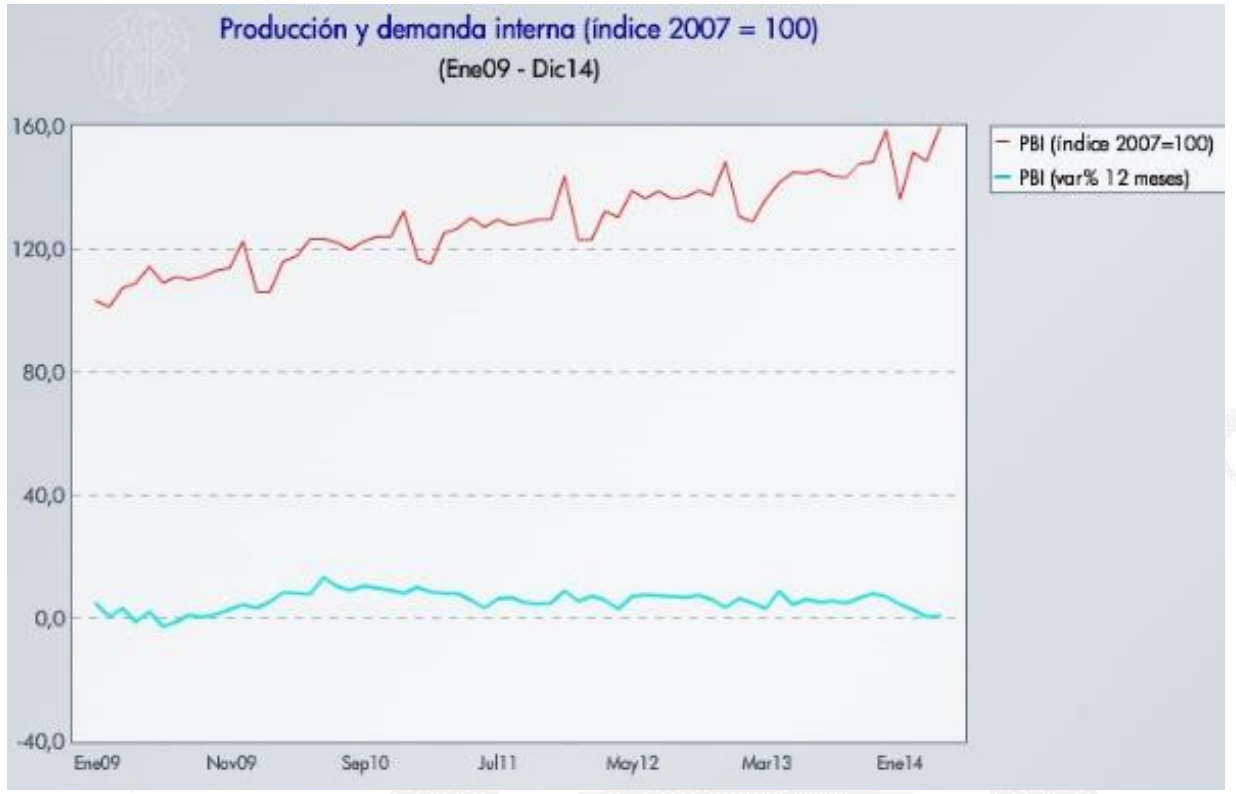

Nota: Tendencia del PBI real y de las variaciones del PBI. Periodo 2009-2014.

Fuente: Banco Central de Reserva del Perú (2018)

En el caso de Perú, el auge económico por el que atravesaba le permitió seguir creciendo a una tasa por encima de otros países del continente. Manteniendo constante su promedio de crecimiento entre $5 \%$ y $7 \%$ para estos años.

En cuanto a la figura mostrada líneas arriba, ésta muestra la tendencia mensual que tuvieron el producto bruto interno y la variación del mismo; desde Enero de 2009 hasta Diciembre de 2014. La línea roja muestra una pendiente positiva ya que el producto ha experimentado un crecimiento sostenido durante los años en mención; presentando picos de rendimiento en algunos meses del año como se ve en la figura.

De la misma forma, se graficó la tendencia de la variación del PBI durante el mismo periodo de tiempo, donde se observa una línea celeste por encima de 0.00 demostrado que las variaciones del producto fueron siempre positivas durante esos años, contrastando a la línea roja que demuestra el crecimiento del PBI. 


\subsubsection{PBI por sectores, $2009-2014$}

Tabla 2.2

PBI por sectores, 2009-2014

\begin{tabular}{c|cccc}
\hline Fecha & $\begin{array}{c}\text { Agropecuario } \\
\text { (mill. S/. de 2007) }\end{array}$ & $\begin{array}{c}\text { Pesca (mill. S/. } \\
\text { de 2007) }\end{array}$ & $\begin{array}{c}\text { Minería e } \\
\text { Hidrocarburos } \\
\text { (mill. S/. de 2007) }\end{array}$ & $\begin{array}{c}\text { Manufactura } \\
\text { (mill. S/. de 2007) }\end{array}$ \\
\hline $\mathbf{2 0 0 9}$ & 20,873 & 2,352 & 50,076 & 53,502 \\
$\mathbf{2 0 1 0}$ & 21,766 & 1,891 & 50,714 & 59,255 \\
$\mathbf{2 0 1 1}$ & 22,658 & 2,892 & 51,043 & 64,330 \\
$\mathbf{2 0 1 2}$ & 23,991 & 1,960 & 52,473 & 65,265 \\
$\mathbf{2 0 1 3}$ & 24,362 & 2,445 & 55,035 & 68,508 \\
$\mathbf{2 0 1 4}$ & 24,814 & 1,762 & 54,605 & 66,005 \\
\hline
\end{tabular}

Nota: Distribución del PBI según los distintos sectores económicos. Periodo 2009-2014.

Fuente: Banco Central de Reserva del Perú (2018)

Tabla 2.3

PBI por sectores, 2009-2014

\begin{tabular}{c|cccc}
\hline Fecha & $\begin{array}{c}\text { Construcción } \\
\text { (mill. S/. de } \\
\mathbf{2 0 0 7})\end{array}$ & $\begin{array}{c}\text { Comercio (mill. } \\
\text { S/. de 2007) }\end{array}$ & $\begin{array}{c}\text { Electricidad y Agua } \\
\text { (mill. S/. de 2007) }\end{array}$ & $\begin{array}{c}\text { Otros Servicios } \\
\text { (mill. S/. de 2007) }\end{array}$ \\
\hline $\mathbf{2 0 0 9}$ & $20,360.00$ & $35,936.00$ & $6,013.00$ & $163,472.00$ \\
$\mathbf{2 0 1 0}$ & $23,993.00$ & $40,420.00$ & $6,501.00$ & $177,840.00$ \\
$\mathbf{2 0 1 1}$ & $24,848.00$ & $44,034.00$ & $6,994.00$ & $190,253.00$ \\
$\mathbf{2 0 1 2}$ & $28,779.00$ & $47,218.00$ & $7,401.00$ & $204,186.00$ \\
$\mathbf{2 0 1 3}$ & $31,353.00$ & $49,984.00$ & $7,811.00$ & $216,603.00$ \\
$\mathbf{2 0 1 4}$ & $31,869.00$ & $52,193.00$ & $8,193.00$ & $227,403.00$ \\
\hline
\end{tabular}

Nota: Distribución del PBI según los distintos sectores económicos. Periodo 2009-2014.

Fuente: Banco Central de Reserva del Perú (2018)

Un tema que es fundamental para analizar a que se debe el crecimiento del producto bruto interno, es evaluar cuales son los sectores que tienen un mayor aporte sobre la economía local. La tabla 2.3 permite ver cuáles son los rubros económicos con mayor significancia para el país. 
Se realizó un análisis por un periodo de 6 años (2009-2014) y se evaluaron los 8 tipos de sectores económicos que se hallaron en las series estadísticas del Banco Central de Reserva del Perú.

A continuación, se presenta la figura de un gráfico de barras para analizar los aportes de los distintos sectores a la economía.

Figura 2.2

PBI por sectores económicos, 2009 - 2014

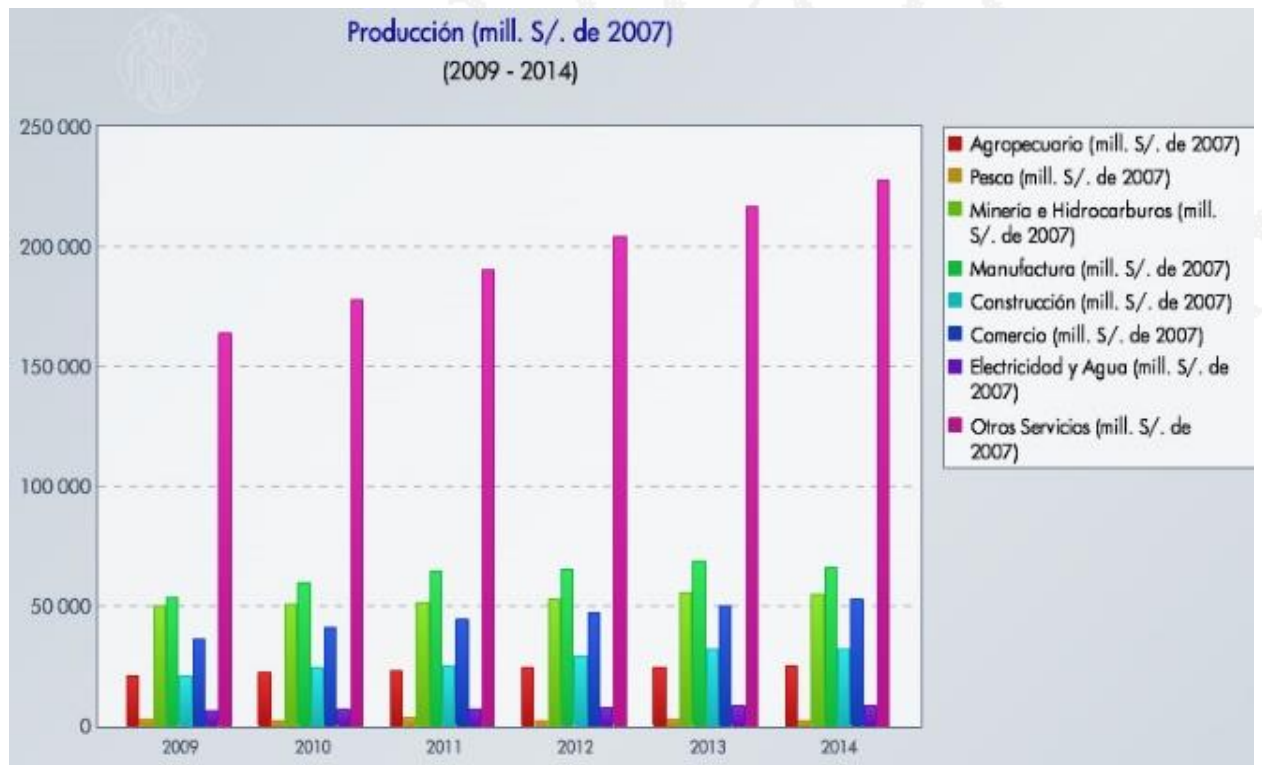

Nota: Distribución gráfica del PBI según los distintos sectores económicos. Periodo 2009-2014.

Fuente: Banco Central de Reserva del Perú (2018)

A través de la figura se puede observar la gran diferencia que existe entre el sector “otros servicios" y el resto de sectores económicos. El gráfico presenta la evolución que han tenido los distintos rubros económicos por un periodo de 6 años $(2009$ - 2014) y cuál ha sido su tendencia durante este periodo.

Se puede observar que el sector agropecuario, minería e hidrocarburos, manufactura, construcción, comercio, electricidad y agua, y otros servicios han presentado un crecimiento constante durante los años analizados (a excepción del año 2014 donde la manufactura cayó ligeramente). Esto a diferencia del otro sector económico que se la pesca y que ha tenido variaciones positivas y negativas entre dichos años. 
La figura del gráfico de barras sirve para observar la diferencia que hay entre un sector y otro para analizar su aporte en la economía año a año, sin embargo, para complementar éste gráfico se puede revisar la tabla que aparece líneas arriba donde se detalla el aporte cuantitativo año a año de los 8 sectores mencionados.

Siendo el 2014 el último año en evaluación, se tomó dicho año para hacer el ranking. Se concluye que el orden de incidencia de los sectores económicos sobre PBI es el siguiente:

Tabla 2.4

Ranking del PBI real por sector económico (2014)

\begin{tabular}{l|ccc}
\hline Sector & Mll de S/. & Ranking & \% del PBI \\
\hline Otros servicios & 227,403 & 1 & $48.71 \%$ \\
$\begin{array}{l}\text { Manufactura } \\
\text { Minería }\end{array}$ & 66,005 & 2 & $14.14 \%$ \\
Hidrocarburos & 54,605 & 3 & $11.70 \%$ \\
Comercio & 52,193 & 4 & $11.18 \%$ \\
Construcción & 31,869 & 5 & $6.83 \%$ \\
Agropecuario & 24,814 & 6 & $5.32 \%$ \\
Electricidad y agua & 8,193 & 7 & $1.75 \%$ \\
Pesca & 1,762 & 8 & $0.38 \%$ \\
TOTAL & $\mathbf{4 6 6 , 8 4 4}$ & & $\mathbf{1 0 0 \%}$ \\
\hline
\end{tabular}

Nota: Ranking del PBI por sector económico. Año 2014.

Fuente: Banco Central de Reserva del Perú (2018)

La intención de esta tabla es identificar el porcentaje de aporte sobre el PBI tienen las distintas actividades económicas. La última columna demuestra numéricamente que proporción del $100 \%$ del producto bruto interno representa cada rubro.

Se puede determinar que el sector con mayor aporte al producto bruto interno es el de "otros servicios", con 227403 millones de soles sobre los 466844 millones del total, es decir, el rubro “otros servicios” representó el $48.71 \%$ del PBI.

Como se puede apreciar en las tablas anteriores, los sectores económicos están divididos en ocho, sin embargo el sector "otros servicios" es la aglomeración de un grupo de actividades económicas que se realizan en el país pero que no son lo suficientemente 
grandes como para estar en el ranking individualmente, por lo tanto la agrupación de las distintas actividades económicas es considerada como "otros servicios".

Además, después de “otros servicios”, los otros sectores que la siguen por aporte económico son: la manufactura $(14.14 \%)$, minería e hidrocarburos $(11.70 \%)$, comercio (11.18\%), construcción (6.83\%), agropecuario (5.32\%), electricidad y agua (1.75\%), y pesca $(0.38 \%)$, respectivamente.

Como se puede apreciar, existe una gran diferencia entre el primero y el segundo del ranking. El sector "otros servicios" representa el $48.71 \%$ del total como se mencionaba líneas arriba, mientras que el sector manufactura representa el $14.14 \%$ del PBI. De esta manera existe una diferencia de $34.57 \%$ entre primero y segundo del ranking. Sin embargo, a partir del tercer lugar en adelante, la brecha de diferencia entre uno y otro sector es corta.

\subsubsection{IPC Lima, $2009-2014$}

Se ha evidenciado una evolución y tendencia significativa en el Índice de Precios al Consumidor a lo largo de los años, variable que afecta en cierto modo la dinámica económica a través del consumo privado.

El Índice de Precios al Consumidor (IPC) es una variable importante para el análisis de la situación económica, ya que este indicador evalúa la evolución de los precios de los bienes y servicios de los principales alimentos (canasta familiar).

El IPC es un indicador que sirve para medir la inflación en un país, por lo que se considera importante colocar este estudio en la investigación.

Como se puede apreciar en la Tabla 2.5, el IPC siempre fue positivo durante los años de estudio y tuvo un promedio de $2.62 \%$ durante ese intervalo, manteniéndose dentro del rango lo esperado según las proyecciones del país de años anteriores.

El año que presentó una mayor variación fue el 2011, ya que hubo un crecimiento de $4.7 \%$ del IPC con respecto al año anterior. 
Tabla 2.5

Variación anual IPC Lima, 2009-2014

\begin{tabular}{c|c}
\hline Fecha & IPC (var. \%) \\
\hline 2009 & 0,2 \\
2010 & 2,1 \\
2011 & 4,7 \\
2012 & 2,6 \\
2013 & 2,9 \\
2014 & 3,2 \\
\hline
\end{tabular}

Nota: IPC de la ciudad de Lima. Periodo 2009-2014.

Fuente: Superintendencia Nacional de Aduanas y de Administración Tributaria (2018)

Figura 2.3

Tendencia IPC Lima y variación IPC Lima anual, 2009-2014

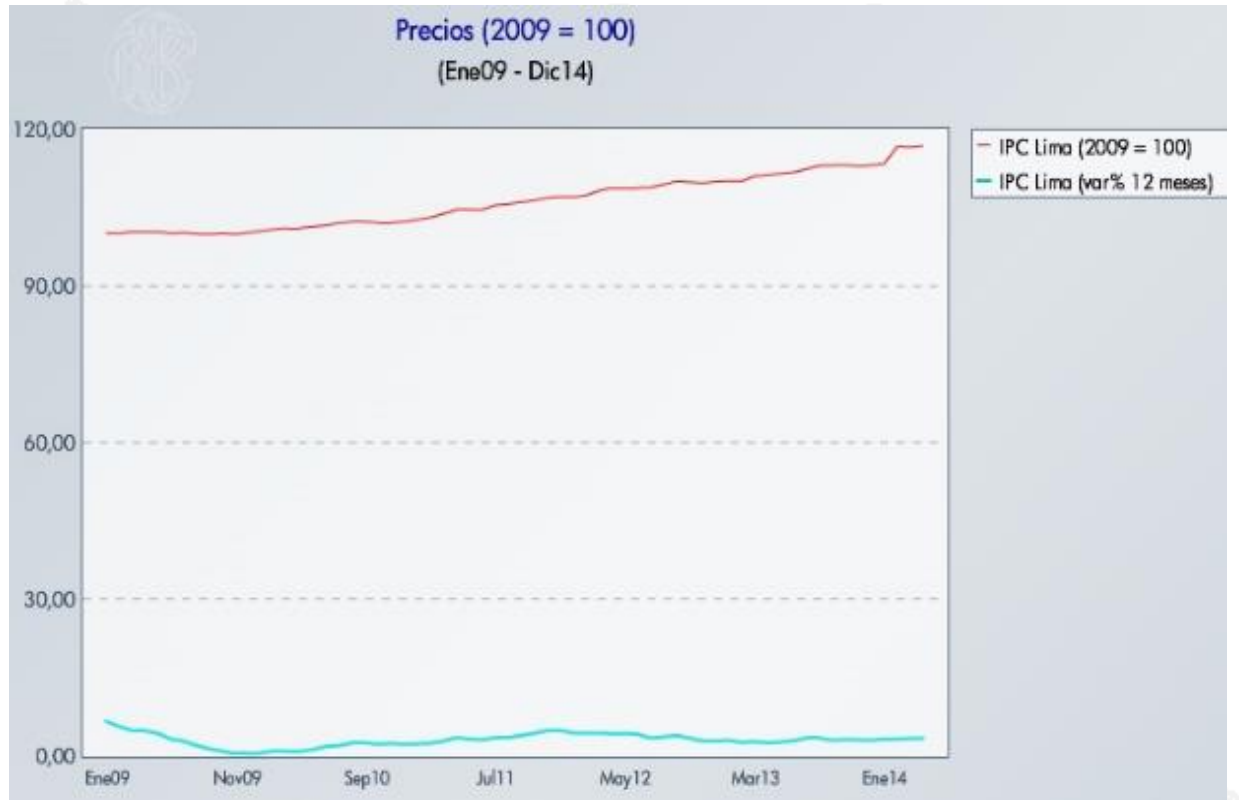

Nota: Evolución y tendencia del IPC Lima y la variación porcentual del IPC Lima. Periodo 2009-2014.

Fuente: Banco Central de Reserva del Perú (2018)

Asimismo, en la figura se ha graficado la tendencia que presentan tanto el IPC de la ciudad de Lima, como la variación porcentual que ha afectado al mismo. Como se ve en la figura, la línea roja es la evolución del IPC de Lima desde Enero de 2009 hasta Diciembre de 2014, donde se ve claramente que cuenta con una pendiente positiva. Esto quiere decir que el índice de precios al consumidor ha ido aumentado progresivamente en la capital peruana. 
Del mismo modo, el gráfico muestra una línea celeste, la cual revela el comportamiento de la variación del IPC de Lima durante el mismo periodo. Como se ve, la variación siempre fue superior a cero y no presenta una tendencia definida, ya que ha tenido pequeñas alzas y bajas durante el tiempo.

El tema del índice de precios al consumidor es importante para la investigación ya que la tendencia creciente que viene demostrando esta variable a lo largo de los años indica un aumento de la inflación en la ciudad y del país. Aun así, el nivel de inflación se encuentra dentro del rango esperado, por lo que no es un problema grande para las empresas, sin embargo es importante entender la relación que tiene el IPC con el financiamiento de las PYMES.

El IPC presenta una subida de los precios durante el periodo analizado (2009 2014), lo que tiene una relación directa con la inflación en el periodo que ha ido en alza. Una mayor inflación hará que aumenten los precios de los principales bienes, por lo que los costos de las empresas aumentan debido a este factor. Un aumento en los costos reduce la liquidez de las PYMES por lo que tienen menos recursos propios para autofinanciarse. En conclusión, el aumento del IPC disminuiría la liquidez de las PYMES, lo que las obligaría a depender en mayor medida de un financiamiento de recursos ajenos, en este caso de un préstamo bancario.

\subsection{Población económicamente activa}

Se puede definir a la población económicamente activa (PEA) como la población que se encuentra en edad de trabajar y que en la actualidad tienen o están en busca de un trabajo.

La población económicamente activa de la ciudad de Lima es un factor importante a analizar para conocer una variable económica importante de la ciudad en la que se realizó la investigación. 
2.3.1. PEA Lima, $2009-2014$

Tabla 2.6

PEA Lima, 2009-2014

\begin{tabular}{c|ccc}
\hline Fecha & $\begin{array}{c}\text { PEA Total en Lima } \\
\text { (miles de personas) }\end{array}$ & $\begin{array}{c}\text { PEA Ocupada en Lima } \\
\text { (miles de personas) }\end{array}$ & $\begin{array}{c}\text { PEA Desocupada en Lima } \\
\text { (miles de personas) }\end{array}$ \\
\hline Dic-09 & 4,758 & 4,332 & 425 \\
Dic-10 & 4,642 & 4,337 & 305 \\
Dic-11 & 4,919 & 4,529 & 390 \\
Dic-12 & 4,840 & 4,589 & 252 \\
Dic-13 & 4,988 & 4,664 & 325 \\
Dic-14 & 4,904 & 4,634 & 271 \\
\hline
\end{tabular}

Nota: PEA de la ciudad de Lima, tomando el mes de Diciembre de cada año como referencia. Periodo 2009-2014.

Fuente: Banco Central de Reserva del Perú (2018)

¿Por qué es importante conocer la PEA de la ciudad de Lima? Porque sirve como indicador para medir el desarrollo social y económico de la ciudad a través de un periodo de tiempo, analizando la evolución que éste ha tenido. Asimismo, permite medir factores como el crecimiento de la cantidad de personas en capacidad de trabajar (PEA total) y contrastarla con la PEA ocupada para evaluar si existió algún tipo de progreso.

Para realizar el análisis se tomó como referencia el mismo mes de cada año (Diciembre) para el periodo 2009 - 2014 con la finalidad de identificar el desenvolvimiento de la población económicamente activa.

Tabla 2.7

Variación anual de la PEA

\begin{tabular}{c|ccc}
\hline Fecha & $\begin{array}{c}\text { Variación PEA } \\
\text { Total }\end{array}$ & $\begin{array}{c}\text { Variación PEA } \\
\text { Ocupada }\end{array}$ & $\begin{array}{c}\text { Variación PEA } \\
\text { Desocupada }\end{array}$ \\
\hline Dic-09 & - & - & - \\
Dic-10 & $-2.44 \%$ & $0.12 \%$ & $-28.24 \%$ \\
Dic-11 & $5.97 \%$ & $4.43 \%$ & $27.87 \%$ \\
Dic-12 & $-1.61 \%$ & $1.32 \%$ & $-35.38 \%$ \\
Dic-13 & $3.06 \%$ & $1.63 \%$ & $28.97 \%$ \\
Dic-14 & $-1.68 \%$ & $-0.64 \%$ & $-16.62 \%$ \\
\hline
\end{tabular}

Nota: Variación de la PEA total, PEA ocupada y PEA desocupada de la ciudad de Lima. Periodo 20092014.

Fuente: Banco Central de Reserva del Perú (2018) 
Se puede observar que la PEA total de la ciudad de Lima no siempre experimentó un crecimiento. Tuvo variaciones positivas como negativas, lo que indica no hubo un aumento progresivo de las personas en edad de trabajar. Sin embargo, si se compara el primer año (2009) con el último (2014), se puede apreciar que la PEA total aumentó de 4758 a 4904 (miles de personas), lo que significa que la PEA total se incrementó en $3.07 \%$ del primer al último año.

Con respecto a la PEA ocupada, ésta tuvo una variación positiva año a año desde el 2009 hasta el 2013, sin embargo experimentó una disminución de -0.64\% del año 2013 al año 2014. La variación más alta sucedió en el año 2011 donde hubo un incremento de $4.43 \%$ con respecto al año anterior.

En cuanto a la PEA desempleada, ésta no tiene un comportamiento definido, ya que durante el periodo evaluado presenta grandes variaciones entre un año y el otro. Las variaciones por las que atraviesa son tanto son positivas como negativas; por lo que no se puede determinar con exactitud un tipo de comportamiento de la variable.

A continuación se presenta una tabla que evalúa el ratio PEA ocupada/PEA total:

Tabla 2.8

Ratio PEA ocupada/PEA total de Lima. 2009-2014

\begin{tabular}{c|ccc}
\hline Fecha & $\begin{array}{c}\text { PEA total en Lima } \\
\text { (miles de personas) }\end{array}$ & $\begin{array}{c}\text { PEA ocupada en } \\
\text { Lima (miles de } \\
\text { personas) }\end{array}$ & $\begin{array}{c}\text { \% PEA ocupada / PEA } \\
\text { total }\end{array}$ \\
\hline Dic-09 & 4,758 & 4,332 & $91.05 \%$ \\
Dic-10 & 4,642 & 4,337 & $93.43 \%$ \\
Dic-11 & 4,919 & 4,529 & $92.07 \%$ \\
Dic-12 & 4,840 & 4,589 & $94.81 \%$ \\
Dic-13 & 4,988 & 4,664 & $93.50 \%$ \\
Dic-14 & 4,904 & 4,634 & $94.49 \%$ \\
\hline
\end{tabular}

Nota: Evaluación del ratio PEA ocupada/PEA total de la ciudad de Lima. Periodo 2009-2014.

Fuente: Banco Central de Reserva del Perú (2018)

Se puede determinar que el año que hubo un mayor ratio de PEA ocupada sobre la PEA total fue el 2012. En dicho año, la PEA ocupada fue de $94.81 \%$, lo que significa que la PEA desempleada solo representaba el 5.19\%. 
Además, es conveniente evaluar cómo evolucionó la PEA ocupada entre el primer y el último año. En el año 2009 la PEA ocupada era de $91.05 \%$ y para el año 2014 la PEA ocupada fue de $94.49 \%$. Este aumento en el ratio demuestra una mejora social y económica, ya que demuestra que la empleabilidad en la ciudad mejoró.

A continuación se presenta una figura en la cual se evalúa la tendencia de las tres variables: PEA total de Lima, PEA ocupada de Lima y PEA desocupada de Lima.

Se considera oportuno realizar una figura que grafique las tendencias para sacar una conclusión de acuerdo al comportamiento general de las variables en el tiempo.

La línea roja representa a la PEA total de Lima y se muestra una tendencia ligeramente positive con algunos picos más altos en los que la PEA total aumentó durante periodos específicos. Se puede determinar que la pendiente es positiva y que la PEA en general ha aumentado desde el primer año al último.

Figura 2.4

Empelo mensual en Lima Metropolitana. 2009-2014

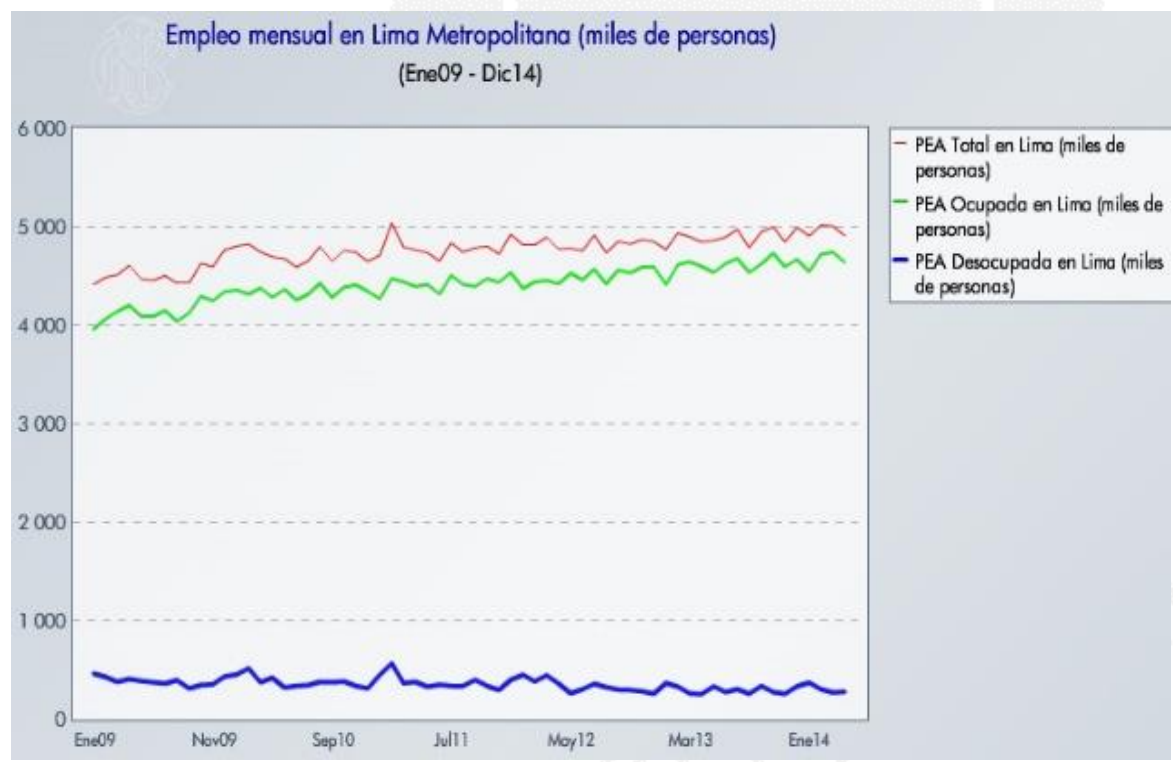

Nota: Tendencia y evolución del empleo en Lima Metropolitana. Periodo 2009-2014.

Fuente: Banco Central de Reserva del Perú (2018)

La línea verde representa a la PEA ocupada en Lima y presenta una tendencia similar a la línea roja. Se concluye que hubo un incremento de la PEA ocupada en la ciudad de Lima entre el primer y el último año y que el promedio entre todos los años fue de 4664 miles de habitantes. 
Por último, la línea azul representa a la PEA desocupada de Lima. Lo que se puede apreciar es que dicha variable presenta una tendencia ligeramente negativa, lo que habla de una disminución de la PEA desempleada en la capital. Ésta disminución da indicios de una mejora en la empleabilidad, por lo tanto en la economía del país durante los años 2009 y 2014.

El aumento de la PEA ocupada en Lima indica que hay más personas trabajando, lo que es un síntoma que hay más empleo. Sabiendo que la mayoría de trabajadores en la ciudad, labora en PYMES, se puede inferir que el crecimiento de las pequeñas y medianas empresas ha brindado trabajo a más personas en la ciudad de Lima.

En ese sentido se puede inferir que el mayor número de empleos ocupados tendrán como consecuencia un mayor flujo de dinero en la economía, cuyo efecto se verá reflejado en el dinamismo de la misma.

\subsubsection{PEA ocupada Lima, por categorías, 2009 - 2014}

Figura 2.5

PEA ocupada en Lima, por categorías. 2009-2014

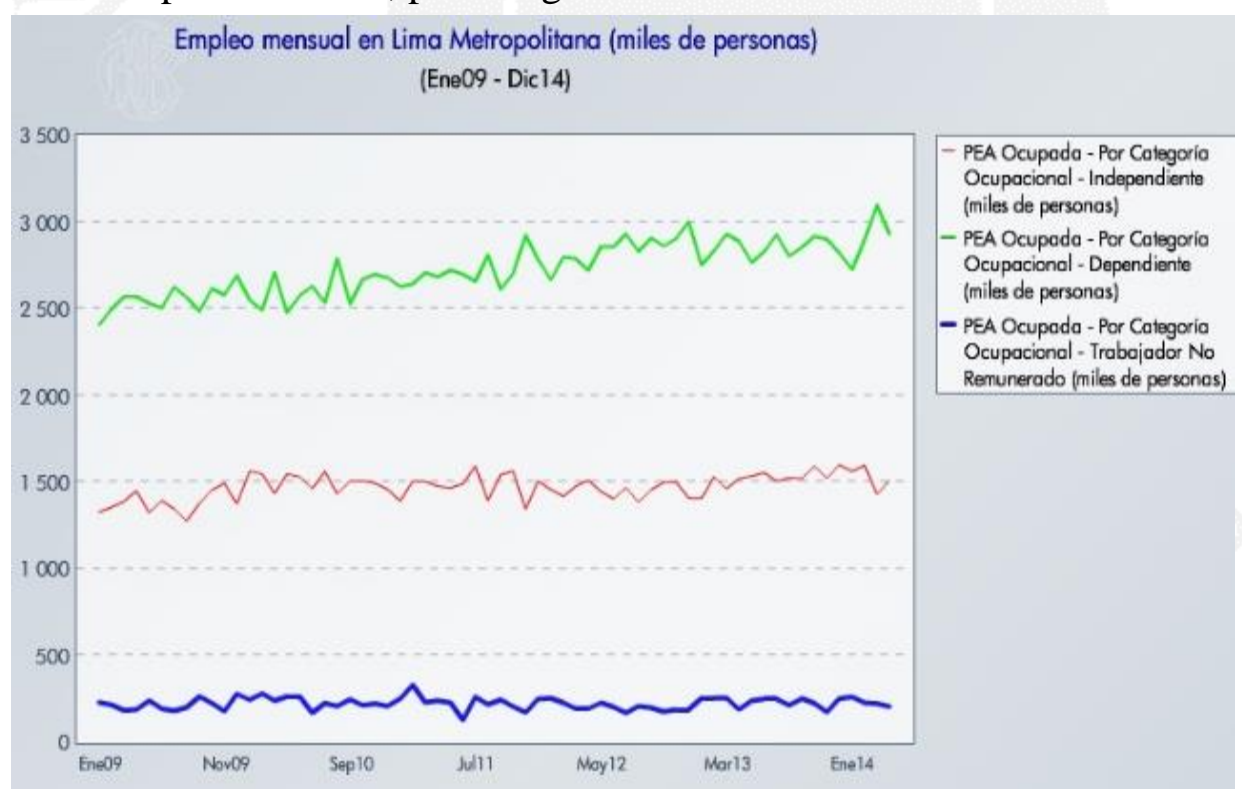

Nota: Tendencia y evolución de la PEA ocupada, según las distintas categorías. Periodo 2009-2014. Fuente: Banco Central de Reserva del Perú (2018)

La PEA ocupada se divide en tres categorías: Trabajador independiente, trabajador dependiente y trabajador no remunerado. La figura muestra la tendencia de las 
tres categorías a través del tiempo. Como se sabe, esta evaluación se realizó entre Enero de 2009 y Diciembre de 2014.

La línea verde representa a los trabajadores dependientes y muestra una pendiente ligeramente positiva, donde se puede afirmar que la cantidad de trabajadores dependientes en la ciudad de Lima, entre el año 2009 y 2014 ha aumentado de manera progresiva pero poco significativa.

La línea roja representa a los trabajadores independientes, es decir aquellos que trabajan en una empresa o que son subordinados de alguien. La tendencia de esta línea presenta pequeñas desviaciones pero con una tendencia horizontal, lo que permite inferir que la cantidad de trabajadores independientes no ha variado mucho a lo largo de los años.

Finalmente, la línea azul es la representación de los trabajadores no remunerados, que como ejemplo se pueden citar a las amas de casa. Con una tendencia similar a la de los trabajadores independientes, la línea de tendencia azul presenta pequeñas desviaciones pero tiene una tendencia horizontal, con lo que podemos afirmar que la cantidad de trabajadores no remunerados no ha variado en gran magnitud.

El aumento de la PEA ocupada independiente y el ligero aumento de la PEA ocupada dependiente, indican que hay una mayor cantidad de ciudadanos con empleo. Al conocerse que las PYMES representan alrededor del 99\% de las empresas, se puede determinar que este aumento de trabajadores se ha dado en las pequeñas y medianas empresas en su mayoría. Esto indica y confirma un crecimiento sostenido de las PYMES en la ciudad.

Cabe resaltar que para impulsar este crecimiento que van teniendo las pequeñas y medianas empresas a través de los años, es necesario el financiamiento tanto para los activos corrientes, como para seguir impulsando este desarrollo que vienen teniendo desde hace algún tiempo atrás. 
Figura 2.6

PEA ocupada Lima, por categorías. Año 2014

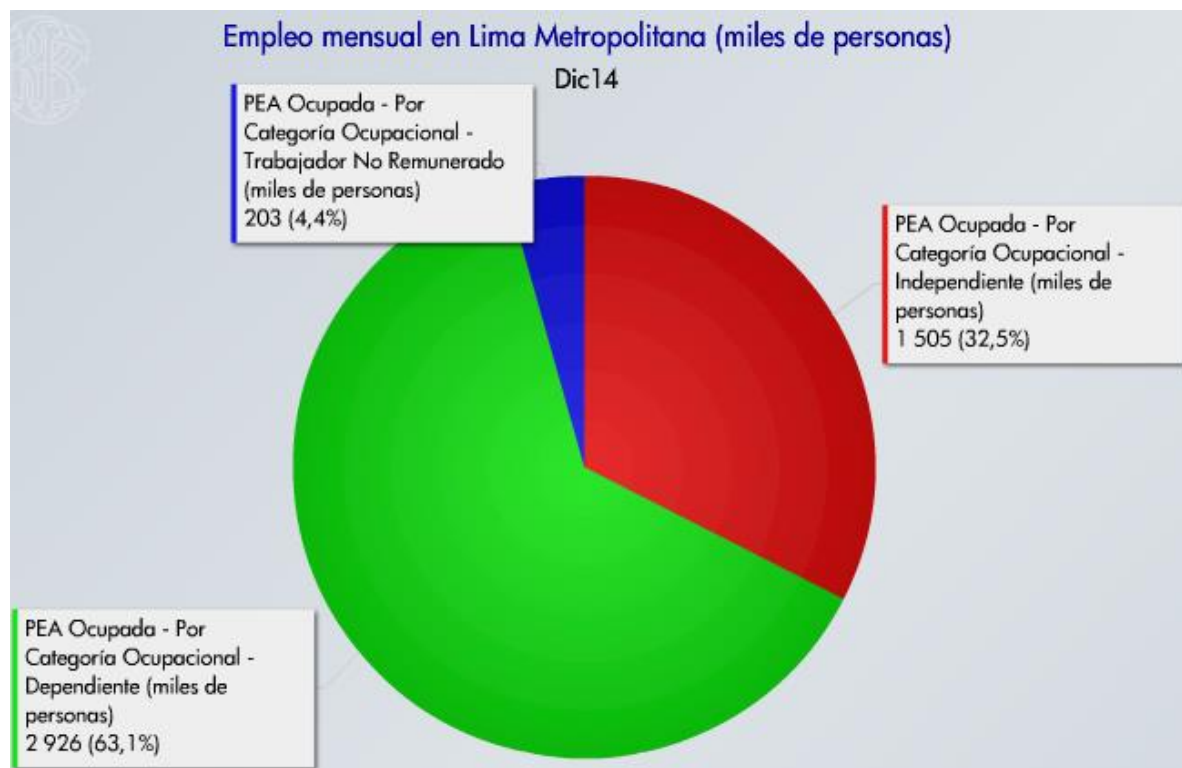

Nota: Distribución de la PEA ocupada por categorías para la ciudad de Lima. Año 2014.

Fuente: Banco Central de Reserva del Perú (2018)

Se consideró oportuno colocar una figura donde se represente en un gráfico circular el porcentaje de los tres tipos de trabajadores sobre el total. Para éste gráfico por categorías, se tomó en cuenta únicamente el último año (2014) para que coincida con el periodo de estudio de ésta investigación.

Se concluye que para el año 2014, los trabajadores dependientes son la categoría más significativa en la ciudad de Lima, ya que representan el $63.1 \%$ del total. Además, el segundo lugar es para los trabajadores independientes que representan el $32.5 \%$ del total. Finalmente, los trabajadores no remunerados componen al $4.4 \%$ del total. 


\subsubsection{PEA ocupada Lima por tamaño de empresa}

De 1 a 10 trabajadores (pequeñas empresas)

Tabla 2.9

PEA ocupada Lima por tamaño de empresa. De 1 a 10 trabajadores (miles de personas)

\begin{tabular}{c|cccccc}
\hline Fecha & $\mathbf{2 0 0 9}$ & $\mathbf{2 0 1 0}$ & $\mathbf{2 0 1 1}$ & $\mathbf{2 0 1 2}$ & $\mathbf{2 0 1 3}$ & $\mathbf{2 0 1 4}$ \\
\hline Enero & 2,465 & 2,857 & 2,625 & 2,688 & 2,655 & 2,707 \\
Febrero & 2,517 & 2,816 & 2,867 & 2,673 & 2,898 & 2,810 \\
Marzo & 2,551 & 2,757 & 2,751 & 2,605 & 2,765 & 2,861 \\
Abril & 2,637 & 2,836 & 2,705 & 2,722 & 2,756 & 2,701 \\
Mayo & 2,527 & 2,737 & 2,693 & 2,701 & 2,757 & 2,672 \\
Junio & 2,512 & 2,637 & 2,602 & 2,602 & 2,782 & 2,704 \\
Julio & 2,594 & 2,790 & 2,857 & 2,741 & 2,796 & 2,686 \\
Agosto & 2,424 & 2,684 & 2,644 & 2,596 & 2,710 & 2,725 \\
Setiembre & 2,513 & 2,682 & 2,721 & 2,690 & 2,740 & 2,692 \\
Octubre & 2,662 & 2,627 & 2,762 & 2,721 & 2,786 & 2,859 \\
Noviembre & 2,648 & 2,735 & 2,553 & 2,734 & 2,652 & 2,710 \\
Diciembre & 2,696 & 2,672 & 2,747 & 2,710 & 2,813 & 2,752 \\
Promedio & 2,562 & 2,736 & 2,711 & 2,682 & 2,759 & 2,740 \\
Variación & - & $6.78 \%$ & $-0.92 \%$ & $-1.06 \%$ & $2.88 \%$ & $-0.70 \%$ \\
\hline
\end{tabular}

Nota: PEA ocupada por categorías. Información para micro y pequeñas empresas (de 1 a 10 trabajadores) Periodo 2009-2014.

Fuente: Banco Central de Reserva del Perú (2018)

Mediante estas tres tablas se evaluarán la cantidad de trabajadores según los tres tamaños de empresas para el año 2014, año que coincide con el periodo de estudio de ésta investigación.

Las micro y pequeñas empresas son las entidades que tienen una mayor proporción de trabajadores de la PEA ocupada en la ciudad de Lima. 2740 mil de los 4 645 mil trabajadores del total trabajan en estas entidades, lo que significa el $58.99 \%$ del total.

Asimismo, las grandes empresas (de 51 a más trabajadores) cuentan con 1432 mil de los 4645 mil trabajadores. Esto significa que la denominadas "grandes empresas" cuentan con el 30.83\% de la PEA ocupada para el año 2014. 
Tabla 2.10

PEA ocupada de Lima por tamaño de empresa. De 11 a 51 trabajadores (miles de personas)

\begin{tabular}{c|cccccc}
\hline Fecha & $\mathbf{2 0 0 9}$ & $\mathbf{2 0 1 0}$ & $\mathbf{2 0 1 1}$ & $\mathbf{2 0 1 2}$ & $\mathbf{2 0 1 3}$ & $\mathbf{2 0 1 4}$ \\
\hline Enero & 454 & 424 & 455 & 470 & 424 & 475 \\
Febrero & 384 & 422 & 398 & 443 & 437 & 476 \\
Marzo & 446 & 422 & 495 & 450 & 486 & 474 \\
Abril & 462 & 436 & 520 & 450 & 456 & 489 \\
Mayo & 393 & 493 & 470 & 533 & 465 & 519 \\
Junio & 361 & 386 & 435 & 442 & 430 & 488 \\
Julio & 397 & 449 & 489 & 478 & 491 & 468 \\
Agosto & 446 & 504 & 495 & 506 & 441 & 503 \\
Setiembre & 388 & 356 & 445 & 489 & 454 & 447 \\
Octubre & 440 & 458 & 466 & 504 & 544 & 406 \\
Noviembre & 423 & 470 & 534 & 490 & 461 & 499 \\
Diciembre & 453 & 478 & 457 & 546 & 456 & 434 \\
Promedio & 421 & 442 & 472 & 483 & 462 & 473 \\
Variación & - & $4.97 \%$ & $6.81 \%$ & $2.51 \%$ & $-4.41 \%$ & $2.40 \%$ \\
\hline
\end{tabular}

Nota: PEA ocupada por categorías. Información para medianas empresas (de 11 a 50 trabajadores) Periodo 2009-2014.

Fuente: Banco Central de Reserva del Perú (2018)

En conclusión, Lima es la ciudad que cuenta con la mayor cantidad de empresas grandes (51 o más trabajadores) en todo el país, es por ello que el $30.83 \%$ de la PEA ocupada trabaja en estas entidades.

En cuanto al nivel de importancia, las micro y pequeñas empresas son las entidades donde trabaja la mayoría de personas de la PEA ocupada. En el caso de Lima, el 58.99\% trabaja en micro y pequeñas empresas. Estas cifras permiten afirmar que las micro y pequeñas empresas son gran parte del motor de la economía, ya que son el tipo de empresas que cuenta con un mayor número de trabajadores.

Por último, al igual que a nivel nacional, las empresas con las que menos trabajadores cuentan en Lima Metropolitana son las medianas empresas. 473 mil de los 4645 mil trabajadores operan en estas entidades, lo que significa el 9.41\% del total, para el año 2014. 
Tabla 2.11

PEA ocupada de Lima por tamaño de empresa. De 51 a más trabajadores (miles de personas)

\begin{tabular}{c|ccccccc}
\hline Fecha & $\mathbf{2 0 0 9}$ & $\mathbf{2 0 1 0}$ & $\mathbf{2 0 1 1}$ & $\mathbf{2 0 1 2}$ & $\mathbf{2 0 1 3}$ & $\mathbf{2 0 1 4}$ \\
\hline Enero & 1,036 & 1,068 & 1,181 & 1,209 & 1,325 & 1,356 \\
Febrero & 1,156 & 1,071 & 1,203 & 1,318 & 1,272 & 1,419 \\
Marzo & 1,137 & 1,193 & 1,186 & 1,394 & 1,388 & 1,356 \\
Abril & 1,099 & 1,003 & 1,165 & 1,242 & 1,380 & 1,395 \\
Mayo & 1,164 & 1,129 & 1,244 & 1,288 & 1,306 & 1,387 \\
Junio & 1,209 & 1,228 & 1,270 & 1,410 & 1,409 & 1,505 \\
Julio & 1,152 & 1,071 & 1,156 & 1,342 & 1,386 & 1,440 \\
Agosto & 1,163 & 1,232 & 1,270 & 1,310 & 1,378 & 1,401 \\
Setiembre & 1,217 & 1,237 & 1,223 & 1,374 & 1,420 & 1,495 \\
Octubre & 1,184 & 1,294 & 1,237 & 1,302 & 1,396 & 1,449 \\
Noviembre & 1,172 & 1,201 & 1,341 & 1,359 & 1,475 & 1,531 \\
Diciembre & 1,183 & 1,187 & 1,324 & 1,332 & 1,395 & 1,447 \\
Promedio & 1156 & 1160 & 1233 & 1323 & 1378 & 1432 \\
Variación & & $0.30 \%$ & $6.37 \%$ & $7.30 \%$ & $4.09 \%$ & $3.94 \%$ \\
\hline
\end{tabular}

Nota: PEA ocupada por categorías. Información para grandes empresas (de 51 a más trabajadores) Periodo 2009-2014.

Fuente: Banco Central de Reserva del Perú (2018)

Ya que ésta investigación consta sobre el financiamiento bancario de corto plazo de las PYMES en la ciudad de Lima, fue necesario evaluar e identificar la importancia que tienen estas pequeñas y medianas empresas para el contexto. Conociendo ésta realidad se podrá tener una idea más clara sobre la magnitud e impacto que pueden tener las PYMES como conjunto sobre la economía.

Resulta interesante para el estudio explicar las tendencias de los tres tipos de empresas según tamaño para conocer su evolución entre Enero de 2009 y Diciembre de 2014.

La línea roja representa a las micro y pequeñas empresas (de 1 a 10 trabajadores). A través de la gráfica se puede inferir que ha habido un pequeño aumento en el tiempo con respecto a la cantidad de personas que laboran en estas entidades. Este aumento se podría deber a nuevos emprendedores que empiezan con el negocio propio y al crédito bancario que ofrecen algunas entidades para la creación de nuevas empresas. 
Figura 2.7

Distribución y evolución de la PEA ocupada por tamaño de empresas

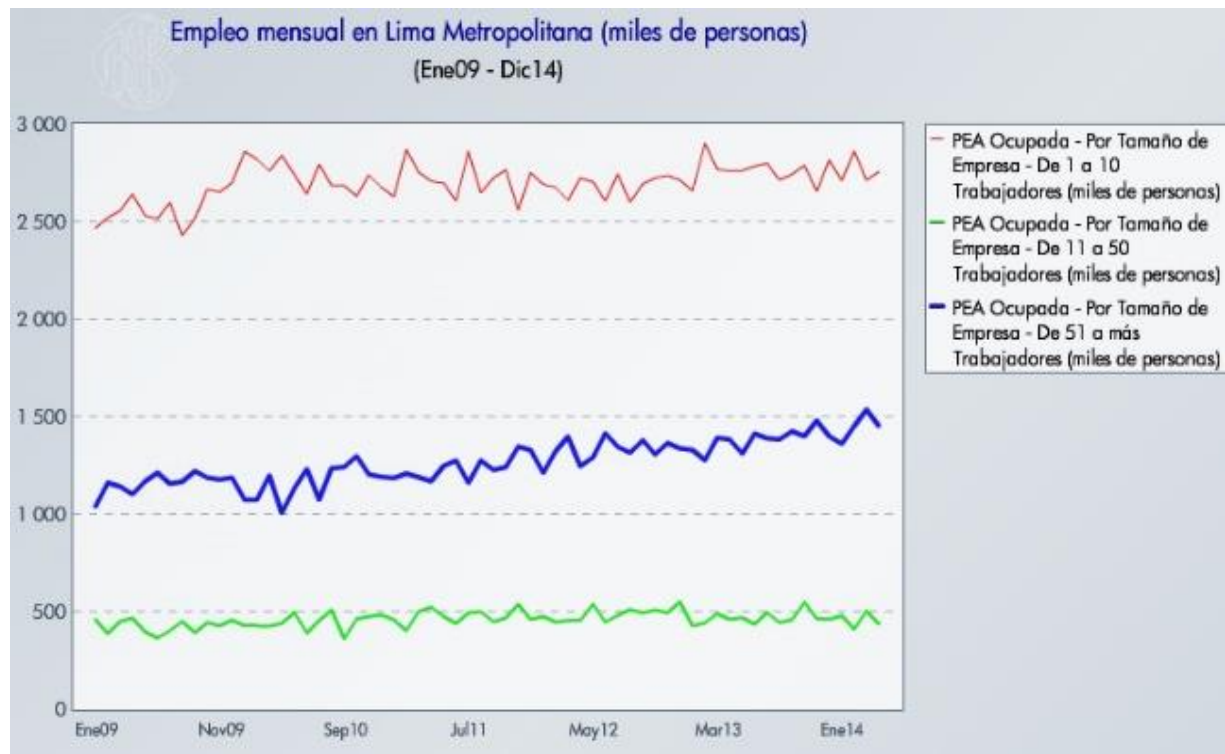

Nota: Tendencia de la PEA ocupada por tamaño de empresas. Periodo 2009-2014.

Fuente: Banco Central de Reserva del Perú (2018)

La línea azul represente a las grandes empresas (de 51 a más trabajadores). Entre las tres líneas de tendencia evaluadas, la pendiente de la de las grandes empresas es la más pronunciada. Ésta pendiente positiva muestra un crecimiento de la cantidad de trabajadores que operan en las empresas más grandes de la ciudad y que últimamente se tiende a trabajar en las empresas denominadas grandes.

La línea verde representa a las medianas empresas (entre 11 y 50 trabajadores). Ésta línea muestra una tendencia horizontal con una ligera dispersión a través del tiempo. Con esta información se puede inferir que la cantidad de trabajadores que realizan sus operaciones en empresas medianas se ha mantenido estable entre los años 2009 y 2014.

Las tendencias mostradas muestran que las empresas más pequeñas son las que más trabajo absorben, es decir, que las pequeñas empresas tienen la capacidad para dinamizar la economía y para impulsar importantes factores como el consumo, ya sea a nivel de los hogares o de las empresas. 


\subsubsection{PEA Lima subempleada}

Figura 2.8

PEA subempleada Lima Metropolitana. 2009 - 2014

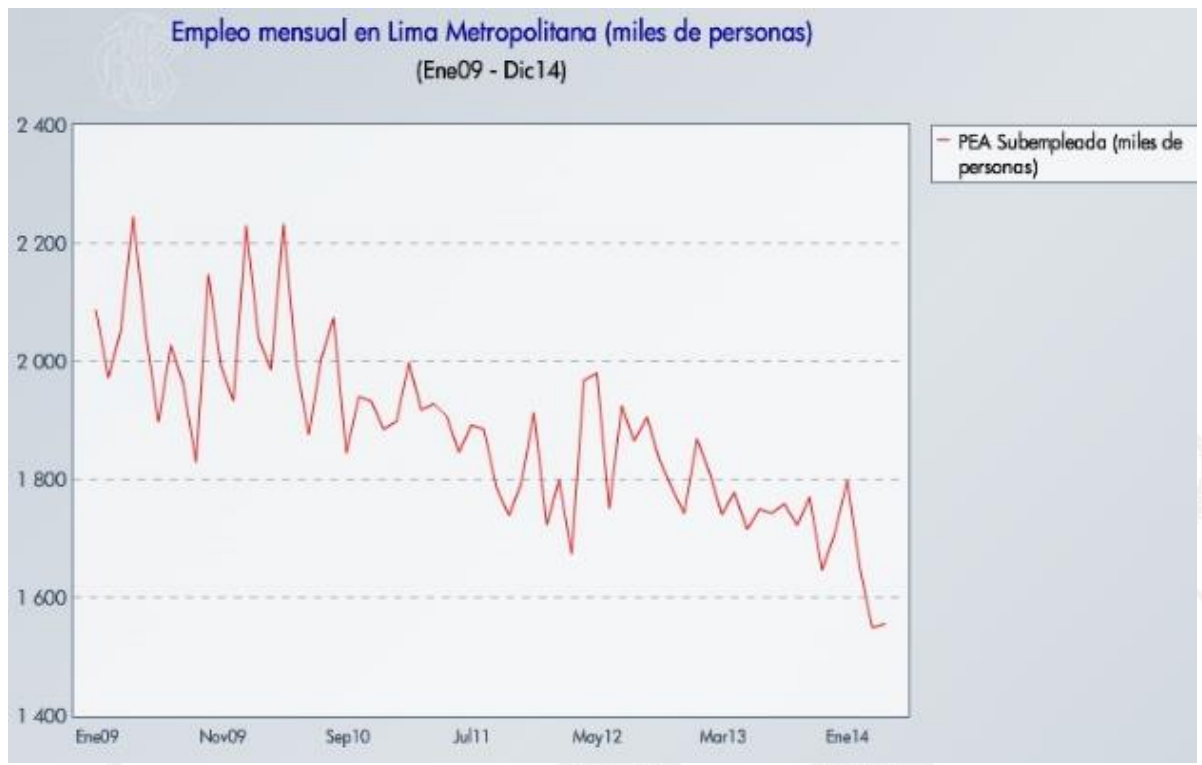

Nota: Tendencia de la PEA subempleada en Lima Metropolitana. Periodo 2009-2014.

Fuente: Banco Central de Reserva del Perú (2018)

La figura sirve para explicar que la cantidad de trabajadores subempleados en la ciudad de Lima se ha ido reduciendo conforme avanzaban los años.

La línea roja muestra la tendencia de la PEA subempleada y la pendiente negativa de ésta, permite sacar la conclusión que ha habido una disminución de la PEA subempleada y los datos de la tabla lo confirman: La variación porcentual en la PEA subempleada entre los años 2009 y 2014 fue negativa.

De esta manera se denota que el subempleo en el tiempo se vio significativamente disminuido, esto se da por diversos factores, como la especialización y la correcta elección de carreras técnicas o universitarias.

Este es un buen síntoma en general para el sistema productivo limeño, ya que existen más personas trabajando en lo que fueron formados o en lo que eligieron como carrera. De esta manera, se denota que hay más gente especializada en las diversas áreas productivas. 


\subsubsection{Tasa desempleo Lima}

Figura 2.9

Tasa de desempleo en Lima Metropolitana. 2009 - 2014

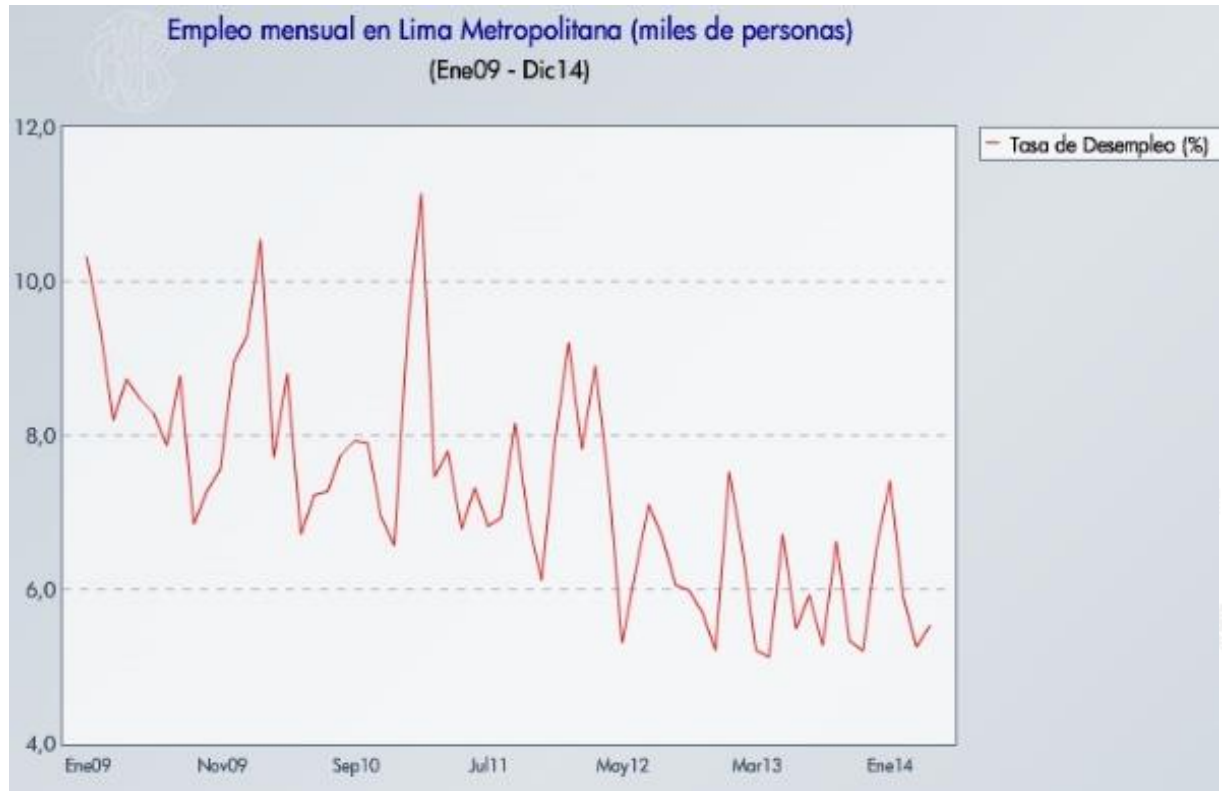

Nota: Tendencia de la tasa de desempleo en Lima Metropolitana. Periodo 2009-2014.

Fuente: Banco Central de Reserva del Perú (2018)

La figura muestra que la tasa de desempleo en la ciudad de Lima ha ido disminuyendo progresivamente.

¿A qué se podría deber esta mejora? En primer lugar, el crecimiento progresivo del PBI durante los últimos años ha traído consigo nuevas y mayores oportunidades de desarrollo para los peruanos. La innovación e inversión en nuevos negocios y una mayor demanda de trabajadores por parte de las empresas resulta un factor determinante para la disminución de la tasa de desempleo.

La figura lo muestra así. Una línea roja, la cual representa a la tasa de desempleo en Lima Metropolitana con una pendiente negativa y un alto grado de dispersión. Se podría concluir que los picos que sobresalen en la gráfica muestran que el desempleo es voluble, sin embargo la mejora en la tendencia es evidente, todo esto en favor de la economía y el desarrollo social.

Resulta importante analizar el comportamiento del desempleo ya que se considera que tiene una relación directa con el crecimiento de las PYMES. El desarrollo de las PYMES en el país tiene un efecto directo sobre la demanda de trabajadores en el mercado. Si las PYMES crecen, necesitaran mejorar su capacidad productiva, por lo que se 
requerirá una mayor cantidad de mano de obra. Como conclusión a este punto se podría mencionar que el financiamiento es la base para el crecimiento empresarial, y el crecimiento de las PYMES tiene una relación inversa con el desempleo. Por lo tanto, se podría determinar que a mayor desarrollo de las PYMES, menor desempleo en la ciudad de Lima y en el país en general.

\subsubsection{Remuneración mínima vital - nominal}

Figura 2.10

Evolución de la remuneración mínima vital en Perú. 2009 - 2014

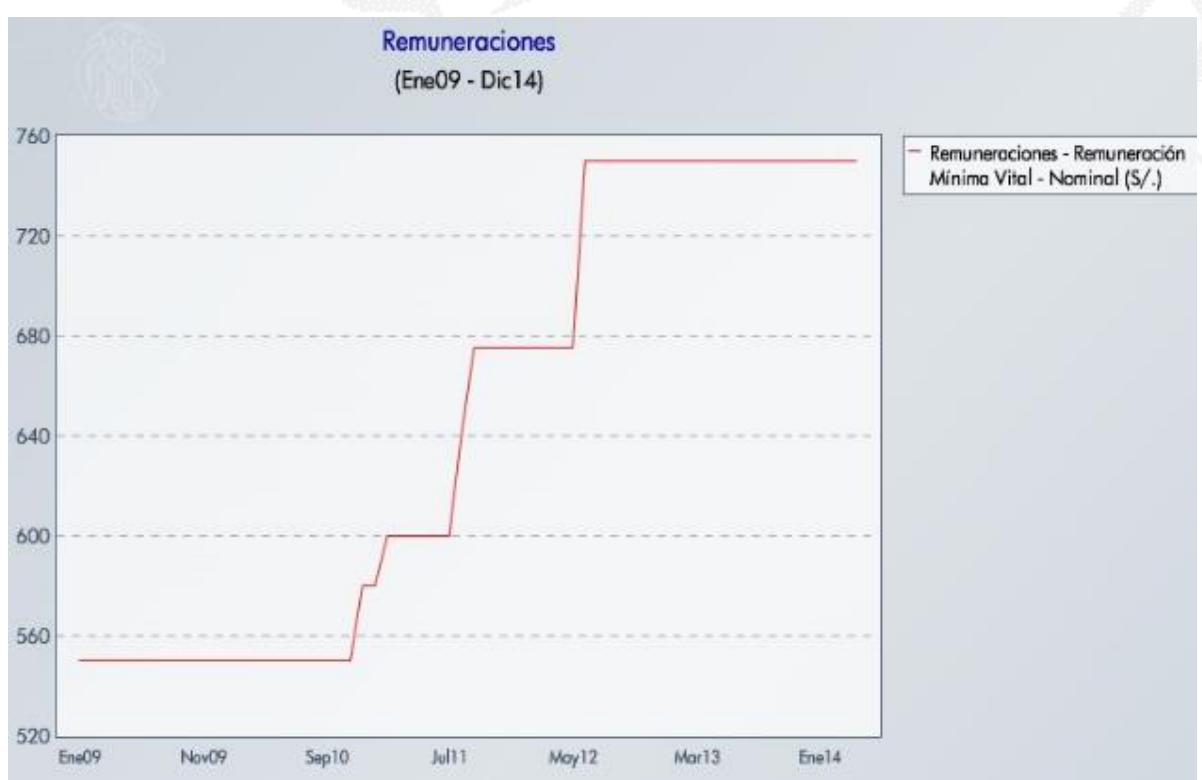

Nota: Tendencia de la remuneración vital mínima en Perú. Periodo 2009-2014.

Fuente: Banco Central de Reserva del Perú (2018)

La primera tabla muestra mes a mes el salario mínimo vital de los habitantes del Perú, detallando mes a mes si éste se mantiene o experimenta una subida. Desde Enero de 2009 a Diciembre de 2014, el salario mínimo en el país ha aumento de 550 a 750 soles al mes, lo que significa que ha habido un incremento porcentual de $36.36 \%$.

La figura muestra de manera evidente un cambio (aumento de sueldo) en favor de los trabajadores, los cuales perciben un mayor salario por su trabajo.

Las subidas del salario mínimo se dieron específicamente en los siguientes meses: Diciembre 2010 (de 550 a 580 soles), Febrero de 2011 (de 580 a 600 soles), Agosto de 2011 (de 600 a 640 soles), Setiembre 2011 (de 640 a 675 soles), Junio de 2012 (de 675 a 
750 soles). El salario mínimo vital se mantiene desde Junio del año 2012 en 750 hasta la fecha.

Contrastando la tabla de las remuneraciones mensuales con el del IPC de Lima, se puede inferir que tanto el alza de sueldos como el del índice de precios han aumentado la inflación local, sin embargo, ésta se mantiene dentro del rango meta que propone el BCRP.

Ahora, se desea evaluar en que afecta la subida de la remuneración mínima vital a las PYMES. Un aumento de los salarios mínimos implica que las empresas tendrán que gastar un monto mayor en pagar a sus trabajadores, lo que afecta directamente sus costos. Una mayor cantidad de costos reduce la utilidad y el flujo de caja de las empresas, por lo que disminuye la liquidez de las mismas. Finalmente, la disminución de liquidez hará que las PYMES necesiten un mayor financiamiento bancario. De esta manera se puede concluir que la subida de sueldos tendría un impacto sobre el financiamiento bancario que solicitan las pequeñas y medianas empresas.

\subsection{Sistema financiero en el Perú}

\subsubsection{Tipo de cambio, 2009 - 2014}

Tabla 2.12

Tipo de cambio, 2009-2014

\begin{tabular}{c|cc}
\hline Fecha & $\begin{array}{c}\text { Tipo de cambio nominal } \\
\text { (promedio anual) }\end{array}$ & $\begin{array}{c}\text { Tipo de cambio nominal } \\
\text { (var. \% anual) }\end{array}$ \\
\hline 2009 & 3,012 & 2,949 \\
2010 & 2,826 & $-6,189$ \\
2011 & 2,755 & $-2,515$ \\
2012 & 2,638 & $-4,230$ \\
2013 & 2,703 & 2,448 \\
2014 & 2,839 & 5,054 \\
\hline
\end{tabular}

Nota: Evolución y variación del tipo de cambio nominal. Periodo 2009-2014.

Fuente: Banco Central de Reserva del Perú (2018) 
Figura 2.11

Tipo de cambio bancario promedio nominal. 2009-2014

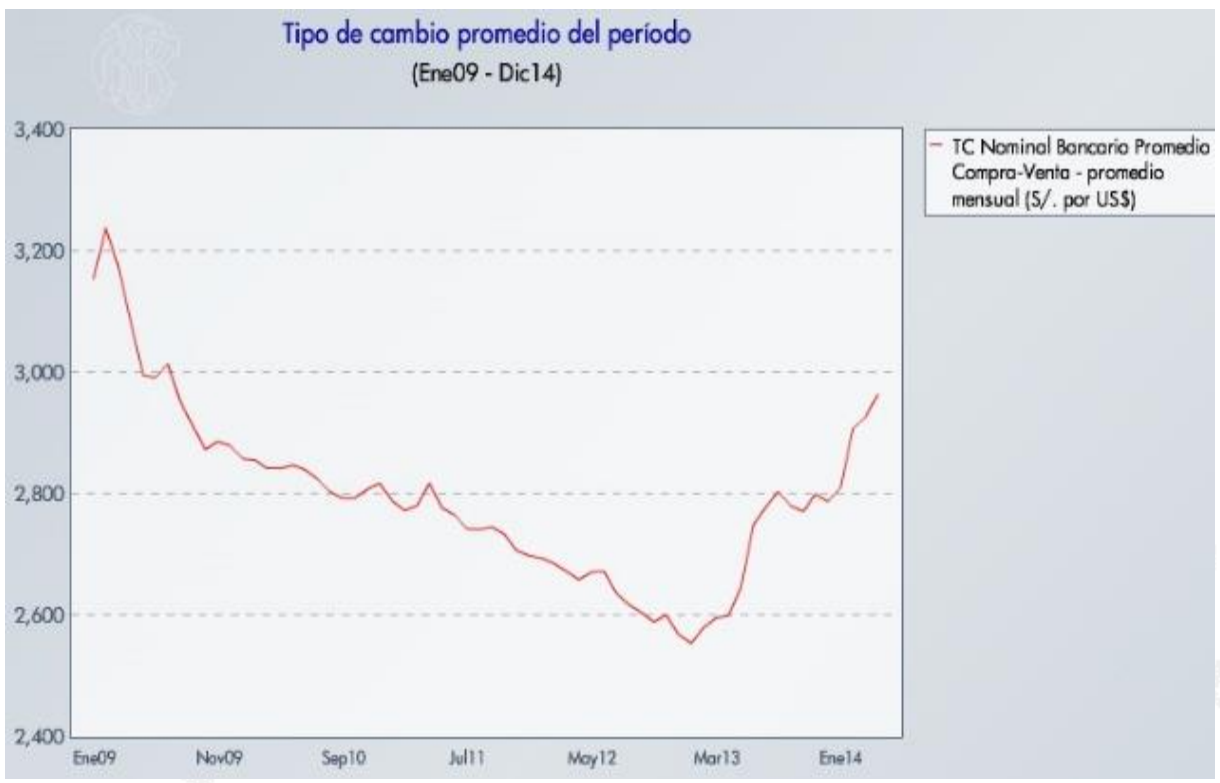

Nota: Evolución del tipo de cambio bancario en Perú. Periodo 2009-2014.

Fuente: Banco Central de Reserva del Perú (2018)

La figura anterior muestra las fluctuaciones del tipo de cambio entre los años 2009 y 2014.

Factores como la crisis internacional del 2009, la inyección de dinero en la economía y la recuperación de la economía norteamericana han sido factores clave para crear esta tendencia en el tipo de cambio del sol con respecto al dólar.

La línea roja representa al tipo de cambio nominal bancario promedio y muestra un comportamiento inestable a través del tiempo. En la figura se ven picos cercanos a 3.30 soles por dólar, como momentos en los que el sol se aprecia y estaba cercano a los 2.50 soles por dólar.

De esta manera, la tendencia se considera bastante propensa a cambios eventuales que provengan de la economía internacional, así como del trabajo del Banco Central de Reserva del Perú para mantener un tipo de cambio sol/dólar acorde con los intereses de nuestra economía.

Se consideró importante incluir el análisis de la tendencia del tipo de cambio a lo largo del periodo 2009 - 2014 ya que aproximadamente el 15\% de las PYMES se endeudan en dólares y el $85 \%$ en soles, por lo que una variación del tipo de cambio para aquellas empresas que solicitan financiamiento en moneda extranjera, descuadraría sus 
finanzas. El problema de aquellas empresas que se endeudan en dólares es que la gran mayoría de ellas realiza sus operaciones en soles, por lo que están expuestas a un riesgo.

Se recomienda tomar deudas bancarias en la misma moneda en la que operan las empresas con el fin de evitar el riesgo cambiario. Es decir, si una empresa realiza sus operaciones en soles, es conveniente que se endeude en soles también.

Como alternativa, si la empresa decide seguir tomando deuda en dólares, se recomienda establecer un tipo de cambio forward para mantener el tipo de cambio fijo y que la entidad elimine el riesgo cambiario ante posibles fluctuaciones de la moneda.

\subsubsection{Evolución de las colocaciones a PYMES del total del sistema bancario}

Figura 2.12

Evolución de las colocaciones a PYMES

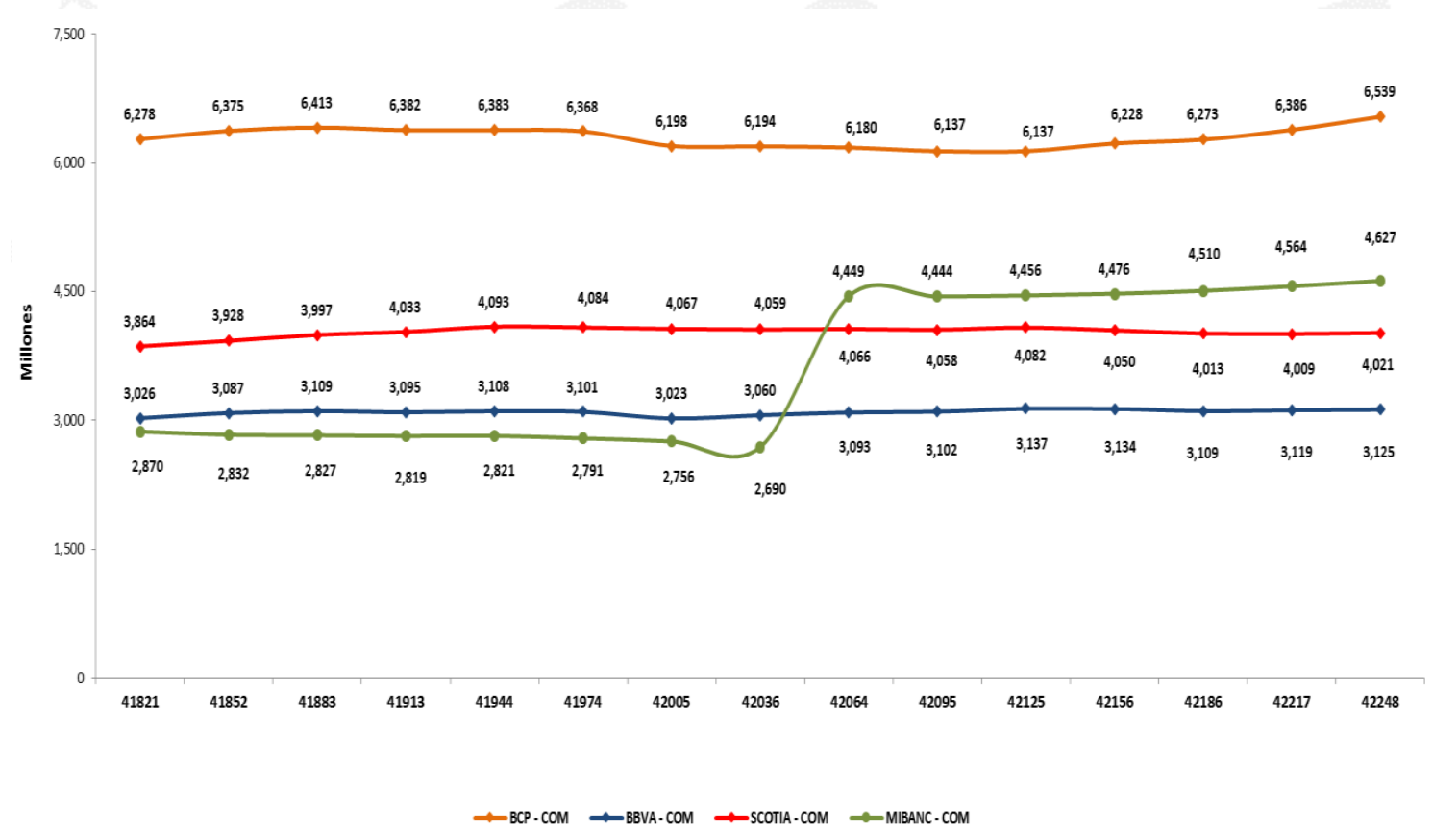

Nota: Comportamiento de las colocaciones a PYMES del total del sistema bancario. Periodo 2009-2014.

Fuente: Banco Central de Reserva del Perú (2018)

En el sistema bancario los bancos BCP, BBVA, Scotiabank y Mibanco son los que más aportan al crédito bancario dirigido a las PYMES. En el siguiente gráfico se muestra la evolución de las colocaciones a las PYMES de estos bancos. En particular, el BCP tiene la mayor participación de mercado; mantuvo una cartera de S/ 6539 millones en setiembre de 2015. En el último año la participación de Mibanco se ha incrementado 
de manera importante, pasó de tener la cuarta participación a la segunda mayor; alcanzado una cartera de S/ 4627 millones. En el caso de Mibanco su crecimiento dio un salto de S/ 2690 millones a S/ 4449 millones. Finalmente, cabe mencionar que las colocaciones del Banco BBVA han mantenido estables alrededor de S/ 3100 millones.

\subsubsection{Créditos directos a microempresas, entidades bancarias (2009 - 2014)}

Tabla 2.13

Crédito directo a microempresas, según entidades bancarias. 2009 - 2014 (miles de nuevos soles)

\begin{tabular}{|c|c|c|c|c|c|c|}
\hline Empresas & 2009 & 2010 & 2011 & 2012 & 2013 & $2014 \mathrm{a} /$ \\
\hline Banca Múltiple & 653637 & 2519373 & 2547571 & 2559500 & 1873384 & 1682837 \\
\hline B.de Crédito & 1954791 & 596233 & 552352 & 588660 & 407466 & 339317 \\
\hline Mibanco & 2190997 & 1189712 & 1198913 & 1265436 & 947349 & 818795 \\
\hline Scotiabank & 175972 & 270840 & 295736 & 183270 & 137790 & 135429 \\
\hline Financiero & 149489 & 156014 & 190399 & 179091 & 174776 & 136991 \\
\hline Continental & 18938 & 208556 & 230918 & 241248 & 86295 & 93061 \\
\hline Interbank 1/ & 144074 & 65661 & 29786 & 33178 & 44515 & 118642 \\
\hline B.de Comercio & 13851 & 16413 & 21043 & 18717 & 15841 & 16343 \\
\hline $\mathrm{BIF}$ & 2270 & 14920 & 14450 & 41519 & 55330 & 23228 \\
\hline B. Santander & - & - & - & - & 3 & 65 \\
\hline B. GNV & - & 402 & 13744 & 1104 & 311 & 768 \\
\hline B. Ripley & 3255 & 614 & 229 & 204 & 141 & 141 \\
\hline Citibank & - & 9 & - & 7074 & 3566 & 56 \\
\hline TOTAL & $\begin{array}{c}10645 \\
310\end{array}$ & 6144873 & 6463308 & 6553677 & 5557503 & 5326717 \\
\hline Variación \% & - & $-42.28 \%$ & $5.18 \%$ & $1.40 \%$ & $-15.20 \%$ & $-4.15 \%$ \\
\hline
\end{tabular}

Se consideró oportuno incluir una tabla de los créditos directos que reciben las empresas, según la entidad bancaria por los siguientes motivos.

- Evaluar la tendencia del crédito otorgado por las entidades bancarias, analizando la cantidad de pequeñas y medianas empresas a las que financian. 
- Analizar cuáles son las entidades bancarias que otorgan financiamiento bancario a un mayor número de PYMES, con la intención de reconocer su aporte a la economía nacional.

- Identificar la aparición de nuevas entidades bancarias, lo que genera una mayor competencia en el mercado bancario.

En cuanto a la tendencia del crédito otorgado por las empresas bancarias, este presenta un comportamiento indefinido, por lo que no se puede identificar una tendencia. Las variaciones fueron tanto positivas como negativas a lo largo del periodo de estudio, por lo que no se pudo determinar un comportamiento definido de la evolución.

Se evaluó un periodo de 6 años entre el 2009 y 2014 en el que las variaciones fueron las siguientes:

Tabla 2.14

Variación del crédito otorgado a las PYMES por las entidades bancarias. 2009-2014

\begin{tabular}{c|c}
\hline Años & Variación \% \\
\hline 2009 & - \\
2010 & $-42.28 \%$ \\
2011 & $5.18 \%$ \\
2012 & $1.40 \%$ \\
2013 & $-15.20 \%$ \\
2014 & $-4.15 \%$ \\
\hline
\end{tabular}

Nota: Variación porcentual del crédito otorgado a las PYMES por las distintas entidades bancarias.

Fuente: Banco Central de Reserva del Perú (2018).

La disminución de la cantidad de PYMES que acceden a un financiamiento bancario en los años 2010, 2013 y 2014, puede deberse a que estas empresas utilizan fuentes de financiamiento alternativas para su crecimiento. El financiamiento con recursos propios es una de las fuentes que prefieren las PYMES ya que esto implica no tener que pagar intereses por el dinero que decidan invertir. Sin embargo, no todas las empresas generan un flujo de caja lo suficientemente alto para poder autofinanciarse, por lo que es un supuesto financiero para justificar estas disminuciones en dichos años. 
Con respecto a las entidades bancarias que otorgan financiamiento bancario a las PYMES, se tomó el año 2014 por ser el último año que se tiene información y por ser el año de estudio de ésta investigación.

La entidad bancaria que financió a una mayor cantidad de PYMES a nivel nacional para el año 2014, fue Mibanco con 818795 empresas de un total de 1682837 de la banca múltiple, lo que significa que Mibanco financia al $48.66 \%$ del total, siendo la empresa más representativa para el año mencionado.

En segundo lugar, se encuentra el Banco de Crédito del Perú, habiendo financiado a 339317 empresas del total de 1682837 de la banca múltiple para el año 2014, lo que representa al 20.16\% del total. El BCP como banco, es el número 1 en facturación a nivel nacional, sin embargo en el rubro de financiamiento bancario a PYMES, se encuentra en el segundo lugar, por detrás de Mibanco.

Por último, el tercer lugar para de los bancos que brindan financiamiento a un mayor número de empresas es el Banco Financiero, el cuál financia a 136991 PYMES del total, lo que significa el $8.14 \%$ del total. Este banco se ha caracterizado por enfocarse en otorgar créditos a empresas pequeñas, lo que le ha permitido posicionarse en este lugar del ranking.

En cuanto a la aparición de nuevas entidades bancarias en los últimos años del periodo de estudio, se puede identificar el ingreso al mercado de nuevos bancos como el HSBC (ahora GNB), el cuál ingresó al mercado peruano en el año 2010 y que financió a 768 pequeñas y medianas empresas en el año 2014. Asimismo, el Banco Santander empezó sus operaciones en el Perú en el año 2013, habiendo financiado a 65 PYMES durante el año 2014, siendo penúltima en este ranking, probablemente debido a que es una empresa nueva en el mercado nacional.

En conclusión, a lo largo de éste capítulo se han evaluado las principales variables de la economía desde el año 2009 al 2014. Como se sabe, la investigación fue un estudio de corte transversal específicamente para el 2014, por lo que se consideró pertinente evaluar el periodo de cinco años previos al año de estudio.

Durante este intervalo de tiempo se explicó el comportamiento de variables como el producto bruto interno, el índice de precios al consumidor, la población económicamente activa, y variables del sector financiero que tendrían un efecto sobre las decisiones de las PYMES. 
Las empresas toman sus decisiones de acuerdo al contexto en el que se encuentran. Por ejemplo, un escenario favorable en la economía haría que el panorama de crecimiento de las PYMES sea mucho más optimista, por lo que un contexto de un país con una economía en desarrollo, sería clave para que las empresas pensaran en invertir y para esto, solicitaran un mayor financiamiento.

Como conclusión general, el capítulo II y su análisis de la economía y el sector financiero a través del tiempo, sirve como referencia tanto para entender el contexto en el que se realiza la investigación, como para conocer el efecto directo que tiene la realidad económica de un país, sobre las decisiones financieras que puedan tomar las PYMES. 


\section{CAPÍTULO III: CONTRASTACIÓN DE HIPÓTESIS}

En este capítulo se evaluarán las hipótesis planteadas. Para ello, se utilizará un modelo econométrico del tipo regresión lineal múltiple, cuyo método de estimación es el de mínimos cuadrados ordinarios (MCO). Además, se aplicarán diferentes pruebas estadísticas para la obtención y evaluación de los resultados del modelo. La información de la investigación es de una muestra de PYMES de la ciudad de Lima.

\subsection{Objetivos e hipótesis}

Se plantean los objetivos y las hipótesis a partir del problema identificado con las PYMES y ciertos aspectos que podrían influenciar de manera significativa

\subsubsection{Objetivo general}

Evaluar si las ventas, nivel de inventarios, el flujo de caja y la tasa de interés influyen en la decisión de financiamiento bancario de corto plazo de las pequeñas y medianas empresas (PYMES).

\subsubsection{Objetivos secundarios}

\section{Objetivo específico 1:}

Evaluar la importancia de las ventas y nivel de inventarios en la determinación del monto de financiamiento bancario de corto plazo de las PYMES.

\section{Objetivo específico 2:}

Evaluar si el flujo de caja y el costo de financiamiento (tasa de interés) influyen sobre el monto del préstamo bancario de corto plazo que demandarán las PYMES. 


\subsubsection{Hipótesis general}

Las ventas y el nivel de inventarios influyen en la decisión de financiamiento bancario de corto plazo de las pequeñas y medianas empresas, y en menor medida, lo hacen el flujo de caja y el costo de financiamiento.

\subsubsection{Hipótesis secundarias}

\section{Hipótesis específica 1:}

Las ventas y el nivel de inventarios son determinantes en la decisión de financiamiento bancario de corto plazo, teniendo las ventas un mayor impacto que los inventarios sobre la deuda bancaria de corto plazo que asumen las PYMES.

\section{Hipótesis especifica 2:}

El flujo de caja y la tasa de interés influyen en la determinación del monto del préstamo bancario de corto plazo que demandan las PYMES, teniendo el flujo de caja una mayor incidencia sobre la deuda que la tasa de interés.

\subsection{Metodología}

\subsubsection{Data y fuentes de información}

Se ha tomado información financiera de una muestra de 54520 PYMES de la ciudad de Lima que obtuvieron un crédito bancario durante el año 2014. La información fue proporcionada por una entidad de crédito, que por razones de confidencialidad de información se mantendrá su nombre en reserva.

\subsubsection{Modelo económico}

Para realizar una representación de la situación de las PYMES en el 2014 en la ciudad de Lima se realizará un modelo econométrico, de tal manera que sea factible replicar de manera eficiente la realidad de las mismas y poder de esa manera hacer un análisis objetivo y sustentable del comportamiento de las variables involucradas. 
En ese sentido se plantea la siguiente ecuación, que responde (en teoría) a la necesidad planteada en la investigación.

$$
\text { Deuda }_{\mathrm{i}}=\widehat{\alpha}+\widehat{\beta}_{1} * \operatorname{Ventas}_{\mathrm{i}}+\widehat{\beta}_{2} * \text { Inventario }_{\mathrm{i}}+\widehat{\beta}_{3} * \text { Flujo_Caja }_{\mathrm{i}}+\widehat{\beta}_{4} * \text { Tasa }_{\mathrm{i}}
$$

Asimismo, se busca que la referida ecuación plasme la evolución de las variables para demostrar la hipótesis propuesta en el presente capítulo.

En la siguiente tabla se presenta la definición de las variables para el modelo:

Tabla 3.1

Definición de variables

\begin{tabular}{|c|c|c|c|c|c|}
\hline Nomenclatura & Definición & Periodicidad & Tipo & Unidades & Fuente \\
\hline DEUDA & $\begin{array}{l}\text { Deuda bancaria } \\
\text { de corto plazo que } \\
\text { asumen las } \\
\text { PYMES para } \\
\text { financiarse }\end{array}$ & $\begin{array}{l}\text { Corte transversal. } \\
\text { Periodo: Año } 2014 .\end{array}$ & Nominal & $\begin{array}{l}\text { En miles de } \\
\text { nuevos soles }\end{array}$ & $\begin{array}{l}\text { Entidad } \\
\text { financiera }\end{array}$ \\
\hline VENTAS & $\begin{array}{l}\text { Nivel de ventas de } \\
\text { las PYMES }\end{array}$ & $\begin{array}{l}\text { Corte transversal. } \\
\text { Periodo: Año } 2014\end{array}$ & Nominal & $\begin{array}{l}\text { En miles de } \\
\text { nuevos soles }\end{array}$ & $\begin{array}{l}\text { Entidad } \\
\text { financiera }\end{array}$ \\
\hline INVENTARIO & $\begin{array}{lr}\text { Nivel } & \text { de } \\
\text { inventarios } & \text { de } \\
\text { productos } & \text { en } \\
\text { proceso } & \text { y } \\
\text { productos } & \\
\text { terminados } & \end{array}$ & $\begin{array}{l}\text { Corte transversal. } \\
\text { Periodo: Año } 2014\end{array}$ & Nominal & $\begin{array}{l}\text { En miles de } \\
\text { nuevos soles }\end{array}$ & $\begin{array}{l}\text { Entidad } \\
\text { financiera }\end{array}$ \\
\hline FLUJO DE CAJA & $\begin{array}{l}\text { Flujo de Caja de } \\
\text { las PYMES }\end{array}$ & $\begin{array}{l}\text { Corte transversal. } \\
\text { Periodo: Año } 2014\end{array}$ & Nominal & $\begin{array}{l}\text { En miles de } \\
\text { nuevos soles }\end{array}$ & $\begin{array}{l}\text { Entidad } \\
\text { financiera }\end{array}$ \\
\hline TASA & $\begin{array}{l}\text { Tasa de interés } \\
\text { bancaria de corto } \\
\text { plazo }\end{array}$ & $\begin{array}{l}\text { Corte transversal. } \\
\text { Periodo: Año } 2014\end{array}$ & Nominal & Porcentual & $\begin{array}{l}\text { Entidad } \\
\text { financiera }\end{array}$ \\
\hline
\end{tabular}

Fuente: Elaboración propia

\subsubsection{Modelo econométrico}

Para evaluar las hipótesis propuestas se plantea el siguiente modelo econométrico:

$$
\text { Deuda }_{\mathrm{i}}=\widehat{\alpha}+\widehat{\beta}_{1} * \operatorname{Ventas}_{\mathrm{i}}+\widehat{\beta}_{2} * \text { Inventario }_{\mathrm{i}}+\widehat{\beta}_{3} * \text { Flujo_Caja }_{\mathrm{i}}+\widehat{\beta}_{4} * \text { Tasa }_{\mathrm{i}}+\widehat{\mathrm{u}}_{\mathrm{i}}
$$

Así, las variables que pretenden explicar a la deuda de corto plazo que toman las empresas son las siguientes: 
- Ventas

- Nivel de inventarios

- Flujo de caja

- Tasa de interés

En cuanto al modelo econométrico, se utilizará un modelo de regresión lineal múltiple y el método de estimación es el de mínimos cuadrados ordinarios (MCO).

Los coeficientes del modelo econométrico $\left(\widehat{\beta}_{1}, \widehat{\beta}_{2}, \widehat{\beta}_{3}\right.$ y $\left.\widehat{\beta}_{4}\right)$ muestran la relación que existe entre el monto utilizado de las PYMES de su línea de crédito bancaria de corto plazo, y las variables exógenas del modelo.

- El coeficiente $\widehat{\beta}_{1}$ representa el efecto de las ventas sobre el monto de deuda de las PYMES. Se espera que dicho coeficiente tenga una relación positiva con la deuda bancaria de corto plazo que asumen las empresas.

- El coeficiente $\widehat{\beta}_{2}$ representa el efecto del nivel de inventario que mantienen las PYMES sobre el monto de deuda que asumen. Se espera que dicho coeficiente tenga una relación positiva con la deuda bancaria de corto plazo que asumen las empresas.

- El coeficiente $\widehat{\beta}_{3}$ representa el efecto del flujo de caja sobre el monto de deuda de las PYMES. Se espera que dicho coeficiente tenga una relación positiva con la deuda bancaria de corto plazo que asumen las empresas.

- El coeficiente $\widehat{\beta}_{4}$ representa el efecto del costo de la deuda (tasa de interés) sobre el monto de deuda que toman las PYMES. Se espera que dicho coeficiente tenga una relación negativa con la deuda bancaria de corto plazo que asumen las empresas.

Finalmente, testear las hipótesis planteadas implica evaluar la significancia estadística de los coeficientes del modelo de regresión múltiple.

Para esto, se realizará la regresión con un modelo logarítmico para las siguientes variables: deuda (endógena), ventas, inventarios y flujo de caja. La tasa de interés se mantendrá sin logaritmo ya que es una variable que se expresa porcentualmente.

El modelo logarítmico será el siguiente: 


$$
\begin{aligned}
\text { LDeuda }_{\mathrm{i}}=\widehat{\alpha} & +\widehat{\beta}_{1} * \text { LVentas }_{\mathrm{i}}+\widehat{\beta}_{2} * \text { LInventario }_{\mathrm{i}}+\widehat{\beta}_{3} * \text { LFlujo_Caja }_{\mathrm{i}}+\widehat{\beta}_{4} * \text { Tasa }_{\mathrm{i}} \\
& +\widehat{\mathrm{u}}_{\mathrm{i}}
\end{aligned}
$$

\subsection{Presentación de los resultados}

En esta sección se muestran los resultados de la regresión lineal múltiple, además, se presentan diversas pruebas que se realizaron y que dan soporte al modelo usado, es decir, que lo someten y le proporcionan una sólida base econométrica. Cabe mencionar que el modelo fue estimado en el programa econométrico Stata.

\subsubsection{Resultados del modelo de regresión}

A continuación se presentan los resultados de la regresión planteada, cabe resaltar que dicha regresión nace a partir de un modelo logarítmico que tiene como variable dependiente la deuda y como variables independientes a las ventas, el inventario, el flujo de caja y la tasa de interés.

Tabla 3.2

Modelo de regresión uno

. Regress Ideuda Iventas linventario Iflujo_caja tasa

\begin{tabular}{r|rrr} 
Source & SS & df & MS \\
\hline Model & 17850.8842 & 4 & 4462.72104 \\
Residual & 58452.4425 & 54515 & 1.07222677 \\
\hline Total & 76303.3267 & 54519 & 1.39957312
\end{tabular}

$$
\begin{array}{rlr}
\text { Number of obs } & = & 54520 \\
\mathrm{~F}(4,54515) & = & 4162.11 \\
\text { Prob }>\mathrm{F} & = & 0.0000 \\
\text { R-squared } & = & 0.2339 \\
\text { Adj R-Squared } & = & 0.2339 \\
\text { Root MSE } & = & 1.0355
\end{array}
$$

\begin{tabular}{r|rrrrrr} 
Ldeuda & Coef. & Std. Err. & $\mathrm{t}$ & $\mathrm{P}>|\mathrm{t}|$ & [95\% Conf. Interval ] \\
\hline Lventas & 0.1810367 & 0.0090476 & 20.01 & 0.0000 & 0.1633033 & 0.1987702 \\
Linventario & 0.0312694 & 0.0033841 & 9.24 & 0.0000 & 0.0246366 & 0.0379022 \\
lflujo_caja & 0.2223365 & 0.0086127 & 25.81 & 0.0000 & 0.2054555 & 0.2392174 \\
Tasa & -3.770862 & 0.0799694 & -47.15 & 0.0000 & -3.927603 & -3614122 \\
cons & 6.971779 & 0.0880463 & 79.18 & 0.0000 & 6.799208 & 7.144351 \\
\hline Fuente: Elaboración propia. & & & & &
\end{tabular}




\subsubsection{Prueba de autocorrelación}

Desde que los datos son de corte transversal no hay problemas de autocorrelación. Recuérdese que la autocorrelación solo se encuentra en datos de series de tiempo.

\subsubsection{Prueba de heterocedasticidad}

La evaluación estadística de los coeficientes estimados asume que los errores son homocedasticos. Sin embargo, la violación de este supuesto implicaría que el estadístico t utilizado para evaluar la hipótesis nula no sea el correcto. Es decir, la presencia de heterocedasticidad haría que evaluación estadística realizada sea incorrecta. Por tal razón, es necesario evaluar si se cumple el supuesto de homocedasticidad. En caso de no cumplirse este supuesto se tiene que corregir el estadístico t para que sea consistente a la presencia de errores heterocedasticos.

A continuación se presentan las pruebas de heterocedasticidad de Breusch-Pagan y de IM-Test. Es necesario resaltar que en ambos casos, se utilizó el programa Stata para su estimación.

Tabla 3.3

Resultados de la prueba de heterocedasticidad

. . estat hettes

Breusch - Pagan / Cook-Weisberg test for heteroskedastic

$\mathrm{H}_{\mathrm{o}}$ : Constant variance

Variables: fitted values of ldeuda

$\begin{array}{lll}\text { chi } 2(1) & = & 119.88 \\ \text { Prob }>\text { chi } 2 & = & 0.0000\end{array}$

. estat imtest

Cameron \& Trivedi's decomposition of IM - test

\begin{tabular}{r|rrr} 
Source & chi2 & df & $\mathrm{p}$ \\
\hline Heteroskedasticity & 87.03 & 14 & 0.0000 \\
Skewness & 458.56 & 4 & 0.0000 \\
Kurtosis & 190.76 & 1 & 0.0000 \\
\hline Total & 736.35 & 19 & 0.0000 \\
\hline
\end{tabular}

Fuente: Elaboración propia 
La hipótesis nula es que los errores son homocedasticos. El p-value de la prueba de Breusch-Pagan es de 0.00 por lo que no se acepta la hipótesis nula de homocedasticidad y se concluye que los errores presentan heterocedasticidad.

La prueba de Camero \& Trivedi (IM-test) también rechaza la hipótesis nula de homocedasticidad (su p-value es de 0.00). Por lo tanto se concluye que los errores presentan heterocedasticidad.

\subsubsection{Modelo de regresión corregido por el problema de heterocedasticidad}

La heterocedasticidad no genera sesgo en el estimador mínimos cuadrados ordinarios; pero si genera que no se pueda hacer inferencia estadística con el usual estimador del error estándar. Por eso, a continuación se estimará el modelo con errores estándar robustos a heterocedasticidad.

Tabla 3.4

Modelo de regresión dos

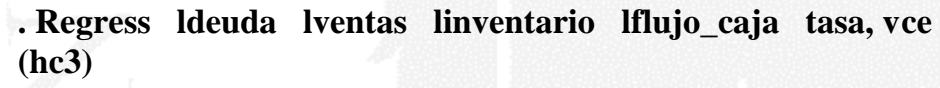

\begin{tabular}{r|rrrrrr} 
Ldeuda & Coef. & $\begin{array}{r}\text { Robust HC3 Std. } \\
\text { Err. }\end{array}$ & $\mathrm{t}$ & $\mathrm{P}>|\mathrm{t}|$ & & [ 95\% Conf. Interval ] \\
\hline Lventas & 0.1810367 & 0.0100068 & 18.09 & 0.0000 & 0.1614233 & 0.2006501 \\
Linventario & 0.0312694 & 0.0038703 & 8.08 & 0.0000 & 0.0236836 & 0.0388553 \\
lflujo_caja & 0.2223364 & 0.0089734 & 24.78 & 0.0000 & 0.2047484 & 0.2399244 \\
Tasa & -3.770862 & 0.0831676 & -45.34 & 0.0000 & -3.933871 & -3.607853 \\
_cons & 6.97178 & 0.0914815 & 76.21 & 0.0000 & 6.792475 & 7.151084 \\
\hline
\end{tabular}

Fuente: Elaboración propia.

Obsérvese que los coeficientes no han cambiado, pero sí los errores estándar, ya que ahora son robustos a la presencia de heterocedasticidad.

Los resultados muestran que las variables explicativas (ventas, inventario, flujo de caja, y tasa de interés) siguen siendo estadísticamente significativas; esto se determina observando que todos los estadísticos t son mayores que el valor crítico de 2.1. Por lo 
tanto, se concluye que las variables ventas, inventario, flujo de caja, y tasa de interés sí explican la variable monto de deuda utilizado.

Los resultados de la regresión muestran que todas las variables explicativas son estadísticamente significativas al $1 \%$ de confianza. Asimismo, los signos de los coeficientes de las variables ventas, inventarios, flujo de caja y tasa de interés sobre el monto de deuda, son conforme se esperaban.

A continuación se explicará de manera individual el efecto de cada una de las variables explicativas sobre la deuda.

\subsubsection{Interpretación de los resultados}

Los resultados de la regresión muestran que las ventas tienen un coeficiente positivo de 0.18; es decir, a mayores ventas, las PYMES utilizan más fondos bancarios. El estadístico t de la variable ventas es de 20.01, superior al valor crítico de 2.1 para un nivel de significancia de 1\%; por lo tanto la variable es estadísticamente significativa en la población y deberá mantenerse en el modelo.

Los resultados del modelo respaldan lo mencionado ya que el coeficiente del logaritmo de las ventas es positivo.

Tal como se esperaba, el coeficiente del logaritmo de las ventas es positivo. Además, las variables deuda y ventas están expresadas en logaritmo natural en la ecuación de regresión, por lo que el coeficiente de la variable ventas (0.18) se interpreta como el cambio porcentual de la deuda ante un incremento de uno por ciento en las ventas (elasticidad).

Es decir, si la PYME incrementa sus ventas en 1\%, esto generaría un incremento de $0.18 \%$ en su deuda financiera de corto plazo.

A continuación se presentará un ejemplo práctico ante un incremento de $1 \%$ en las ventas y el efecto que tiene esta variación sobre la deuda bancaria de corto plazo. Para el ejemplo se tomó una muestra de la base de datos utilizada para la regresión.

En el escenario inicial se detallan los valores de deuda, ventas, inventario, flujo de caja y tasa de interés sin ningún tipo de variación. En el escenario final se aplica una variación de $1 \%$ a las ventas, mientras que el inventario, flujo de caja y tasa de interés se mantienen constantes. El ejemplo sirve para evaluar como un incremento de $1 \%$ en las 
ventas genera un aumento de $0.18 \%$ en la deuda bancaria de corto plazo que asumen las PYMES.

Dentro del análisis se puede precisar que los resultados de la regresión muestran que el nivel de los inventarios tiene un coeficiente positivo de 0.031; es decir, para mantener mayores niveles de inventario, las PYMES utilizan más fondos bancarios. Esto indicaría que el capital de trabajo de la empresa (recuérdese que los inventarios forman parte del capital de trabajo) estaría siendo financiado con mayor deuda bancaria. El estadístico t de la variable inventario es de 9.24, superior al valor crítico de 2.1 para un nivel de significancia de $1 \%$; por lo tanto la variable es estadísticamente significativa en la población y deberá mantenerse en el modelo.

Tabla 3.5

Ejemplo práctico del efecto de las ventas en la deuda

\begin{tabular}{l|lllll}
\hline & Deuda & Ventas & Inventario & Flujo_caja & Tasa \\
\hline $\begin{array}{l}\text { Escenario } \\
\text { inicial }\end{array}$ & 68,817 & 190,800 & 68,900 & 46,525 & $20 \%$ \\
Escenario final & 68,941 & 192,708 & 68,900 & 46,525 & $20 \%$ \\
Variación \% & $0.18 \%$ & $1.00 \%$ & $0.00 \%$ & $0.00 \%$ & $0.00 \%$ \\
\hline
\end{tabular}

Nota: Efecto en la deuda ante un cambio en las ventas.

Fuente: Elaboración propia.

Los resultados del modelo respaldan la relación positiva entre el nivel de inventarios y la deuda bancaria de corto plazo que asumen las PYMES, tal como se propuso inicialmente.

El coeficiente del logaritmo de los inventarios es positivo. Además, las variables deuda e inventarios están expresadas en logaritmo natural en la ecuación de regresión, por lo que el coeficiente de la variable inventario (0.03) se interpreta como el cambio porcentual de la deuda ante un incremento de uno por ciento en los inventarios.

Es decir, si la PYME incrementa sus inventarios en 1\%, esto generaría un incremento de $0.03 \%$ en su deuda financiera de corto plazo. 
A continuación se presentará un ejemplo práctico ante un incremento de $1 \%$ en los inventarios y el efecto que tiene esta variación sobre la deuda bancaria de corto plazo. Para el ejemplo se tomó una muestra de la base de datos utilizada para la regresión.

En el escenario inicial se detallan los valores de deuda, ventas, inventario, flujo de caja y tasa de interés sin ningún tipo de variación. En el escenario final se aplica una variación de $1 \%$ a los inventarios, mientras que las ventas, flujo de caja y tasa de interés se mantienen constantes. El ejemplo sirve para evaluar como un incremento de $1 \%$ en los inventarios genera un aumento de $0.03 \%$ en la deuda bancaria de corto plazo que asumen las PYMES.

Al analizar el flujo de caja mediante los resultados de la regresión, se muestra que el flujo de caja tiene un coeficiente positivo de 0.22 ; es decir, la mayor disponibilidad de liquidez hace que las PYMES utilicen más fondos bancarios. Ello se debería a que una mayor capacidad de pago (un mayor flujo de caja) permite a las PYMES tomar un mayor nivel de deuda. El estadístico t de la variable flujo de caja es de 25.81, superior al valor crítico de 2.1 para un nivel de significancia de $1 \%$; por lo tanto la variable es estadísticamente significativa en la población y deberá mantenerse en el modelo.

Tabla 3.6

Ejemplo práctico del efecto de los inventarios en la deuda

\begin{tabular}{l|lllll}
\hline & Deuda & Ventas & Inventario & Flujo_caja & Tasa \\
\hline $\begin{array}{l}\text { Escenario } \\
\text { inicial }\end{array}$ & 68,817 & 190,800 & 68,900 & 46,525 & $20 \%$ \\
Escenario final & 68,838 & 190,800 & 69,589 & 46,525 & $20 \%$ \\
Variación \% & $0.03 \%$ & $0.00 \%$ & $1.00 \%$ & $0.00 \%$ & $0.00 \%$ \\
\hline
\end{tabular}

Nota: Efecto en la deuda ante un cambio en los inventarios.

Fuente: Elaboración Propia.

Los resultados del modelo respaldan la relación positiva entre el flujo de caja y la deuda bancaria de corto plazo que asumen las PYMES, tal como se propuso inicialmente.

El coeficiente del logaritmo del flujo de caja es positivo. Además, las variables deuda y flujo de caja están expresadas en logaritmo natural en la ecuación de regresión, por lo que el coeficiente de la variable flujo de caja (de 0.22 ) se interpreta como el cambio 
porcentual de la deuda ante un incremento de uno por ciento en el flujo de caja de las PYMES.

Es decir, si una PYME genera un mayor flujo de caja en $1 \%$, su deuda de corto plazo se incrementaría en $0.22 \%$.

A continuación se presentará un ejemplo práctico ante un incremento de $1 \%$ en el flujo de caja y el efecto que tiene esta variación sobre la deuda bancaria de corto plazo. Para el ejemplo se tomó una muestra de la base de datos utilizada para la regresión.

En el escenario inicial se detallan los valores de deuda, ventas, inventario, flujo de caja y tasa de interés sin ningún tipo de variación. En el escenario final se aplica una variación de $1 \%$ al flujo de caja, mientras que las ventas, el inventario y tasa de interés se mantienen constantes. El ejemplo sirve para evaluar como un incremento de $1 \%$ en el flujo de caja genera un aumento de $0.22 \%$ en la deuda bancaria de corto plazo que asumen las PYMES.

Tabla 3.7

Ejemplo práctico del efecto del flujo de caja en la deuda

\begin{tabular}{c|ccccc}
\hline & Deuda & Ventas & Inventario & Flujo_caja & Tasa \\
\hline $\begin{array}{c}\text { Escenario } \\
\text { inicial }\end{array}$ & 68,817 & 190,800 & 68,900 & 46,525 & $20 \%$ \\
Escenario final & 68,969 & 190,800 & 68,900 & 46,990 & $20 \%$ \\
Variación \% & $0.22 \%$ & $0.00 \%$ & $0.00 \%$ & $1.00 \%$ & $0.00 \%$ \\
\hline
\end{tabular}

Nota: Efecto en la deuda ante un cambio en el flujo de caja.

Fuente: Elaboración Propia.

Según se pudo observar en los resultados de la regresión, la tasa de interés que cobran los bancos a las PYMES tiene un coeficiente negativo de -3.77 ; es decir, las PYMES utilizan menos fondos bancarios cuando la tasa de interés se incrementa. Este resultado es conforme se esperaba, por lo que un mayor costo del crédito desincentiva a las PYMES a financiarse con recursos externos. El estadístico t de la variable tasa es de -47.15, superior al valor crítico de -2.1 para un nivel de significancia de 1\%; por lo tanto, la variable es estadísticamente significativa en la población y deberá mantenerse en el modelo. 
Los resultados de la regresión muestran una relación negativa entre la tasa de interés y la deuda de corto plazo, tal como se esperaba.

La interpretación es la siguiente: si la tasa de interés aumenta en una unidad (uno por ciento, o 100 puntos básicos) la deuda se reduce en $3.77 \%$.

A continuación se presentará un ejemplo práctico ante un incremento de $1 \%$ en la tasa de interés (pasa de 20 a 21\%) y el efecto que tiene esta variación sobre la deuda bancaria de corto plazo. Para el ejemplo se tomó una muestra de la base de datos utilizada para la regresión.

En el escenario inicial se detallan los valores de deuda, ventas, inventario, flujo de caja y tasa de interés sin ningún tipo de variación. En el escenario final se aplica una variación de $1 \%$ a la tasa de interés, mientras que las ventas, el inventario y el flujo de caja se mantienen constantes. El ejemplo sirve para evaluar como un incremento de $1 \%$ la tasa de interés genera una disminución de $-3.77 \%$ en la deuda bancaria de corto plazo que asumen las PYMES.

Tabla 3.8

Ejemplo práctico del efecto de la tasa de interés en la deuda

\begin{tabular}{c|ccccc}
\hline & Deuda & Ventas & Inventario & Flujo_caja & Tasa \\
\hline $\begin{array}{c}\text { Escenario } \\
\text { inicial }\end{array}$ & 68,817 & 190,800 & 68,900 & 46,525 & $20 \%$ \\
Escenario final & 66,270 & 190,800 & 68,900 & 46,525 & $21 \%$ \\
Variación \% & $-3.77 \%$ & $0.00 \%$ & $0.00 \%$ & $0.00 \%$ & $1.00 \%$ \\
\hline
\end{tabular}

Nota: Efecto en la deuda ante un cambio en la tasa de interés.

Fuente: Elaboración Propia.

\subsubsection{Contrastación hipótesis general}

\section{Hipótesis general}

Las ventas y el nivel de inventarios influyen en la decisión de financiamiento bancario de corto plazo de las pequeñas y medianas empresas, y en menor medida, lo hacen el flujo de caja y el costo de financiamiento. 


\section{Contrastación hipótesis general:}

Se concluye que las cuatro variables son significativas para el modelo y tienen una incidencia sobre la deuda de corto plazo que asumen las empresas.

Las ventas, el nivel de inventarios y el flujo de caja tienen una relación positiva con la variable dependiente, además, la tasa de interés tiene una relación inversa con la deuda, tal como se esperaba inicialmente.

La variable con mayor incidencia en el modelo es la tasa de interés, seguida por el flujo de caja, las ventas y el nivel de inventarios respectivamente.

La hipótesis general afirma que las ventas y el nivel de inventarios tienen una mayor influencia sobre la deuda que el flujo de caja y el costo de financiamiento (tasa de interés), por lo tanto, dicha hipótesis es rechazada.

\subsubsection{Contrastación hipótesis específica 1}

\section{Hipótesis específica 1:}

Las ventas y el nivel de inventarios son determinantes en la definición del monto de financiamiento bancario de corto plazo de las PYMES, teniendo las ventas una mayor incidencia sobre la endógena que lo inventarios.

\section{Contrastación hipótesis específica 1:}

Los resultados obtenidos en el modelo afirman que las ventas y el nivel de inventarios son significativos para determinar el monto de financiamiento bancario de corto plazo de las PYMES. Asimismo, se concluye que las ventas tienen una mayor incidencia sobre la endógena que los inventarios, por lo que se acepta la hipótesis específica 1.

\subsubsection{Contrastación hipótesis específica 2}

\section{Hipótesis especifica 2:}

El flujo de caja y la tasa de interés influyen en la determinación del monto del préstamo bancario de corto plazo que demandan las PYMES, teniendo el flujo de caja una mayor incidencia sobre la deuda que la tasa de interés. 


\section{Contrastación hipótesis específica 2:}

Los resultados obtenidos señalan que el flujo de caja y la tasa de interés si tienen influencia en la determinación del monto del préstamo bancario de corto plazo que demandan las PYMES, ya que ambas son significativas. Sin embargo, se rechaza la hipótesis específica 2, debido a que el flujo de caja tiene un coeficiente $0.22 \%$ y la tasa de interés tiene un coeficiente de $-3.77 \%$, por lo que la segunda variable es más significativa para el modelo.

En conclusión, la regresión econométrica sirvió para evaluar las hipótesis propuestas. Se evaluaron tres hipótesis: una general y dos específicas. Se rechazó la general ya que se concluyó que todas las variables eran significativas para el modelo, sin embargo, el flujo de caja y el costo de financiamiento tuvieron una mayor incidencia sobre el modelo que las ventas y los inventarios.

La hipótesis específica 1 fue aceptada, ya que afirmaba que las ventas eran más significativas para la deuda bancaria que los inventarios. Los resultados fueron que el coeficiente de las ventas fue de $0.18 \%$ y el de los inventarios de $0.03 \%$. Ambas variables fueron significativas y las ventas tuvieron mayor incidencia, tal como lo afirmaba la hipótesis.

La hipótesis específica 2 fue rechazada. Se determinó que la tasa de interés tiene una mayor incidencia que el flujo de caja sobre la deuda bancaria. Los resultados fueron que el coeficiente de la tasa de interés fue de $-3.77 \%$ y el del flujo de caja de $0.22 \%$. Ambas variables fueron significativas, pero la tasa de interés tuvo mayor incidencia que el flujo de caja, a diferencia de lo que afirmaba la hipótesis. 


\section{CONCLUSIONES}

El estudio realizado a las PYMES durante la investigación fue útil para determinar la influencia que tienen las cuatro variables explicativas sobre la deuda bancaria de corto plazo. El modelo econométrico permitió explicar las relaciones de causalidad entre las variables, por lo que se llegaron a obtener conclusiones en base a la investigación realizada y a los resultados obtenidos por la regresión del modelo.

- Con respecto al objetivo general y a la hipótesis general de la investigación, se analizaron a las cuatro variables propuestas. Se tomaron en cuenta a las ventas, los inventarios, el flujo de caja y las tasas de interés como variables explicativas porque se creía que las cuatro variables explicarían el modelo por su relación económica con la endógena.

El resultado fue acertado, las cuatro variables explicaban el modelo, sin embargo hubo un tema que llamó la atención. Si bien es cierto que todas las variables fueron significativas, se obtuvo un R2 bajo (23.39\%).

El R2 indica que tan explicado está el modelo según las variables utilizadas, por lo que se esperaba que este indicador sea más alto ya que las cuatro variables fueron significativas.

Se concluye que el R2 no fue el que se esperaba debido a que se tomaron sólo cuatro variables para explicar la deuda bancaria que asumen las PYMES. Sin embargo, para mejorar el R2 se podrían incluir un mayor número de variables explicativas que hagan que el modelo se vuelva más preciso.

De la misma manera, se propone incluir variables dummy como el riesgo y el sector de la PYME para analizar la incidencia que tienen estas variables cualitativas sobre la deuda, esperando que el R2 mejore.

Con respecto a la hipótesis general, las variables ventas e inventarios fueron significativas por lo que ambas debían mantenerse en el modelo. Sin embargo, el flujo de caja y la tasa de interés también fueron significativas y con un coeficiente mayor que las dos primeras; por lo que la hipótesis general fue rechazada. 
- Se evaluó la importancia de las variables ventas e inventarios para el modelo. La hipótesis específica 1 planteaba que las ventas tenían una mayor incidencia sobre el modelo que los inventarios. Se propuso esta hipótesis debido a que se pensaba que una mayor cantidad de ventas de una PYME haría que ésta llegue a su tope en capacidad de producción. Si la empresa desea continuar con ese crecimiento sostenido debería asumir un financiamiento bancario que le permita mejorar su capacidad productiva y continuar con esa curva ascendente camino a la expansión empresarial.

De la misma forma, se esperaba que una mayor cantidad de ventas, genere la necesidad de cubrir una mayor brecha del ciclo de efectivo, por lo que se debería requerir más financiamiento bancario de corto plazo.

De acuerdo a lo propuesto por la teoría, el nivel de significancia de las variables demostró que ambas explicaban a la deuda y que se debía aceptar a la hipótesis específica 1, ya que según los resultados obtenidos, las ventas tenían una mayor influencia sobre el modelo que los inventarios.

- Se evaluó la incidencia del flujo de caja y el costo de financiamiento (tasa de interés) sobre la deuda bancaria de corto plazo que asumían las PYMES. La hipótesis específica 2 planteaba que el flujo de caja tenía una mayor incidencia que la tasa de interés. Se propuso esta hipótesis debido a que se pensaba que las PYMES al tener ciertas restricciones para la obtención del financiamiento por parte de los bancos (como se vio en el capítulo I), aceptarían la tasa de interés que se les imponga así sea alta, debido a su necesidad de acceder al crédito.

Luego de realizar la regresión, los resultados obtenidos fueron otros. Se determinó que la tasa de interés tiene una mayor incidencia sobre la deuda, que el flujo de caja. Según los resultados del modelo, las PYMES si consideran en gran medida a la tasa de interés para determinar el monto de préstamo solicitado.

Con los resultados obtenidos, se concluye que se rechaza la hipótesis específica 2.

- Los coeficientes de cada variable en la regresión indicaron la incidencia e importancia que tiene cada una de las variables para el modelo. En primer lugar 
se determinó que todas las variables eran significativas por lo que todas debían permanecer en el modelo. En segundo lugar, el nivel de importancia de las variables fueron: la tasa de interés, el flujo de caja, las ventas y los inventarios; respectivamente.

Este orden permite inferir que la tasa de interés es clave para la decisión de financiamiento. Las tasas impuestas a las PYMES por las entidades bancarias son realmente altas, mucho mayores que las que les ofrecen a las grandes empresas. Esto se debe a que un préstamo a una PYME implica un mayor riesgo para el banco, por lo que para compensar este riesgo le impone una tasa mayor que el de las empresas de mayor tamaño.

La respuesta de las PYMES ante esto es la siguiente:

Debido a la relación inversa entre la tasa y la deuda, y siendo la tasa la variable más explicativa del modelo; se puede deducir que ante un incremento en la tasa de interés o ante una tasa de interés muy alta, las PYMES buscan otras alternativas de financiamiento o solicitan niveles de deuda no tan elevados.

Las alternativas que buscan según la teoría, son la autofinanciación, tratando de cubrir sus necesidades utilizando recursos propios. Además, otra alternativa sería utilizar financiamiento por otro tipo de entidades que no sean bancarias, como lo son las cajas municipales o el ingreso al mercado de capitales si tuviesen acceso. 


\section{RECOMENDACIONES}

Se considera importante incluir dentro de este punto, una serie de recomendaciones para las pequeñas y medianas empresas en favor de impulsar su crecimiento. La investigación sirvió como base para conocer la realidad de las PYMES, por lo que a partir del entendimiento del tema, se recomendarán medidas que las empresas deberían adoptar para obtener mejores resultados económicos.

- Programas de capacitación para los pequeños empresarios. Las PYMES representan más del 90\% de las empresas del país. Además, en la investigación se identifica al financiamiento como una herramienta clave para el crecimiento. Por estos dos motivos, con la intención de impulsar el desarrollo económico del país, se recomienda que exista una capacitación constante por parte del gobierno hacia los pequeños empresarios con la finalidad que estén aptos para evaluar los beneficios y responsabilidades que implica financiarse. Es necesario que conozcan que mientras más organizada y seria sea la empresa, hay mayores posibilidades de obtener crédito y de recibir una mejor tasa de interés.

La capacitación permitiría a los emprendedores un mayor conocimiento administrativo y financiero, lo que les permitiría tomar mejores decisiones empresariales en favor de su negocio.

Los estudios les permitirán a los empresarios estar capacitados para evaluar las condiciones que el banco les impone. Hacer un análisis sobre el retorno del dinero, tasa de interés, plazos establecidos, entre otros.

- Promover la formalidad empresarial por parte del gobierno, creando incentivos como la reducción de impuestos y/o imponer sanciones económicas mayores para los informales, aumentando así el número de empresas que operen correctamente. Si el índice de formalidad de las PYMES aumenta, habrá una mayor cantidad de empresas que puedan acceder al crédito bancario, lo que generará mayor desarrollo. 
- Realizar una evaluación entre los bancos a ver cuál ofrece mejores condiciones de financiamiento. Es conveniente para las PYMES analizar las condiciones de financiamiento que les ofrecen los bancos. Para esto, no solo se debe evaluar la tasa de interés para tomar una decisión, sino también la periodicidad y cuota de pago que hay que cumplir; entre otras condiciones que son claves para definir cuál es la alternativa más conveniente para las necesidades de cada empresa.

Este punto se complementa con la preparación y capacitación de los pequeños empresarios, ya que una persona capacitada podrá tomar mejores decisiones a través de una evaluación financiera de las alternativas.

Elegir mejores condiciones de financiamiento permitirá pagar menos intereses, lo que significa un efecto positivo sobre las finanzas de las PYMES.

- Analizar otras alternativas de financiamiento. En búsqueda de obtener un menor costo de financiamiento, se deberán evaluar que otras alternativas existen para la obtención de liquidez.

Como se mencionó en el capítulo I, lo ideal para las empresas es utilizar el autofinanciamiento para cubrir sus necesidades, sin embargo, la liquidez con la que cuentan las PYMES para autofinanciarse no es tan alta.

De esta manera, se propone utilizar los recursos propios que se tengan para el financiamiento. Sin embargo, como estos recursos seguramente serán insuficiente, se recomienda evaluar otras alternativas (además de los préstamos bancarios) para complementar el monto requerido por la empresa.

- Crear valor a través de reducir el ciclo del efectivo. Se propone reducir el ciclo de efectivo de las PYME a través de aumentar el periodo de pago además de reducir el periodo de inventarios y el periodo de cobro. Cuanto más corto sea el ciclo del efectivo menor será el financiamiento que requiera una compañía, por lo tanto tendrá un menor costo por la deuda que asuma.

La reducción de la brecha del ciclo del efectivo, le permitirá a la PYME lograr el objetivo principal de toda empresa: la creación de valor.

- Responsabilidad social empresarial (RSE). Todas las operaciones que realice la empresa deben ser en favor del cuidado del medio ambiente y de la sociedad en 
general. Éste principio beneficia tanto a la sociedad como a la propia empresa, ya que mejora su imagen ante el mercado.

La imagen empresarial es importante ya que genera una mejor reputación para la empresa, lo que le permitiría obtener más clientes y mejorar las ventas. Éste impacto favorable en las ventas hará que mejore la liquidez y por lo tanto se necesiten menos fondos externos para cubrir las necesidades de la empresa. Por tal motivo, se concluye que realizar las operaciones actuando con responsabilidad social tendrá un impacto en las finanzas de la empresa, en su imagen y en el medio ambiente.

- Inversión en tecnología. A pesar de las limitaciones económicas de las PYMES, se considera que la inversión en tecnología es un tema importante en la búsqueda del crecimiento empresarial. La mejora productiva permitirá buscar nuevos clientes y estar en condiciones de abastecer la demanda, lo que mejorará las ventas y las utilidades de la compañía. 


\section{REFERENCIAS}

Acedo, G. (2011). Gestión administrativa y tributaria de PYMES. Madrid: Ayana Multimedia.

Banco Central de Reserva del Perú (2018). Series estadísticas. Recuperado de https://estadisticas.bcrp.gob.pe/estadisticas/series/

Bertossi, R. (2009). Financiamiento de pequeñas y medianas empresas. Buenos Aires: El Cid Editor.

Biasca, R. (2005). PYMES más competitivas. Experiencias prácticas de transformación de empresas en América Latina. Buenos Aires: El Cid Editor.

Galindo, L. (2005). La utopía del mercado: una revisión de la economía dominante. Recuperado de https://ebookcentral.proquest.com

Jaramillo, M. y Valdivia, N. (2005). Las políticas para el financiamiento de las PYMES en el Perú. Lima: CEPAL.

Ministerio de la Producción (2012). Distribución de las MIPYME según su tamaño y ubicación. Recuperado de geográfica http://demi.produce.gob.pe/images/publicaciones/publi7f308c9e5f8468f9c_63.p df

Morales, A. y Morales, J. (2014). Planeación financiera. Guadalajara: Grupo editorial Patria.

Ross, S., Westerfield, R. y Jordan, J. (2010). Fundamentos de finanzas corporativas (9. ${ }^{\text {a }}$ ed.). México D.F.: McGraw Hill.

Ruiz, M. (2008). Gestión de la empresa familiar. Madrid: McGraw-Hill España.

Schlemenson (2013). Análisis organizacional en PYMES y empresas de familia. Buenos Aires: Granica.

Stallings, B., y Rogério, S. (2006). Financiamiento para el desarrollo: américa latina desde una perspectiva comparada. Recuperado de https://ebookcentral.proquest.com

Superintendencia Nacional de Aduanas y de Administración Tributaria (2018). Índices y tasas. Recuperado de http://www.sunat.gob.pe/indicestasas/

Tirado, C., Granger, J. y Nieto, C. (1995). La PYME del ciclo XXI. Tecnologías de la información, mercados y organización (18. ${ }^{\mathrm{a}}$ ed.). Madrid: Fundesco. 
Vázquez, T., Carbajo, V., y López, P. (2010). Manual para la financiación de la PYME. Recuperado de https://ebookcentral.proquest.com 


\section{BIBLIOGRAFÍA}

Avalos, M. y Hernández, F. (2006). Competencia bancaria en México. México D. F.: CEPAL.

Carrasco, Z. C., \& Pallerola, C. J. (2014). Gestión financiera. Recuperado de https://ebookcentral.proquest.com

Castañeda, F., Aguirre, J., Ormazábal, F., Contreras, F., y Madariaga, L. (2014). Manual de finanzas corporativas (2. ${ }^{\text {e }}$ ed.). Santiago de Chile: Editorial USACH.

Garcia, V. (2014). Introducción a las finanzas (9. a ed.). Guadalajara: Grupo editorial Patria.

Gujarati, D. y Porter, D. (2010). Econometría (15. ${ }^{\mathrm{a}}$ ed.). Madrid: McGraw-Hill Interamericana.

Junco, J. (2009). Finanzas I. Buenos Aires: El Cid Editor.

Lecuona, R. (2014). Promoción de finanzas incluyentes mediante prácticas innovadoras de la banca de desarrollo: El caso de las PYMES en México. Santiago de Chile: CEPAL.

Morales, A. y Morales, C. (2014). Finanzas. Guadalajara: Grupo editorial Patria.

Noetzlin, M., y Barroso, P. (2009). Administración financiera. Recuperado de https://ebookcentral.proquest.com 
ANEXOS 
ANEXO 1: PBI variaciones porcentuales reales, 2013 - 2017

\begin{tabular}{|c|c|}
\hline Año & $\begin{array}{l}\text { Variaciones } \\
\text { porcentuales reales }\end{array}$ \\
\hline 2013 & 5.8 \\
\hline 2014 & 2.4 \\
\hline 2015 & 3.3 \\
\hline 2016 & 4.0 \\
\hline 2017 & 2.5 \\
\hline
\end{tabular}

Nota: Evolución del PBI real y variación del PBI real. Periodo 2013-2017.

Fuente: Banco Central de Reserva del Perú (BCRP).

En: https://estadisticas.bcrp.gob.pe/estadisticas/series/ 
ANEXO 2: Índice de Competitividad Mundial, 2018 - 2017

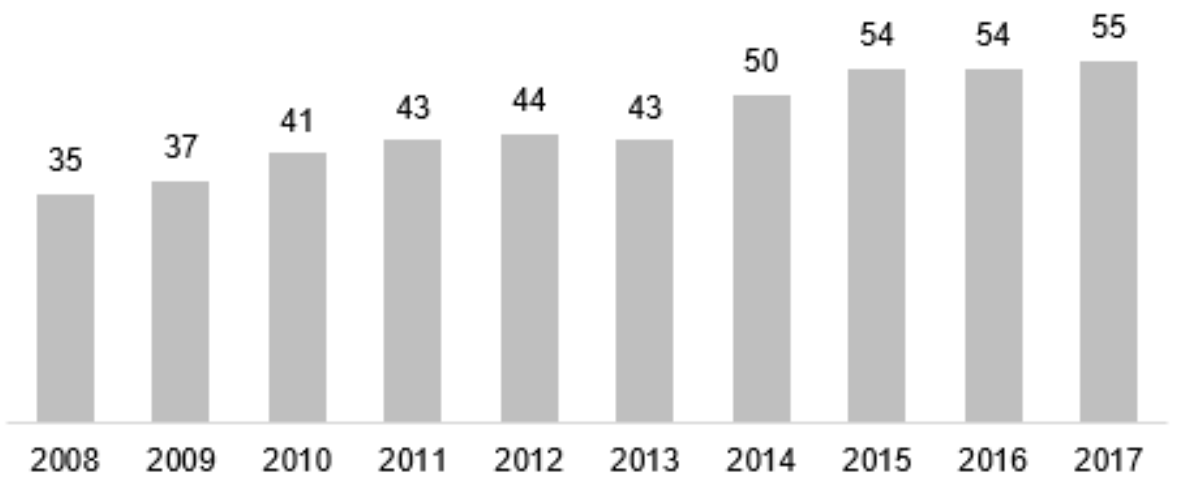

Fuente: CENTRUM Católica.

Elaboración: Aurum Consultoría y Mercado. 


\section{ANEXO 3: Consumo Privado, 2007 - 2016}

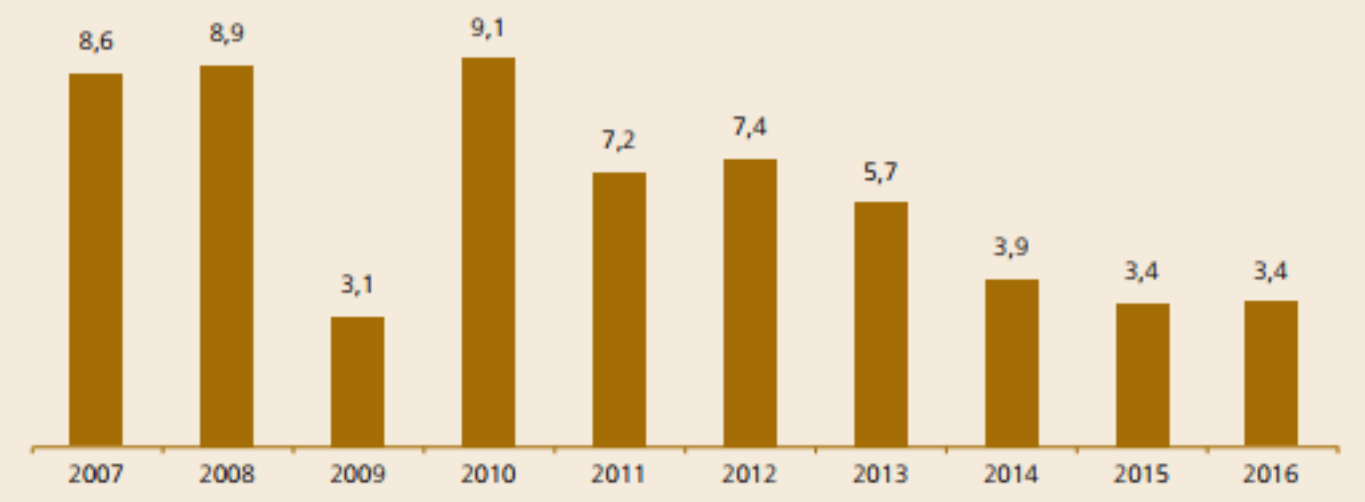

Nota: Variación porcentual real

Fuente: INEI y BCRP (2017) 
ANEXO 4: Demanda Interna, 2007 - 2016

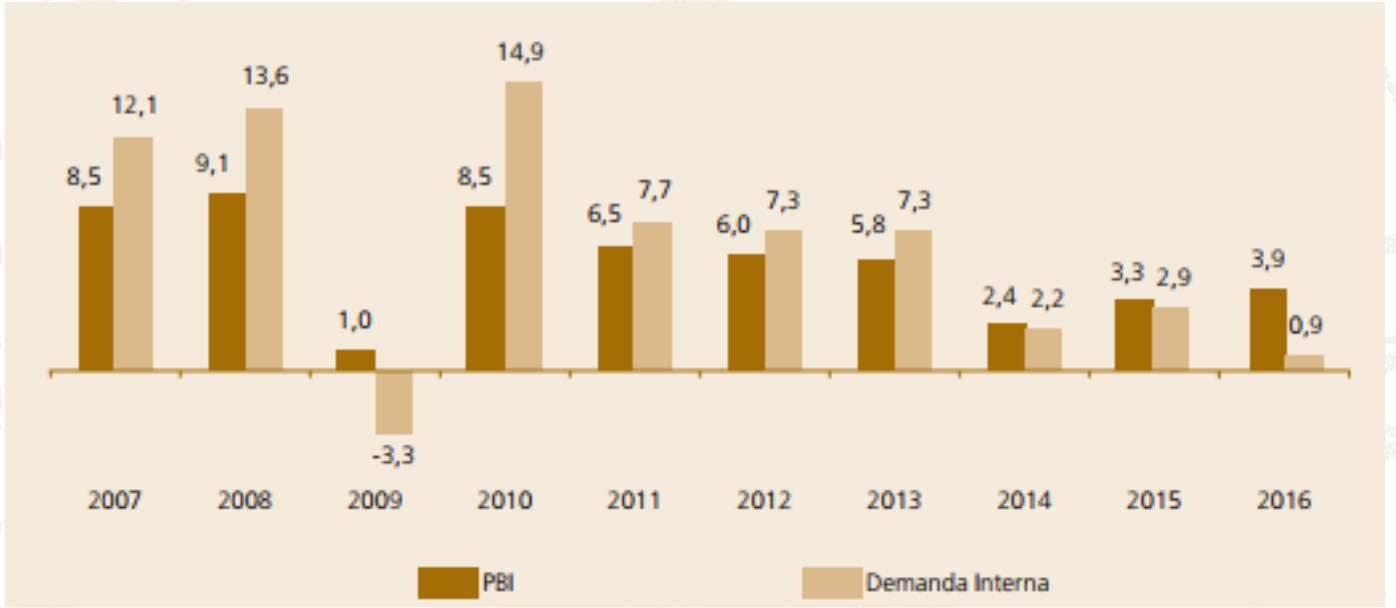

Nota: Variaciones porcentuales reales

Fuente: INEI y BCRP (2017) 


\begin{tabular}{|c|c|c|c|c|}
\hline & 2014 & 2015 & 2016 & $2007-2016$ \\
\hline Demanda Interna & 2,2 & 2,9 & 0,9 & 6,4 \\
\hline a. Consumo privado & 3,9 & 3,4 & 3,4 & 6,1 \\
\hline b. Consumo público & 6,0 & 9,8 & $-0,5$ & 6,3 \\
\hline c. Inversión bruta fija & $-2,1$ & $-5,4$ & $-4,5$ & 8,0 \\
\hline - Privada & $-2,3$ & $-4,4$ & $-5,7$ & 7,7 \\
\hline - Pública & $-1,1$ & $-9,5$ & 0,6 & 9,2 \\
\hline $\begin{array}{l}\text { Variación de existencias } \\
\text { (\% del PBI nominal) }\end{array}$ & $-0,9$ & 0,1 & 0,2 & 0,1 \\
\hline Exportaciones & $-0,8$ & 4,1 & 9,5 & 3,8 \\
\hline Menos: & & & & \\
\hline Importaciones & $-1,4$ & 2,4 & $-2,2$ & 7,2 \\
\hline Producto Bruto Interno & 2,4 & 3,3 & 3,9 & 5,5 \\
\hline Nota: & & & & \\
\hline Gasto público total & 3,6 & 3,6 & $-0,2$ & 7,0 \\
\hline
\end{tabular}

Nota: Variaciones porcentuales reales

Fuente: INEI y BCRP (2017) 


\section{ANEXO 6: Ahorro e Inversión, 2014 - 2016}

\begin{tabular}{lrrr}
\hline & 2014 & 2015 & 2016 \\
\hline I. Inversión (=II+III) & 24,9 & 24,4 & 22,8 \\
Inversión bruta fija & 25,8 & 24,3 & 22,6 \\
$\quad$ Inversión pública & 5,6 & 5,0 & 4,8 \\
$\quad$ Inversión privada fija & 20,1 & 19,3 & 17,8 \\
Variación de inventarios & $-0,9$ & 0,1 & 0,1 \\
& & & 20,0 \\
II. Ahorro interno & 20,5 & 19,7 & 2,7 \\
Sector público & 5,9 & 3,7 & 17,4 \\
Sector privado & 14,6 & 15,9 & 2,7 \\
III. Ahorro externo & & 4,8 & \\
\hline
\end{tabular}

Nota: Porcentaje del PBI nominal

Fuente: BCRP (2017) 


\section{ANEXO 7: Precios mundiales de diversos productos básicos,}

$2010-2014$

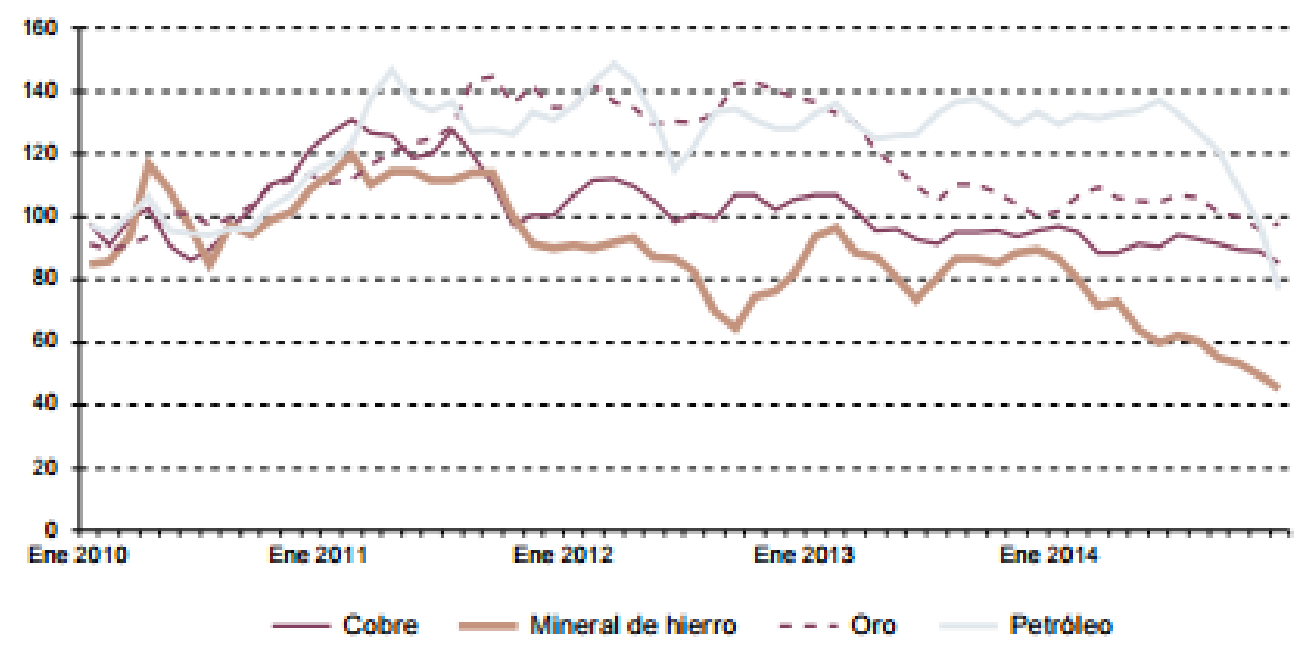

Nota: Índice, $2010=100$

Fuente: CEPAL (2015) 